Issued by Sandia National Laboratories, operated for the United States Depart-ment of Energy by Sandia Corporation.

NOTICE: This report was prepared as an account of work sponsored by an agency of the United States Government. Neither the United States Govern-ment, nor any agency thereof, nor any of their employees, nor any of their contractors, subcontractors, or their employees, make any warranty, express or implied, or assume any legal liability or responsibility for the accuracy, completeness, or usefulness of any information, apparatus, product, or process disclosed, or represent that its use would not infringe privately owned rights. Reference herein to any specific commercial product, process, or service by trade name, trademark, manufacturer, or otherwise, does not necessarily constitute or imply its endorsement, recommendation, or favoring by the United States Government, any agency thereof, or any of their contractors or subcontractors. The views and opinions expressed herein do not necessarily state or reflect those of the United States Government, any agency thereof, or any of their contractors.

Printed in the United States of America. This report has been reproduced directly from the best available copy.

Available to DOE and DOE contractors from Office of Scientific and Technical Information

P.O. Box 62

Oak Ridge, TN 37831

Prices available from (703) 605-6000

Web site: http://www.ntis.gov/ordering.htm

Available to the public from

National Technical Information Service

U.S. Department of Cornmerce

5285 Port Royal Rd

Springfield, VA 22161

NTIS price codes

Printed copy: A05

Microfiche copy: A01

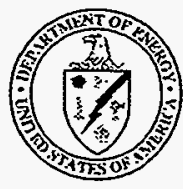




\section{DISCLAIMER}

Portions of this document may be illegible in electronic image products. Images are produced from the best available original document. 
SAND99-0819

Unlimited Release

Printed April 1999

\title{
DESIGN, DEVELOPMENT AND TESTING OF A DRILLABLE STRADDLE PACKER FOR LOST CIRCULATION CONTROL IN GEOTHERMAL DRILING
}

\author{
G.E. Staller, D.A. Glowka, J. Gabaldon, P. Gronewald, S.D. Knudsen, D.W. Raymond, \\ J.J. Westmoreland, G.L. Whitlow, J.L. Wise, and E.K. Wright \\ Geothermal Research Department \\ Sandia National Laboratories \\ P.O. Box 5800 \\ Albuquerque, NM 87185-1033
}

\begin{abstract}
Lost circulation is a widespread problem encountered when drilling geothermal wells, and often represents a substantial portion of the cost of drilling a well. The U.S. Department of Energy sponsors research and development work at Sandia National Laboratories in an effort to reduce these lost circulation expenditures. Sandia has developed a down hole tool that improves the effectiveness and reduces the cost of lost circulation cement treatment while drilling geothermal wells. This tool, the Drillable Straddle Packer, is a low-cost disposable device that is used to isolate the loss zone and emplace the cement treatment directly into the region of concern. This report documents the design and development of the Drillable Straddle Packer, the laboratory and field test results, and the design package that is available to transfer this technology to industry users.
\end{abstract}




\section{Acknowledgments}

The authors would like to acknowledge the technical support provided by R. D. Jacobson, Sandia Geothermal Research Department. We would also like to acknowledge the technical support for video coverage provided by R. F. Gardner, R. N. Sanderville, and E. V. Sisneros, Sandia Video Services Department.

This work was sponsored by the U. S. Department of Energy, Office of Geothermal Technologies. 


\section{TABLE OF CONTENTS}

Page

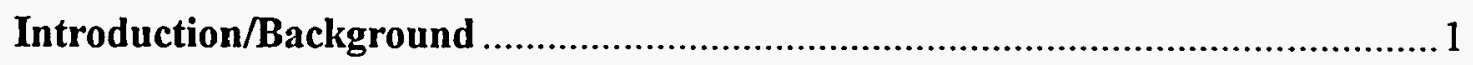

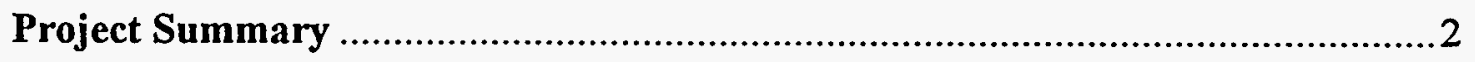

Conceptual Hardware Design and Deployment Procedures ............................... 3

Laboratory Prototype Development and Testing ...........................................4

A.) Fabric Selection ....................................................................4

B.) Prototype Design and Development .......................................... 5

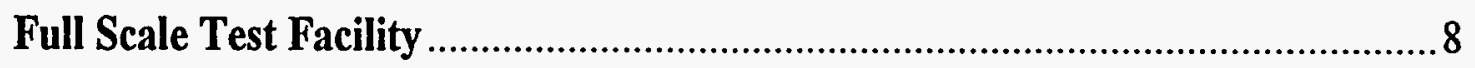

A. ) $1 / 5$ Scale Test Configuration .................................................. 8

B.) Full Scale Test Facility Construction....................................... 10

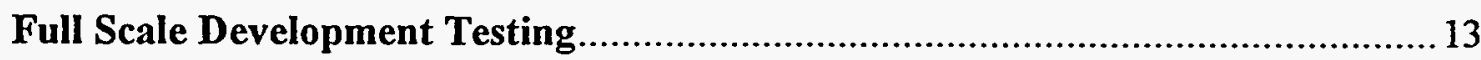

A.) 15" ID Concrete Pipe Wellbore Tests 1 and 2 without DSP...............13

B.) $15^{\prime \prime}$ ID Concrete Pipe Wellbore Tests 3 with DSP ............................ 19

C.) ELTF Modifications.................................................................. 21

D.) 8" Transparent Wellbore Test without DSP ......................................22

E.) 8 " Transparent Wellbore Test with DSP ..........................................25

F.) 16" Transparent Wellbore Test without DSP (Static Wellbore)...........26

G.) 16" Transparent Wellbore Test with DSP (Static Wellbore) ..............27

H.) 16" Transparent Wellbore Test without DSP (Flowing Wellbore) 29

I.) 16" Transparent Wellbore Test with DSP (Flowing Wellbore)..............30

J.) 16" Transparent Wellbore Test without DSP (Mud-Filled Wellbore)....32

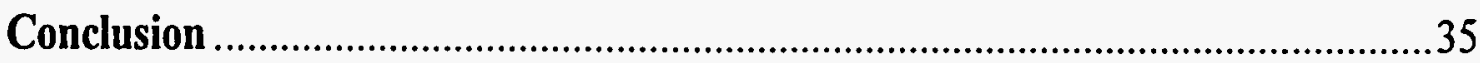

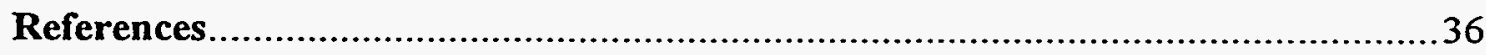




\section{APPENDICES}

Appendix A - Summary of Fabric Testing Data .............................................

Appendix B - Summary of Bag Testing Data............................................ B1

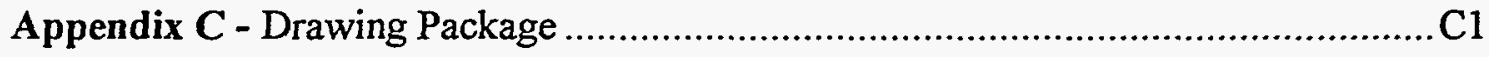

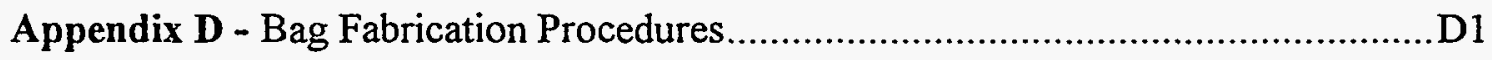

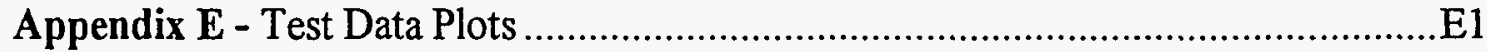




\section{Introduction/Background}

One of the most common problems encountered when drilling geothermal wells is the loss of drilling fluids to cracks or voids in the formation being drilled. This loss, commonly referred to as lost circulation, represents approximately $10 \%$ to $20 \%$ of the cost of drilling the well ${ }^{1}$. Reducing the costs associated with lost circulation treatments will reduce the overall cost of drilling geothermal wells and thus make this energy source more competitive with traditional electric utility generating techniques.

In an effort to assist the geothermal industry in reducing lost circulation costs, the U.S. Department of Energy sponsors the Lost Circulation Technology Program at Sandia National Laboratory ${ }^{2,3}$. The goal of this program is to develop and transfer to industry new technology that can be used to reduce lost circulation expenditures. One new device developed at Sandia, that may be a useful tool for effective economic cement plugging of geothermal well loss zones, is the Drillable Straddle Packer ${ }^{4}$. The Drillable Straddle Packer (DSP) has been under going development and testing at Sandia and is currently ready for field applications. Results of this development process as well as the results from reduced and full-scale laboratory testing conducted at Sandia, are documented in this report.

The basic concept for the DSP is shown in Figure 1. The DSP is designed to be low cost

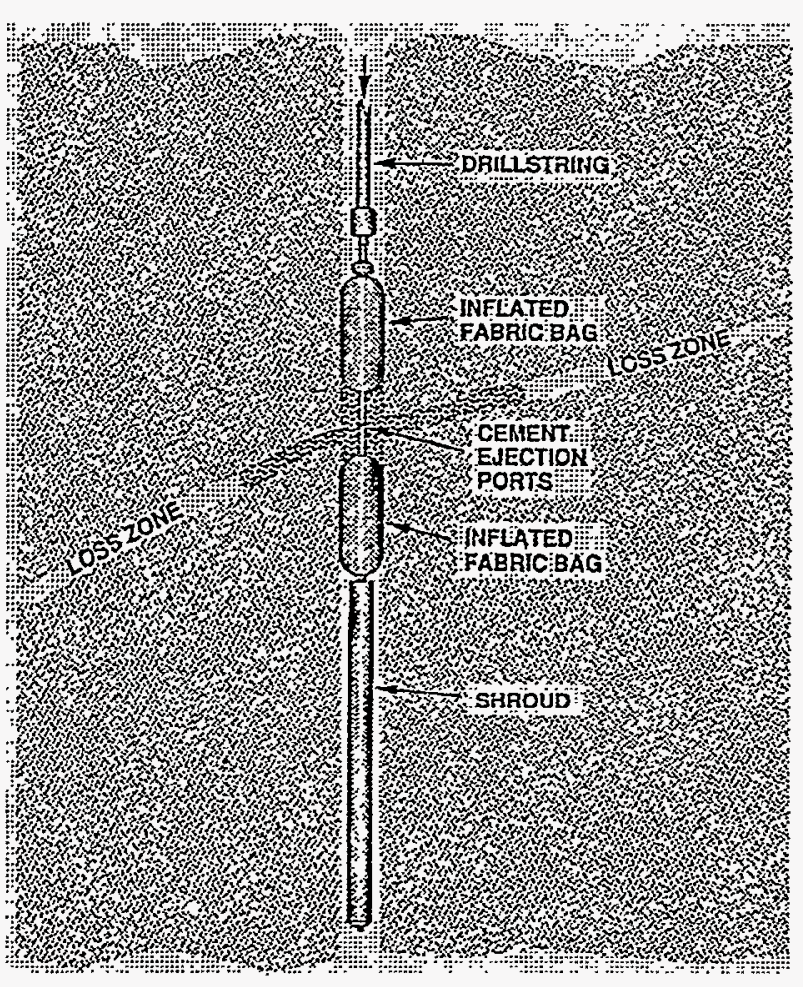

Figure 1 - Drillable Straddle Packer Concept and readily drillable after treatment of a loss zone (LZ). When a LZ has been identified the DSP can be assembled in the field with enough spacing between inflatable bags to span the $\mathrm{LZ}$ area. The DSP is deployed on the end of the drillstring and positioned in the wellbore such that the inflatable fabric bags straddle the area of concern. When cement is pumped into the well through the drill pipe, the differential pressure across the cement injection ports inflates the fabric bags and isolates the LZ from the remainder of the wellbore. The inflated bags force the cement between them to flow directly into the $\mathrm{LZ}$ and, at the same time, prevent other wellbore fluids from flowing into the $\mathrm{LZ}$ and diluting or otherwise adversely affecting the cement. After the cementing operation is completed the DSP is disconnected from the drillstring and left in place until the cement properly cures. When drilling resumes the DSP is drilled out and the well can be drilled ahead. 
The concept of two bags straddling a loss zone is not the only possible application for this technology. The use of one bag located near or just off the bottom of a well that encountered lost circulation while drilling can be envisioned. Plugging a loss zone near the bottom of the well utilizes the well bottom as the lower bag in the DSP concept. This technique is of value, especially, when gas treated cements, such as nitrogen foamed cement, are used to plug the loss zone. Unless held down by an inflated packer bag, these lightweight cements may tend to rise in the wellbore fluid and not efficiently flow into and plug the LZ. Use of a low cost drillable bag in such applications may provide a costeffective treatment for the $\mathrm{LZ}$, in place of drilling ahead using lost circulation material and risking later placement of a cement plug in an open well.

The shroud is another area where the DSP design can be different than the one described in the foregoing concept. The use of centralizers above and below the DSP bags may be sufficient to protect the bags during insertion into a well. In addition, other shroud designs may be desirable to accommodate large loss zones that require long spans between the bags or for reusable shrouds that can be removed with the drillstring.

\section{Project Summary}

Through a vigorous development and testing program a low cost drillable straddle packer that can be used in geothermal well environments has been produced. Full-scale laboratory testing has been conducted that indicates that this packer technique is superior to the industry standard open-end-drill-pipe technique for placing cement into a geothermal well loss zone. These laboratory tests were conducted using standard industry cement pumping equipment and techniques to evaluate and compare lost circulation treatment technologies. Test results have been documented showing that the DSP can successfully pack-off a wellbore and seal against the wellbore walls. This 30 to 40 psi differential pressure seal is adequate enough to force cement into a loss zone and seal the remainder of the wellbore sufficiently to prevent production zone contamination and/or excessive use of cement during lost circulation treatments.

Material studies completed during this development project resulted in identification of a high-temperature flexible fabric for DSP bag construction. This material can withstand differential burst pressures of $50 \mathrm{psi}$ and wellbore temperatures of $450^{\circ} \mathrm{F}$. Techniques to fabricate the packer bags that employ standard industry procedures and processes have also been developed. Commercial suppliers were found to assemble and attach DSP bags to the DSP aluminum pipe.

A full-scale test bed, the Engineered-Lithology Test Facility, was designed, constructed and utilized to conduct ten full-scale OEDP and DSP experiments. This facility was designed to be adaptable and can be used for other full-scale geology experiments where a controlled engineered lithology and real-time or recoverable test results are required. 


\section{Conceptual Hardware Design and Deployment Procedures}

The following steps are required to deploy the drillable straddle packer downhole.

Figures 2 a through $\mathbf{2 d}$ show the hardware and the steps in schematic form. The

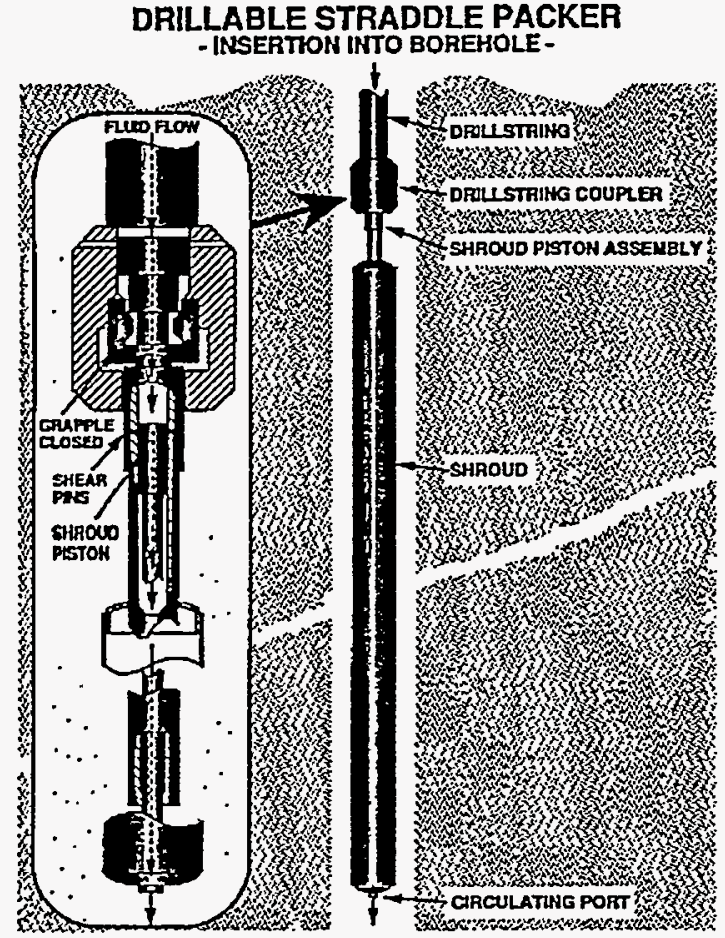

Figure 2a

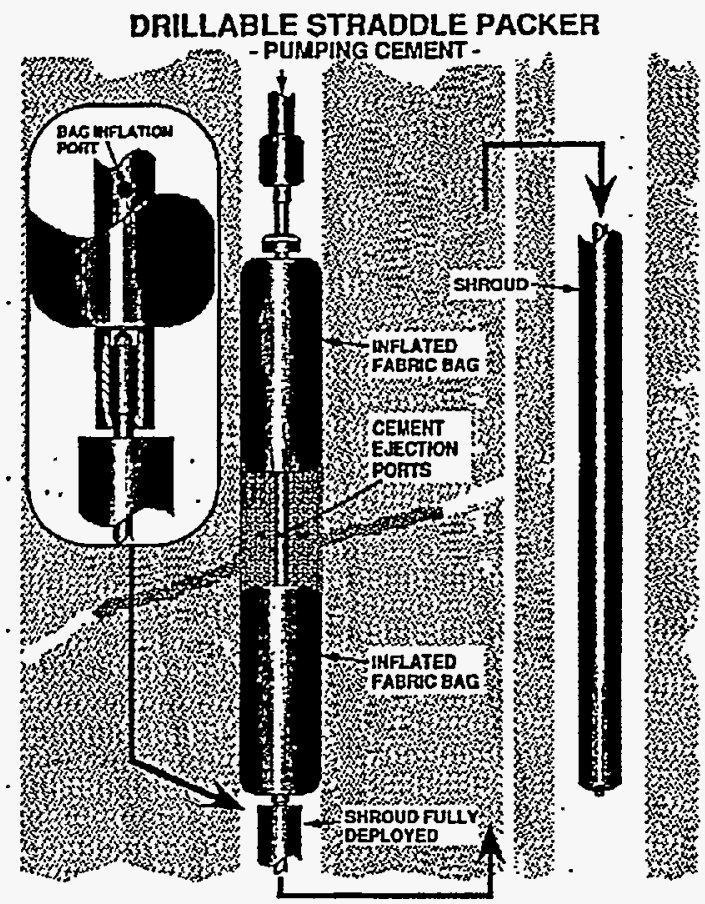

Figure 2c

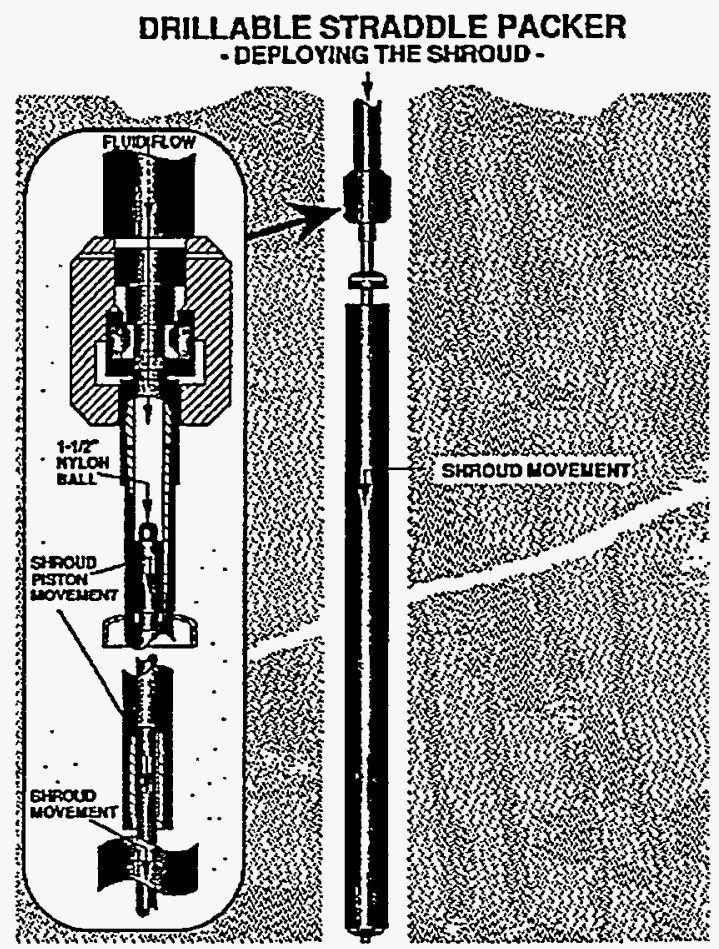

Figure 2b

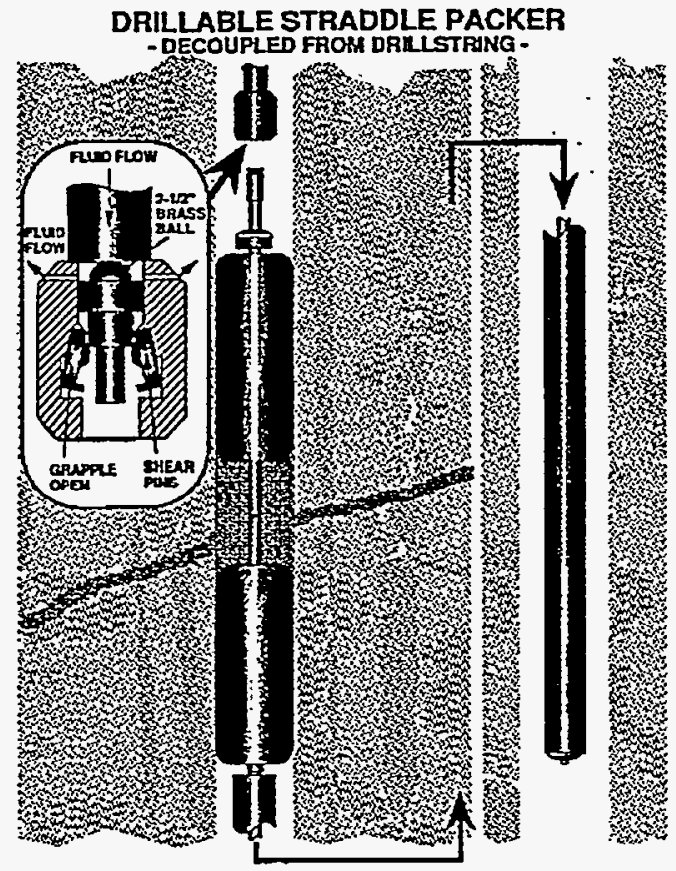

Figure 2d 
following procedures are used when deploying the DSP: A.) Thread the drillstring coupler and packer assembly onto the end of the drill pipe (Figure 2a). The packer assembly consists of all hardware below the drillstring coupler. B.) Trip the assembly into the wellbore, circulating through the drillstring and packer assembly as necessary during the trip in. The circulating passage through the tool is 1-inch minimum diameter. The packer shroud protects the fabric bags from abrasion during the trip in. The packer assembly should be positioned so that it straddles the loss zone. C.) Drop a 1-1/2 inch nylon ball down the drillstring to deploy the packer shroud and inflate the packer bags (Figure 2b). When the ball reaches the packer assembly, it seats in the top of the shroud piston, causing pressure to build above the piston, thereby breaking shear pins that hold the piston in the shroud piston assembly. The piston is pumped down through the packer tube, pushing the shroud ahead of it and opening the bag inflation ports to the fluid inside the packer tube (Figure 2c). D.) Begin pumping cement as soon as the 1-1/2 inch nylon ball is dropped into the drillstring. The cement follows the ball downhole and begins to flow out the cement ejection ports shortly after the bags are inflated. Pump a specified volume of cement while controlling the flow rate to achieve the desired bag inflation pressure. E.) After the specified volume of cement is pumped downhole, drop a 2-1/2 inch brass ball down the drillstring to decouple the drillstring from the packer assembly (Figure 2d). When the ball reaches the drillstring coupler, it seats in the top of the coupler piston, causing pressure to build above the piston, thereby breaking shear pins that hold the grapple closed. When the shear pins break, the grapple opens, releasing the top of the packer assembly. Movement of this piston also opens four 3/4-inch diameter circulating ports for pumping through the drillstring and clearing it of residual cement. F.) Trip the drillstring out of the wellbore. G.) When the cement hardens, trip into the wellbore with a bit and drill out the packer assembly and surrounding cement.

\section{Laboratory Prototype Development and Testing}

\section{A.) Fabric Selection:}

A search for fabric that could be used to manufacture the DSP bags was conducted. The fabric must withstand geothermal wellbore temperatures of up to $500^{\circ} \mathrm{F}$, be flexible enough to conform to the shape of a wellbore, have enough strength to contain a 40-psi pressure differential, be drillable, and provide an adequate wellbore seal. Several candidate materials were investigated, and a fiberglass fabric that was coated with silicone rubber was considered to be the best choice to meet our design requirements. To determine how this fabric would react under the tensile loading caused by inflation of the DSP bag, 75 stress tests on the fabric were conducted. Figure 3 shows the side view of a typical test setup for a fabric stress test. Loads were applied by securing the top shackle and applying an increasing load to the bottom shackle until fabric or clamp failure occurred. Several sets of components, including a simulated O-ring, were fabricated to enable us to clamp 2" wide strips of the test fabric and apply the tensile load. All clamping assemblies were fabricated from CPVC plastic, and the hardware used to secure the clamps to the fabric were all aluminum. These materials were selected since the DSP 


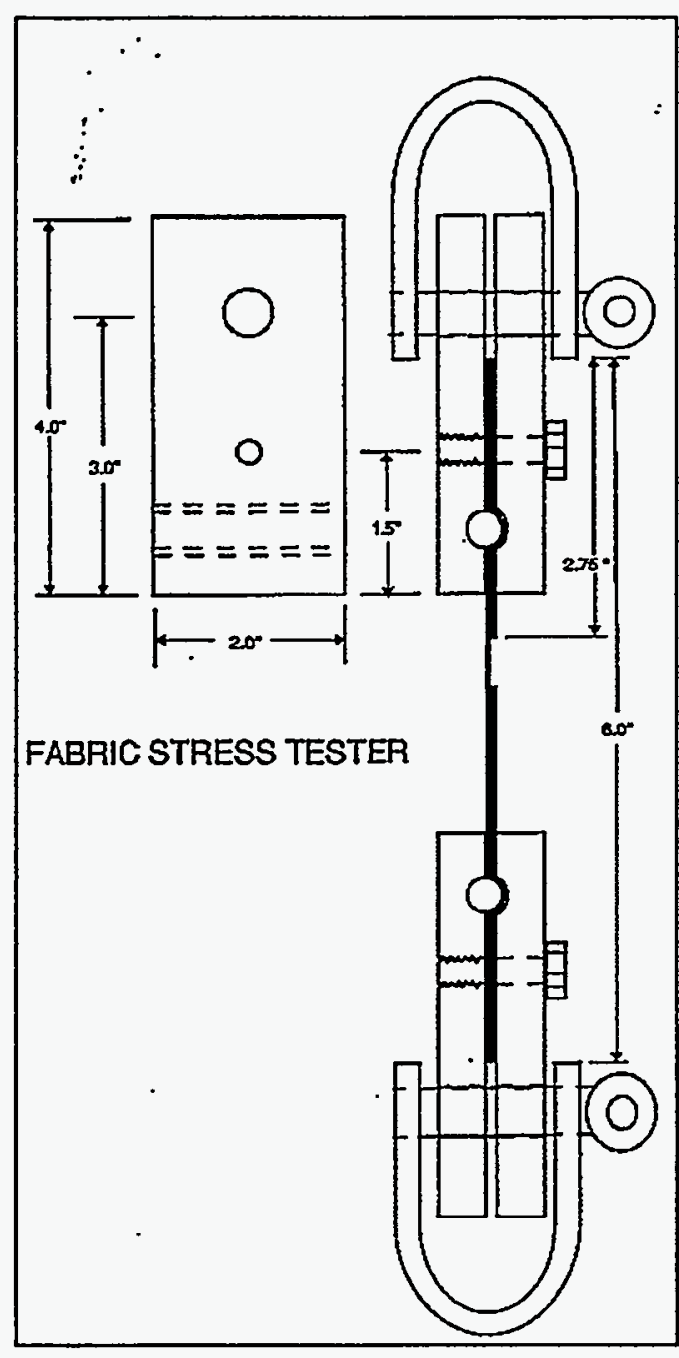

Figure 3 - Typical Fabric Test Setup.

was to be fabricated from drillable materials. Different clamping arrangements and fabric configurations within the clamps, as well as different thicknesses of fabric, were evaluated. Figure 4 shows a side view of the various clamping techniques employed. Test

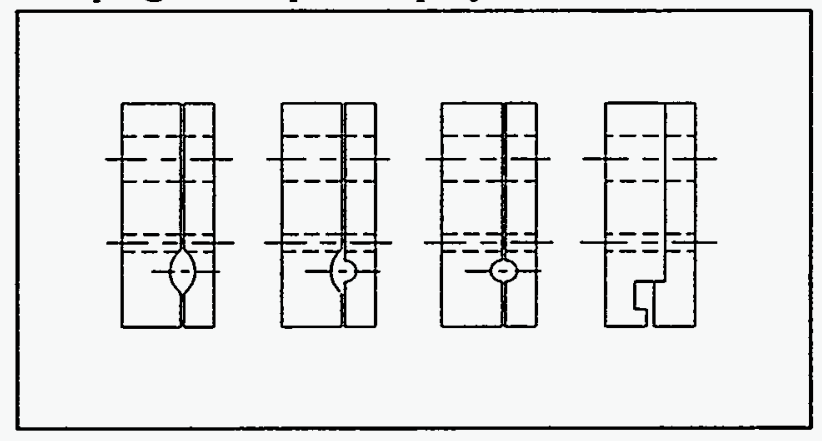

Figure 4 - Fabric Test Clamping Configurations configurations were driven by the foreseen bag design, bag-clamping methods for a DSP, and the calculated total required load for the fabric. All testing was done at ambient temperatures. Data from this testing is presented in Appendix A. The fabric ultimately selected to produce the DSP bags is a cured 50-mil weave, red siliconecoated fiberglass, produced and sold by Fabri Cote Division of A\&S Glass Fabrics Co., Inc., Los Angeles, CA, Part No. 1588. This material weighs $61 \mathrm{oz} . / \mathrm{sq}$. yd., is nominally .062" thick, and has a temperature rating of $450^{\circ}$ to $500^{\circ} \mathrm{F}$.

B.) Prototype Design and Development:

To evaluate the DSP prototype designs in a laboratory setting with full size simulation capability, a Packer Test Facility was designed, fabricated and installed, as shown in Figure 5. The purpose of this facility is to simulate the geometry and flow conditions of a typical geothermal wellbore. The facility contains a $16^{\prime \prime}$ diameter X $14^{\prime}$ high steel pipe, with American Standards Association (ASA) steel flanges welded to each end. The pipe is mounted vertically with the bottom flange secured inside an existing rectangular steel mud tank and the pipe secured to an existing steel structure. Side ports were installed in the pipe to model production and loss zones and evaluate DSP performance under simulated lost circulation conditions. A work mezzanine and a chain hoist were added to the facility for DSP handling and installation. This system is designed to produce flows up to $280 \mathrm{gpm}$ at pressures up to $1150 \mathrm{psi}$ during tests. 
The first prototype design of the DSP bag assembly is shown in Figure 6. This design utilized standard blank ASA type CPVC flanges for the bag bulkheads. The bulkheads were secured to CPVC pipe after being spaced apart along the length of the pipe to provide the desired length for the bag. Holes were drilled in the CPVC pipe, between the bag attachment bulkheads, to allow inflation of the bag through the I.D. of the pipe. The fabric bag was constructed in the form of a tube with a sewn longitudinal seam. This fabric tube was in turn attached to the bulkheads using steel hose clamps that were positioned in a groove machined around the O.D. of the CPVC flange. When pressurized, this bag failed at only 2.5 psi, well under the design differential pressure of 40 psi. Failure was due to the bag slipping under the band clamp and off the flange. when

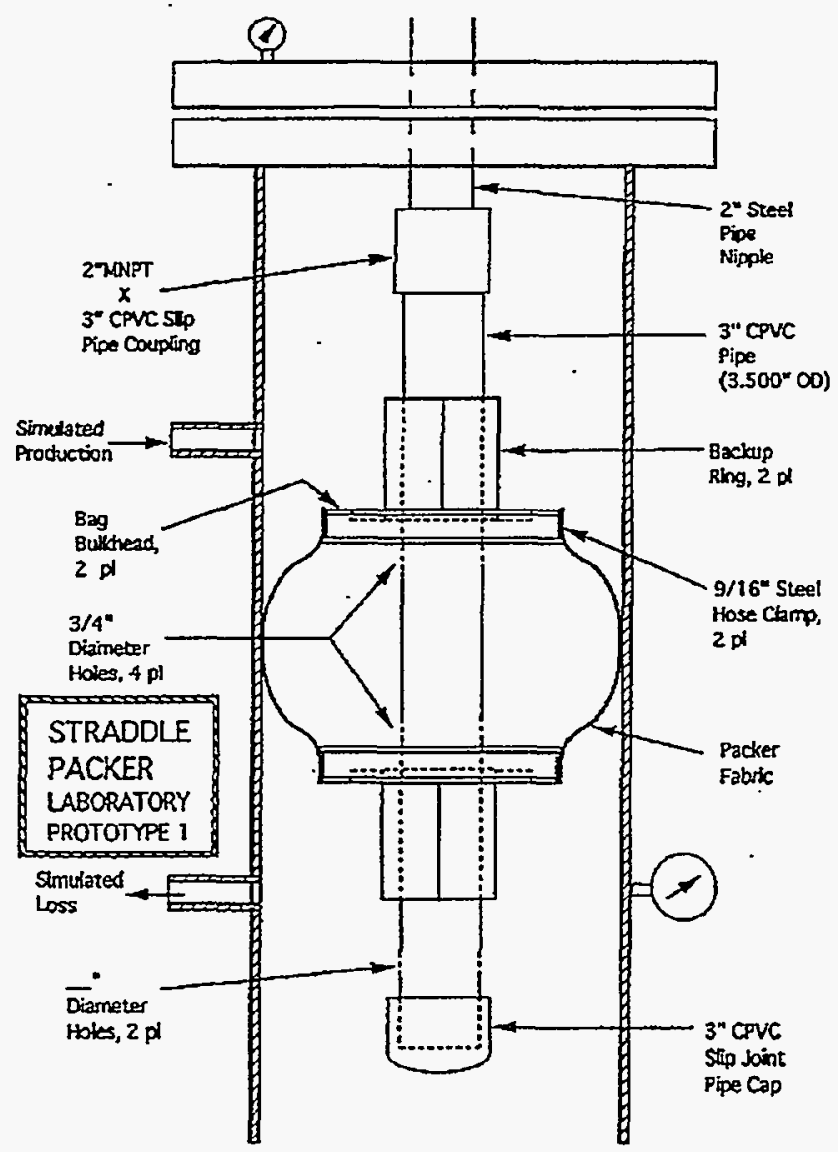

Figure 6 - First Prototype Bag Design

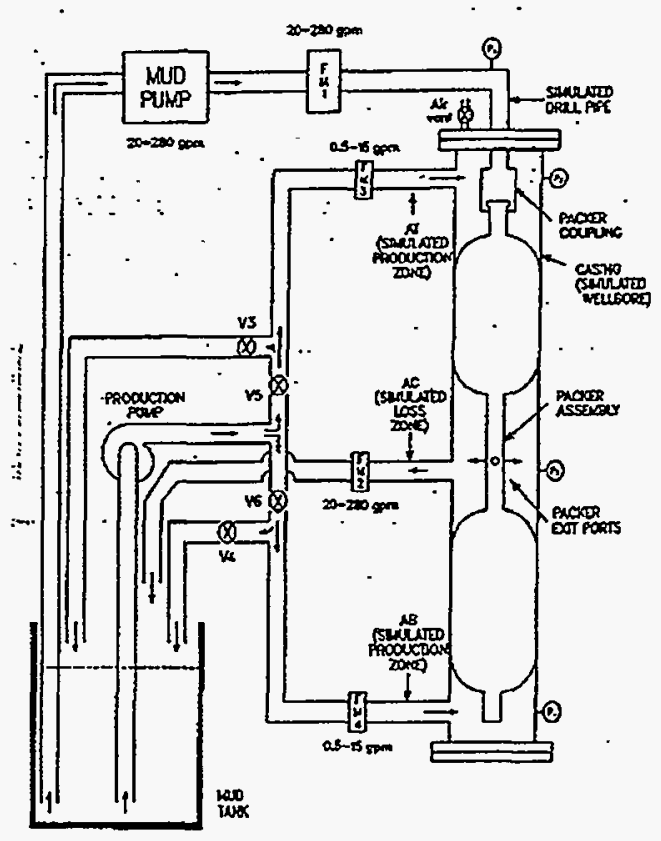

Figure 5 - Packer Test Facility Diagram

water filled the bag and the pressure began to increase. The bag-to-flange attachment method was revised and another test was conducted. Failures of the fabric bag material and/or the bag clamp at pressures below the design requirements continued. A total of 22 tests were conducted in an attempt to finalize the prototype DSP bag design. The method used to attach the bags to the flanges underwent continual improvement, as test results were evaluated. The final successful prototype of a flanged bag attachment design is shown in Figure 7. Even though successful in reaching minimum design pressure requirements, this bag attachment method was not considered to be totally adequate for DSP applications. This method was complicated and resulted in time-consuming assembly procedures.

An alternate method for attaching the bags to the pipe was found. This 


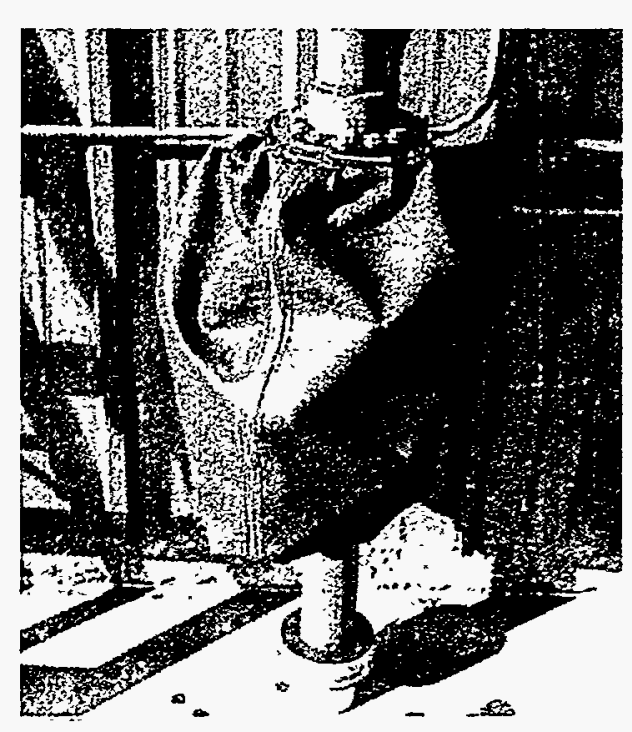

Figure 7 - Final Flanged Prototype Bag

method employs aluminum rings that are swaged to aluminum pipe, with the fabric bag material being clamped between the rings and the pipe. Petersen Products Co., Fredonia, WI produces inflatable sewer-pipe plugs using this attachment method. These plugs are made from canvas bags with internal rubber bladders, as shown in Figure 8. To produce the sewer plugs, a ring-swaging

the DSP were fabricated at Sandia and sent to Petersen Products for attachment, using their ringswaging process. The performance of these DSP bags showed marked improvement over bags produced using other end-attachment methods. Test results show that this is the most reliable

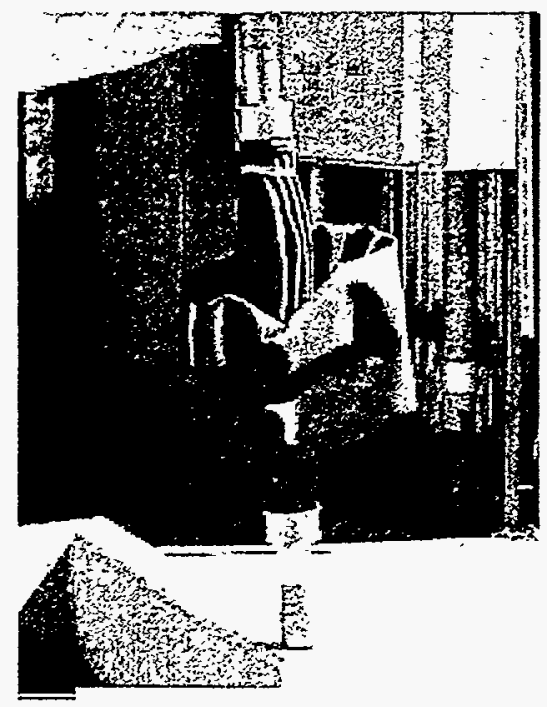

Figure 9 - DSP Bag with Peterson Swaged Rings process was developed by Petersen to attach their bags to metal pipe nipples. Bags and aluminum pipes for

method found, to date, for attaching the DSP bags to aluminum pipe. Figure 9 shows a

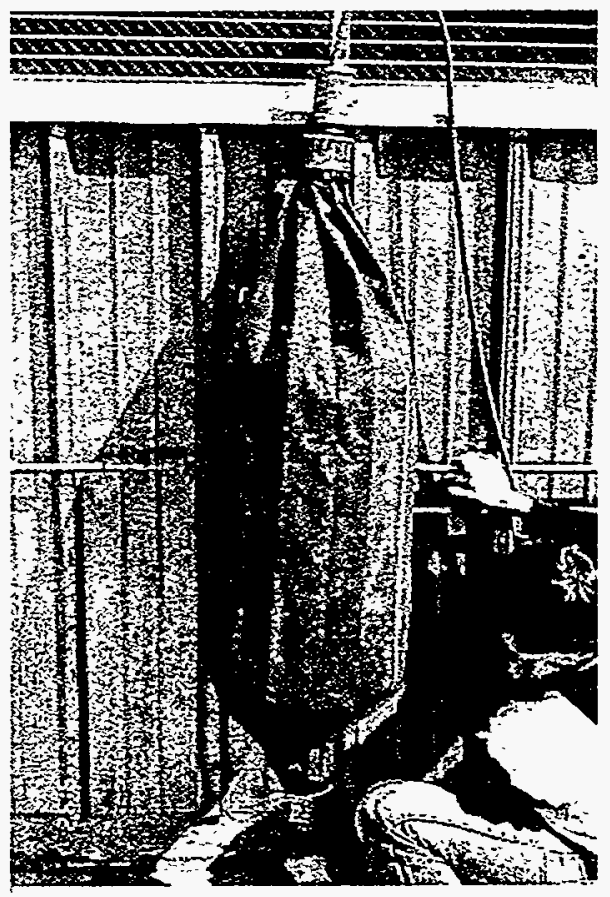

Figure 8 - Peterson Sewer Pipe Plug typical DSP bag attached to an aluminum pipe using the Petersen swaged aluminum ring method. Differential burst pressures greater than 50 psi were recorded (see Appendix E) using these bags, and no failures as a result of the bag fabric material pulling out of the swaged ring were noted.

Summary results of this testing are provided in Appendix B, and complete documentation of bag development can be found in the Geothermal Research Department project files. These files are available for review upon request. 


\section{Full Scale Test Facility}

To evaluate the DSP in a full-scale test environment, a test facility was envisioned that would allow the test bed lithology to be engineered to meet various specialized experimental requirements. It would utilize concrete pipe for a wellbore, clay soil for impermeable geologic zones, and gravel beds for permeable geologic zones. The facility would contain a fluid-flow plumbing system to permit water re-circulation (both ambient and hot water) into and out of the permeable layers to model geothermal production and loss zones. Finally, it needed to be large enough to test the DSP in full scale when using actual cement pumping equipment employed at typical geothermal well sites.

\section{A.) 1/5 Scale Test Configuration:}

Prior to finalizing a design for this new facility, a test plan was formulated to construct a $1 / 5$ scale model and conduct a test to demonstrate the viability of the overall approach, validate requirements for full scale development, and provide design input for a full-scale facility. A 1/5 scale test plan was formulated, and materials were procured. As shown in Figure 10, a containment structure was constructed of plywood and $2 \times 4$ lumber. The plumbing to flow water and/or cement into a gravel bed was constructed of 3 " Schedule

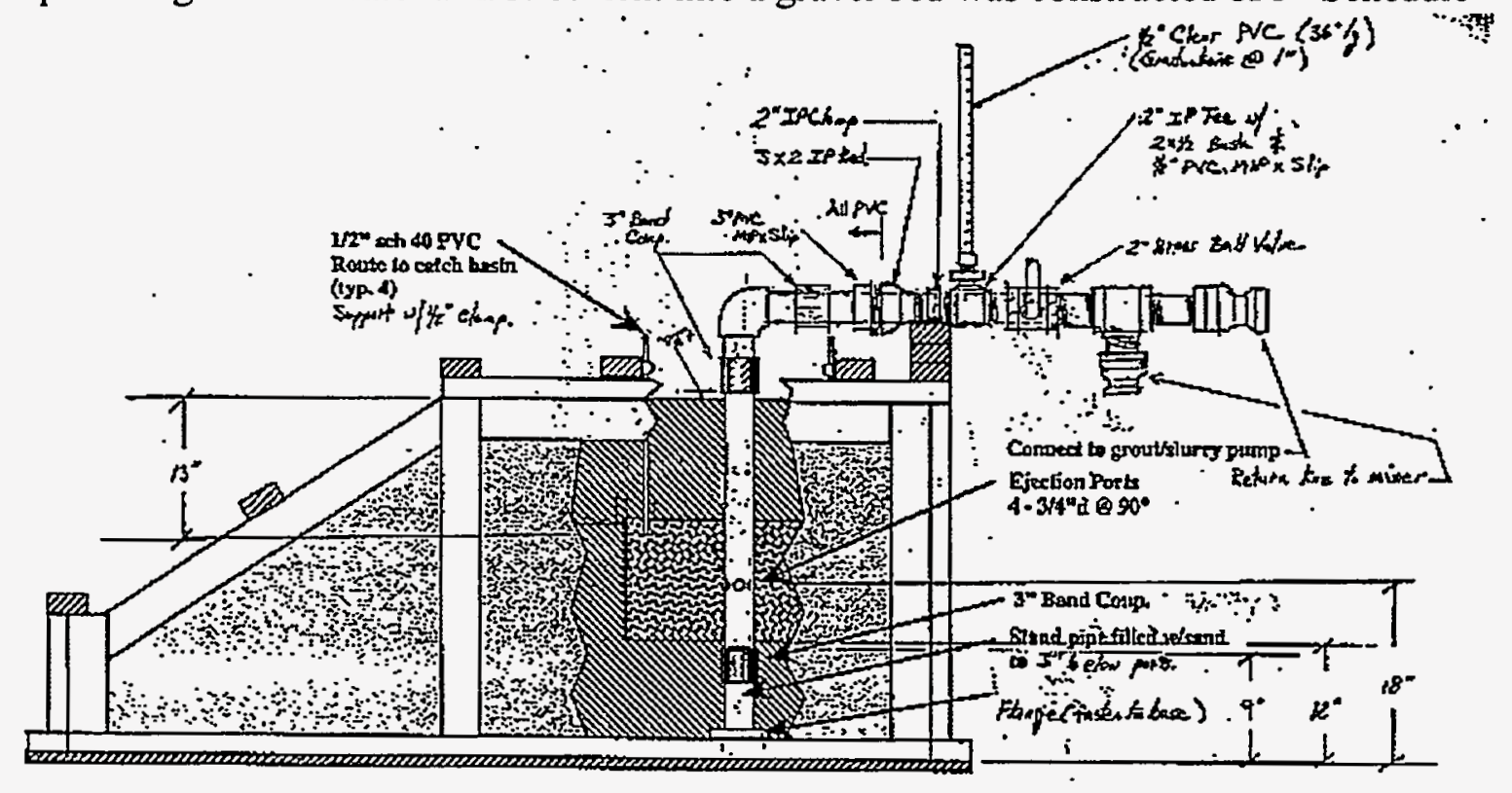

Figure 10- 1/5 Scale Test Bed Assembly

40 PVC pipe with 3/4" diameter holes for injection ports and steel pipe and fittings, as required. A 24" X 24" X 15" high box/frame was fabricated from 14-gage sheet metal for use as a form when installing the gravel in the test bed. This form had an open top and bottom so it could be removed after the gravel was placed inside and the clay placed and packed around the outside.

A 3" PVC pipe was used to model the wellbore and was placed in position inside the plywood structure. Clay was then placed in the plywood structure and around the 3" 
PVC pipe and compacted to a depth of $12^{\prime \prime}$. The sheet metal form was then placed on top of the 12" of compacted clay and centered around the 3" PVC wellbore. A screen was placed over the holes in the PVC wellbore to keep out gravel. Gravel was placed inside the sheet metal form to a depth of 12 " to form a gravel bed, as shown in Figure 11. A second layer of clay was then placed around the outside of the sheet metal form and compacted to an additional 12" of depth. The sheet metal form was then removed. Four $1 / 2$ inch schedule-40 PVC vent pipes were installed in the gravel and routed to the outside of the plywood structure. A piece of 5-mil plastic

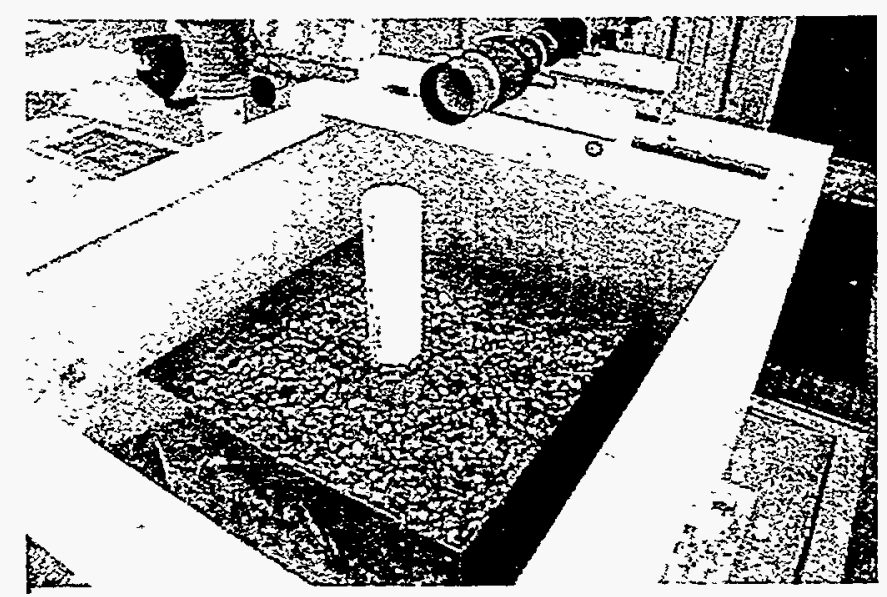

Figure 11 - Gravel Bed Installation sheet was placed on top of the gravel bed, to isolate it from the clay. The third and final 12"-thick layer of clay was then placed in the plywood structure and compacted to completely fill the test bed. The total depth of compacted clay, including the clay layer with the gravel bed, was 3 feet.

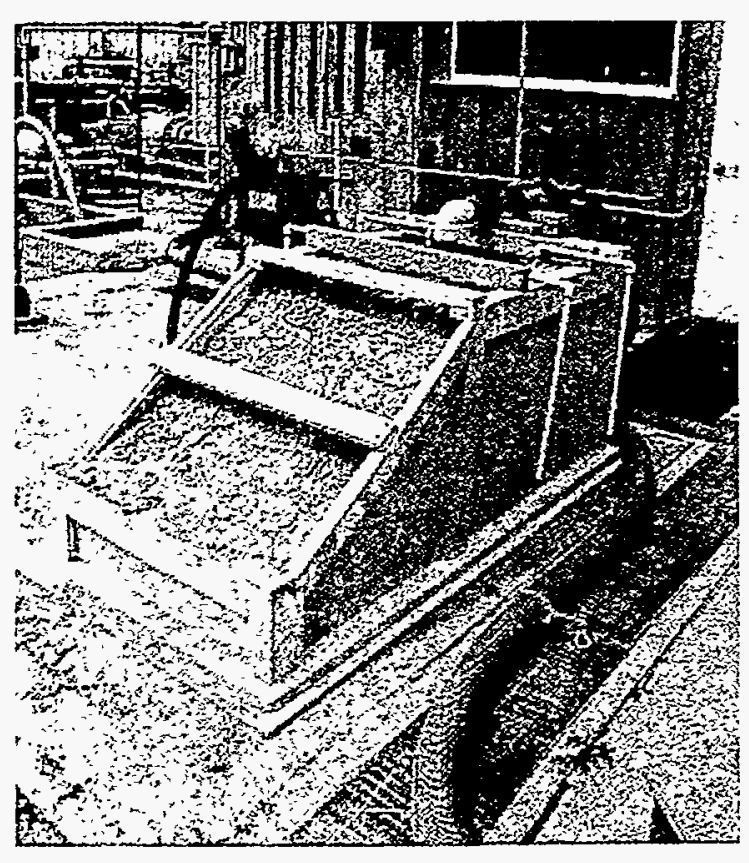

Figure 12 - 1/5 Scale Test Bed Ready for Test

Water was poured slowly into the 3" PVC wellbore and, as required, additional water was added until absorption of the water by the gravel and clay stopped and water remained in the wellbore. The 3" PVC elbow and the remaining plumbing was then attached to the wellbore pipe, including connections to the cement pump and mixer, as shown in Figure 12

Enough Portland cement was mixed in the portable mixer to fill the voids in the gravel bed, the PVC wellbore, and the system plumbing. A red iron-oxide dye was added to the cement during the mixing operation to make it easier to distinguish the cement from the gravel during post-test excavation. A grout pump was used to pump the cement from the mixer into the PVC wellbore and out into the gravel bed through the four $3 / 4$ "-diameter injection ports in the wellbore. The peak head pressure required to force the cement into the gravel was $20 \mathrm{psi}$. Cement was pumped until the cement and/or red dye flowed out of the vent pipes. Different amounts of overflow were recorded from the four vent pipes. 
After the proper cement curing time elapsed, the test bed was excavated to examine the gravel bed and verify how well cement flowed in the voids in the gravel. Figure 13 shows clearly that, except for the very corners, the cement flowed freely through the gravel bed and completely filled all voids. The saturated clay retained the water in the gravel bed well enough to conduct the test.

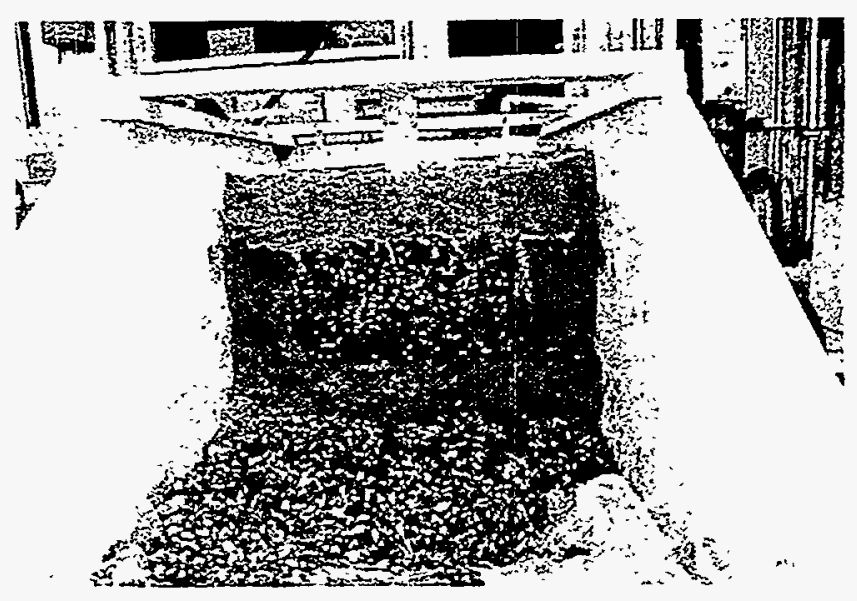

As a result of this test, design specifications for a full scale Figure 13 - 1/5 Scale Cemented Gravel Bed Engineered Lithology Test Facility were developed and finalized.

\section{B.) Full Scale Test Facility Construction:}

The Engineered Lithology Test Facility (ELTF) was constructed on the Geothermal Research Department's Geotechnology Test Range located in the southeast quadrant of Sandia Technical Area 3. A novel approach to procuring this facility was used in an attempt to minimize design and construction costs. Specifications were prepared to meet our test chamber requirements and an engineering drawing, reference Figure 14, showing the basic facility design requirements was prepared.

A statement of work was prepared, and requests for quotations were solicited. This approach permitted the bidder to provide the test chamber using any acceptable method of fabrication that would meet our basic specifications, while allowing them the freedom to use the design and fabrication method best suited to their particular capabilities. All bid proposals were reviewed by Sandia, this included the Civil Engineering Department in the Facilities organization, to verify compliance with the statement of work, structure construction procedures, and civil engineering design standards. A competitive cost contract was awarded that required the work to be completed in two phases. The concrete foundation was emplaced during the first phase under a separate contract, while the test chamber was completed and installed under the second contract, as phase two. Since the concrete foundation had to be formed and poured in place in Technical Area 3, the work was done under a standard facilities contract placed through the Facilities organization. The foundation was installed to be compliant with the design provided by the test chamber contractor. After inspection and approval of the foundation by the test chamber contractor, the test chamber was fabricated off-site, moved to Tech Area 3 and installed to complete Phase 2. 
The site was prepared, the foundation formed, and the concrete poured as shown in

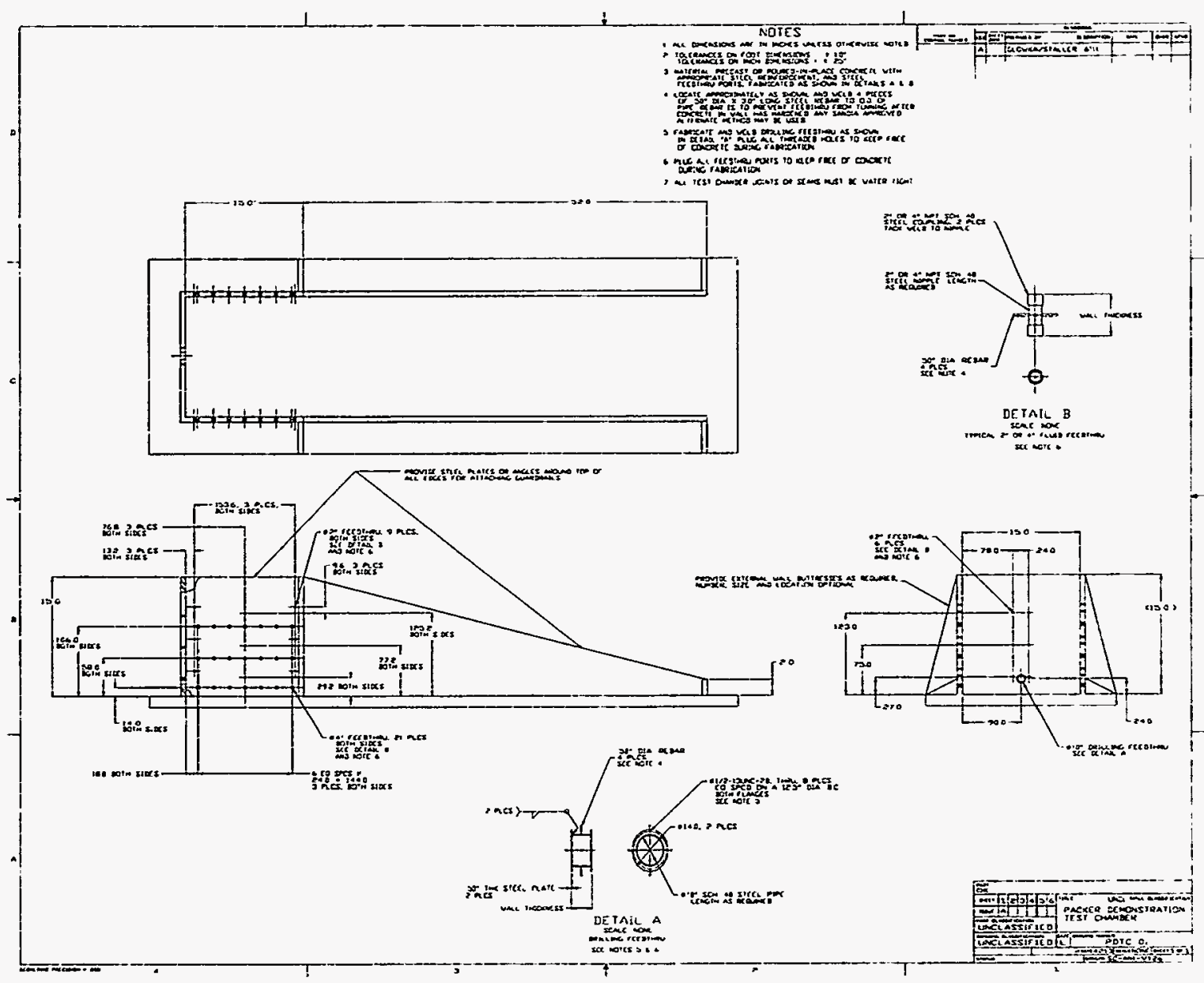

Figure 14 - Test Chamber Drawing

Figure 15. After the forms were removed the foundation was back-filled and the concrete allowed to fully cure prior to installation of the test chamber. The test chamber
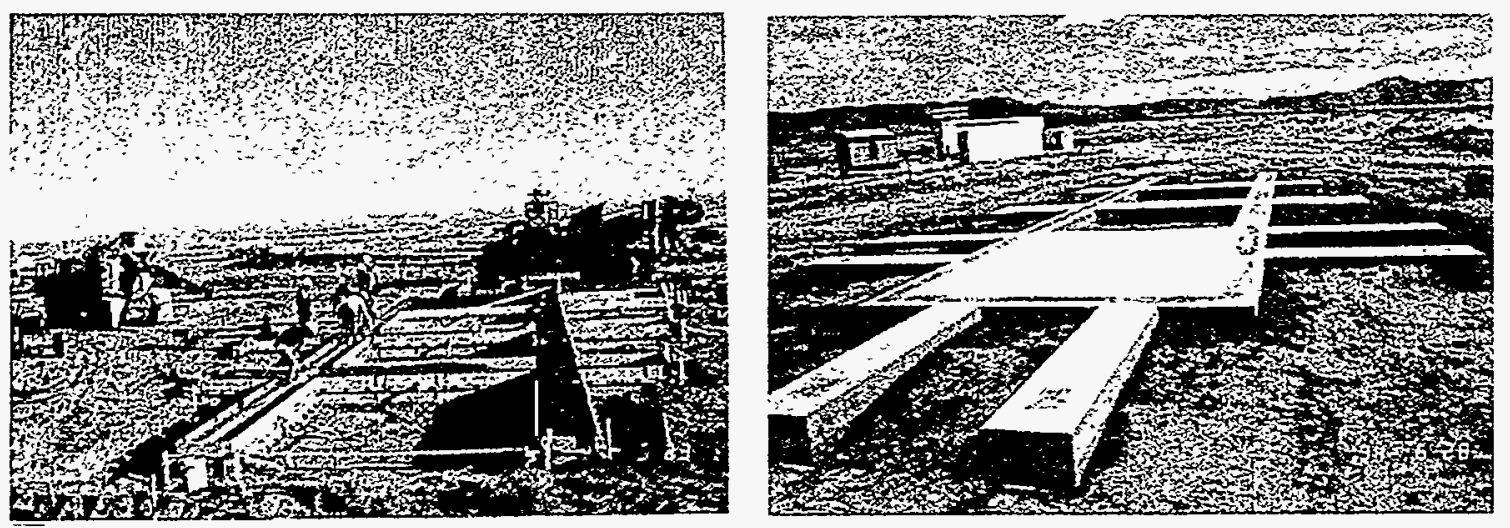

Figure 15 - Test Chamber Foundation 
walls were fabricated off site and designed to be portable and to be installed promptly on the foundation. A total of nine sections of chamber and ramp retaining wall were fabricated to produce the test chamber. As shown in Figure 16, the wall sections were
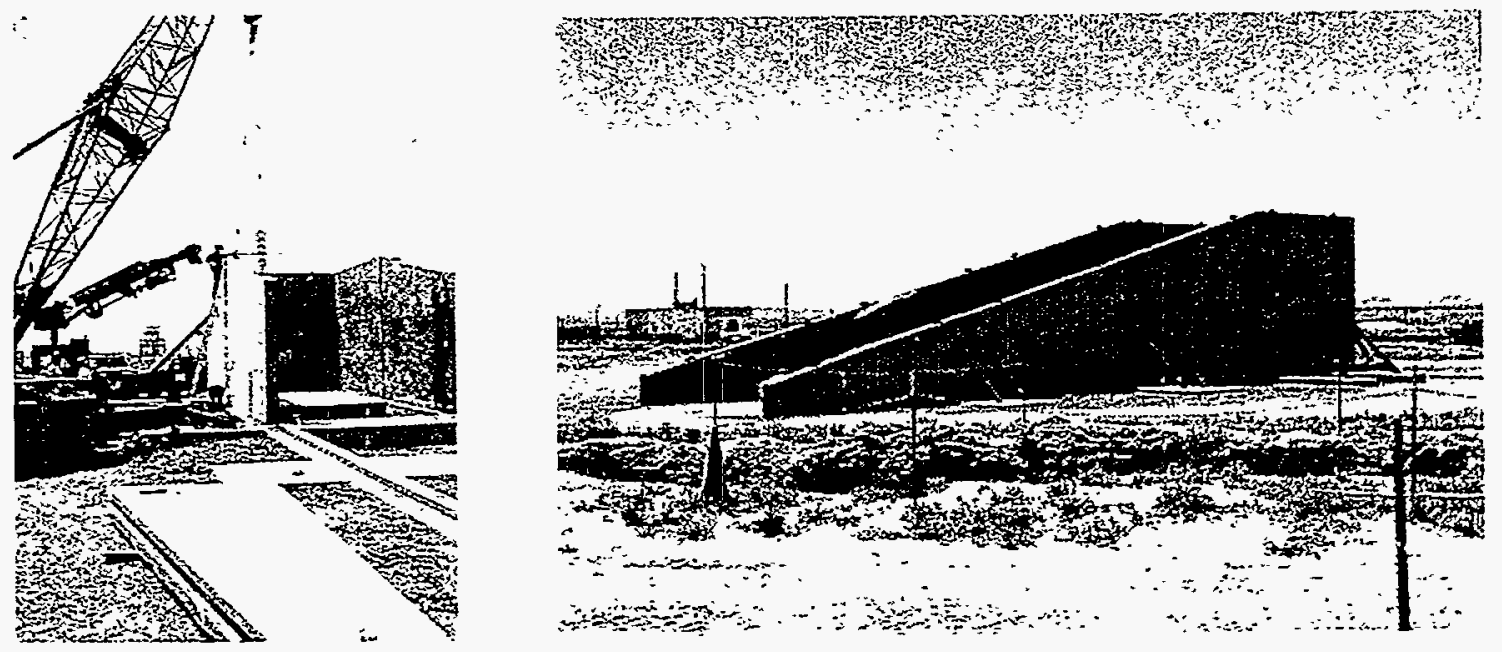

Figure 16 - Test Chamber Installation

transported to Tech Area 3, positioned on the foundation with a crane, braced, and welded in place by the contractor. Upon completion of the test chamber, a CPVC piping system was designed, procured, and installed to flow water into and out-of the test chamber at three independent levels and at various flow rates. Figure 17 shows the

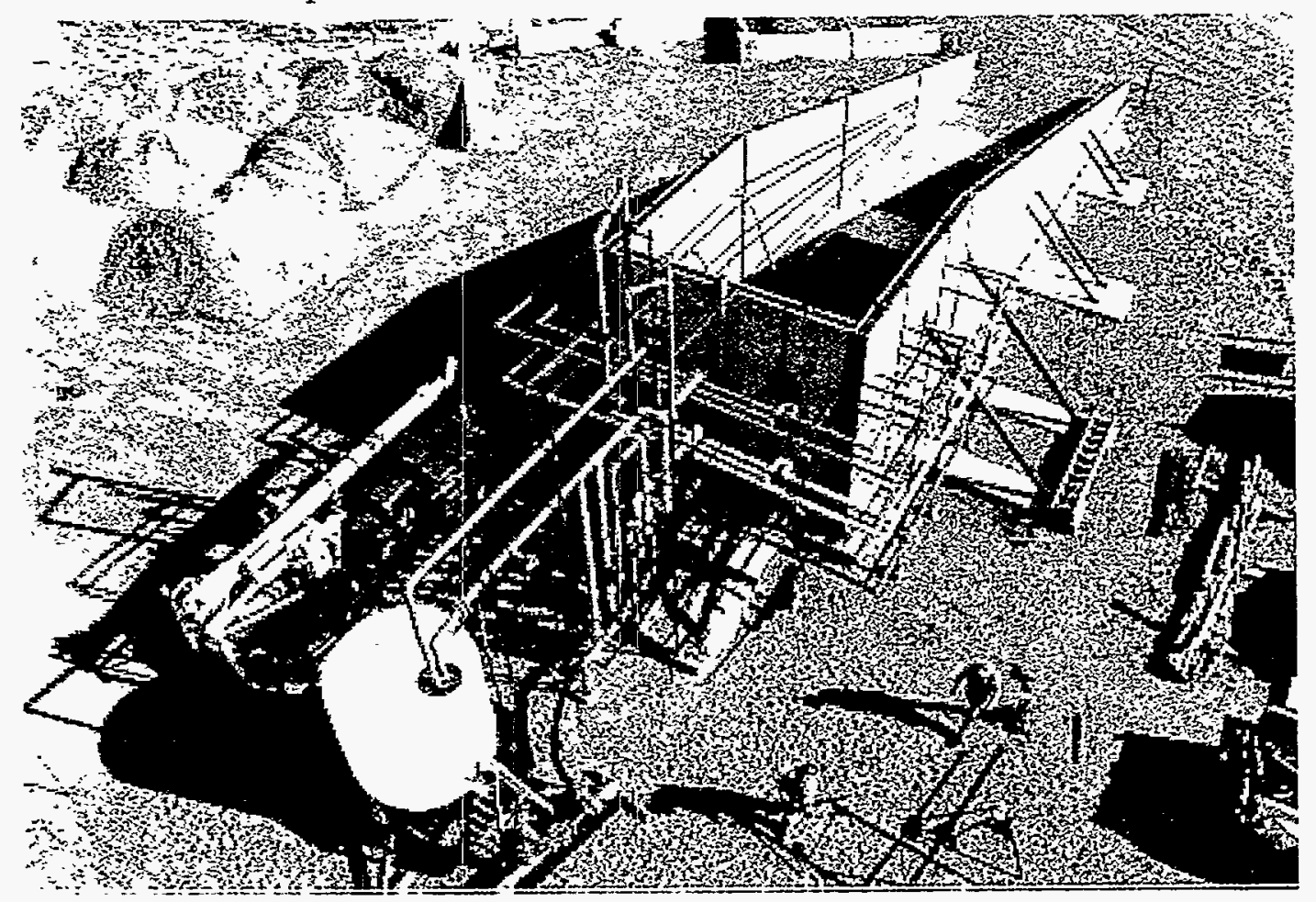

Figure 17- Engineered Lithology Test Facility

ELTF with the plumbing system piping in place. Water flow rates up to $425 \mathrm{GPM}$ at 
temperatures up to $200^{\circ} \mathrm{F}$ are available. Flow through the various levels is monitored with flowmeters and valve manifolds are used to direct the flow to or from the three levels during a test.

\section{Full-Scale Development Testing}

Based on the results of the $1 / 5$ scale test, a test plan was formulated to basically duplicate the $1 / 5$ scale test, at full scale, in the ELTF. Enough clay and gravel was procured to fill the test chamber and the access ramp for the first test. This initial test was to be a baseline loss-zone cementing experiment using the standard industry open-end-drill-pipe method to place the cement in the loss zone. This method involves pumping cement into the wellbore from the end of an open drill pipe located just above the loss zone. The method assumes that cement from the open drill pipe forms a standing balanced plug in the wellbore, at the loss zone, and cement then flows into the permeable zone and plugs the loss. After cement is pumped into the ELTF test bed, and cures, the test bed is excavated and the gravel beds can be examined to determine where the cement was deposited. Results of this test were then to be used to directly compare open-end-drillpipe loss-zone cementing with the results of the drillable straddle packer loss-zone cementing technique.

\section{A.) 15" ID Concrete-Pipe Wellbore Tests 1 and 2 without DSP:}

The first test bed was designed with three $12^{\prime} \mathrm{X} 12^{\prime} \mathrm{X} 1^{\prime}$ thick gravel beds stacked vertically and separated by 36 inches of clay between layers, see Figure 18. Each gravel

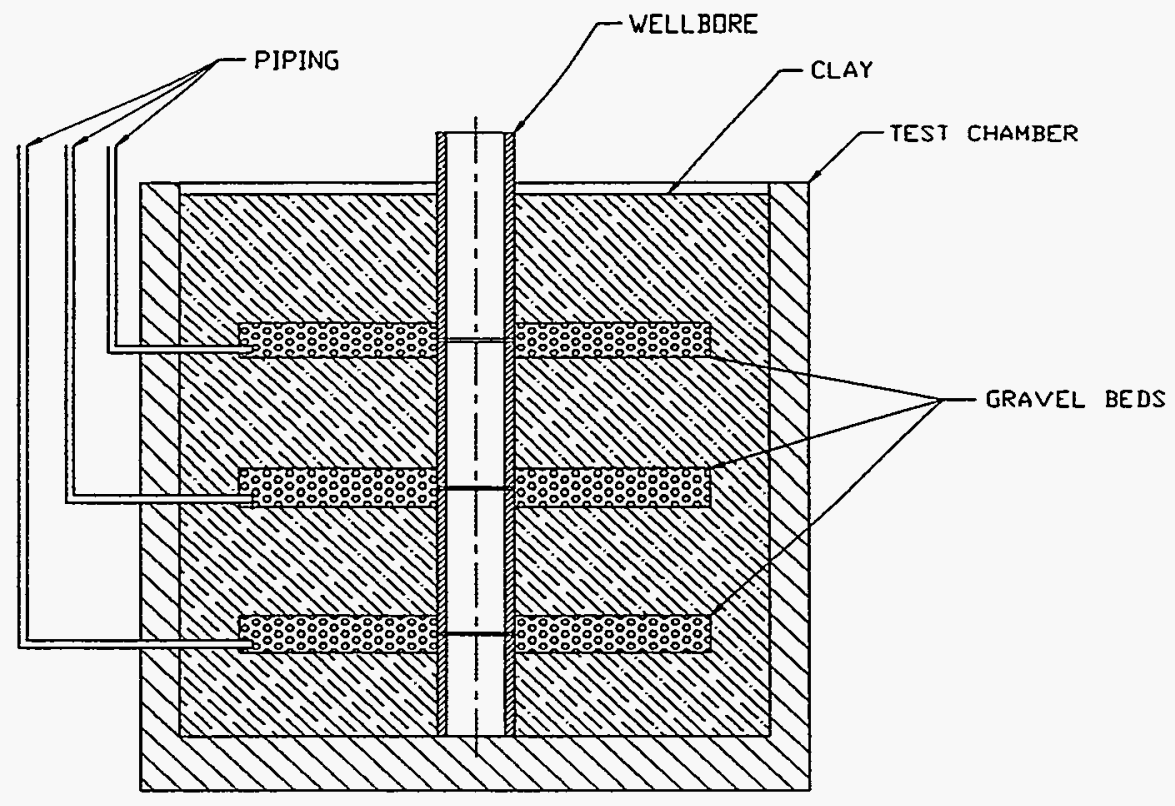

Figure 18 - ELTF Test Bed Cross Section

bed represented a permeable loss or production zone, while the $15^{\prime} \times 15^{\prime} \times 15^{\prime}$ volume of clay formed impermeable zones. The access ramp consisted entirely of clay. In order to 
model the wellbore, four pieces of 15 "I.D. X 20" O.D. reinforced concrete pipe were purchased and cut to required lengths. The sections of pipe were stacked vertically with $0.5^{\prime \prime}$ gaps between pipe sections to simulate a crack in the wellbore that communicated directly with the gravel bed. The top gravel bed modeled a production zone, and water flowed into the wellbore from this zone. The middle gravel bed represented the loss zone, and water flowed out of the wellbore into this zone and returned to the ELTF system storage tank. The bottom gravel bed was closed (no water flowing in or out) and provided additional volume to model a deeper wellbore. Each gravel bed was instrumented with 20 thermocouples to monitor cement temperature while curing, thus providing cement distribution information. Pressure transducers ( 8 total) were located in the gravel beds, wellbore, and drill pipe to monitor cement pumping pressures during cementing operations. Figure 19a shows the bottom gravel bed plywood forms with a plastic sheet liner and a PVC water flow distribution manifold installed. Figure 19b shows the middle gravel bed with the gravel and temperature instrumentation installed, while 19c shows the top bed during the final installation of the temperature sensor instrumentation.

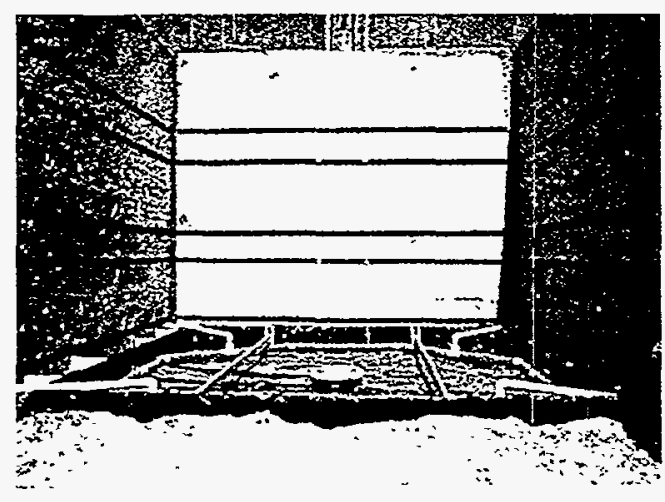

Figure 19a - Bottom Gravel Bed Test 1

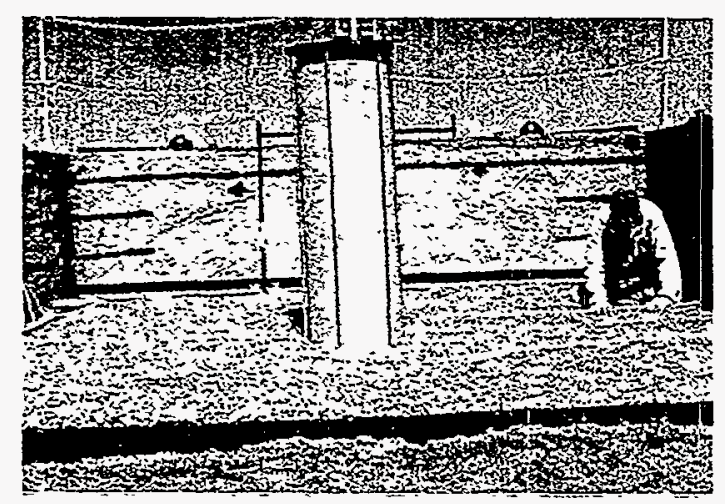

Figure 19c - Top Gravel Bed Test 1

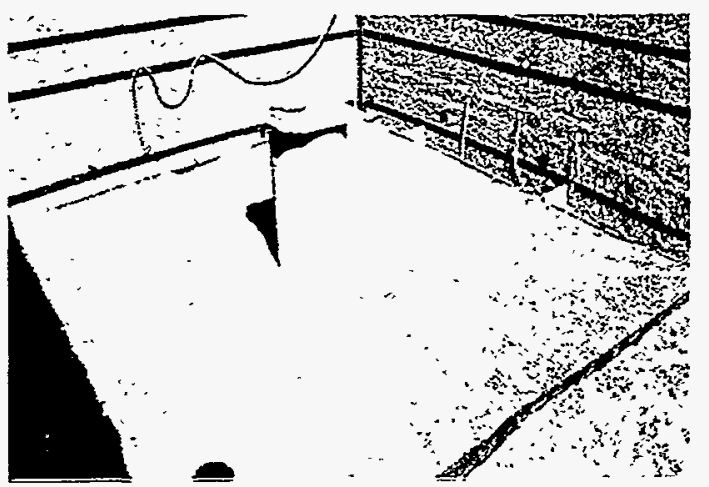

Figure 19b - Middle Gravel Bed Test 1

Figure 20a shows the top of the test chamber after all the clay has been installed and compacted. Four inch PVC simulated drill pipe and the top plate for the well are also shown. The clay ramp with the Halliburton truck and the piping to pump the cement are shown in Figure 20b.

\section{In preparation for the first test, water was} pumped into the top gravel bed (simulated production zone) and thus into the wellbore through the top gravel bed and flow rates were recorded. During this flow test leakage was visible around several ports on the test chamber wall. Leakage was also noted when the water inflow was terminated and the water level in the wellbore dropped indicating some leakage into the clay from the various gravel beds. 


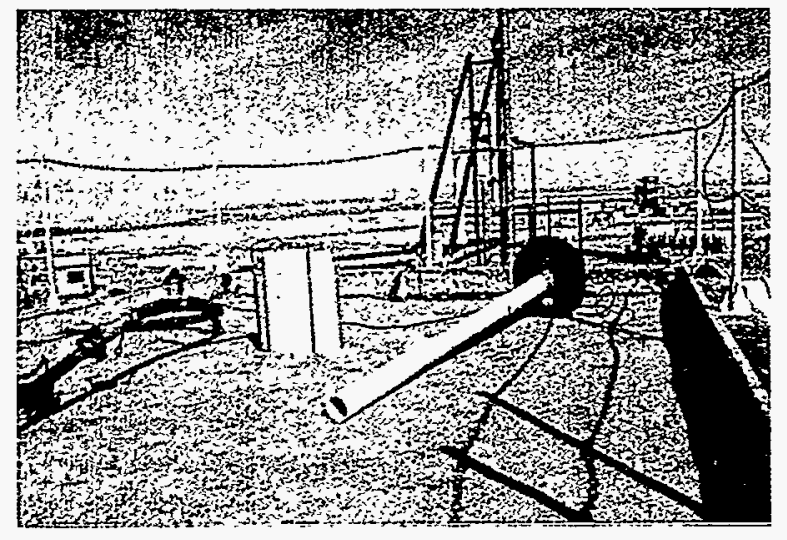

Figure 20a - Top of Test Chamber

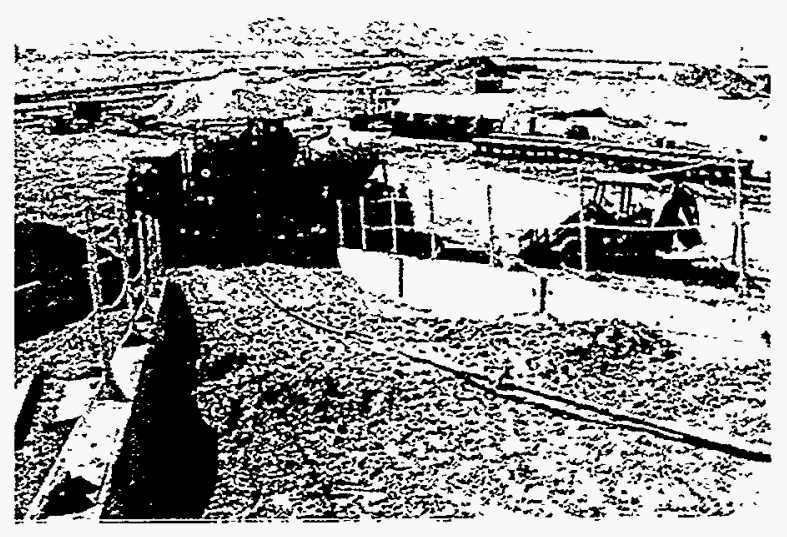

Figure 20b - Clay Ramp

The first test was conducted on 5/4/95. In order to quickly fill and keep the wellbore full of water, during the test, the inflow flow rate was initially set at $400 \mathrm{gpm}$ then reduced to approximately $50 \mathrm{gpm}$ during the time the cement was being pumped. Several leaks were observed around the test chamber walls and on the clay ramp during the test. It was believed that the initial surge of water into the top gravel bed may have washed away some of the clay covering the gravel bed and thus contributed to additional erosion paths for leakage The wet clay did not provide the needed sealing between the concrete test chamber walls and the clay, therefore when water migrated to the walls it immediately formed a flow path along this interface and washed out the clay. This leakage did not, however, adversely affect the test, and Class $\mathrm{G}$ oil well cement was successfully pumped into the wellbore, through the open-end PVC drill pipe, from the Halliburton truck. The outlet from the drill pipe was located 12" above the middle gravel bed (loss zone) in the wellbore. To make it easier to track the cement flow in the gravel beds during post test excavation, the cement was dyed red with an iron oxide powder that was added to the cement during the mixing process in the Halliburton truck. Prior to pumping the cement into the wellbore, one barrel of cement, as measured by the gauge on the Halliburton truck, was pumped into an empty 55 gallon drum. The amount of cement in this drum was then measured to calibrate the Halliburton gauge. Thirteen barrels of cement were

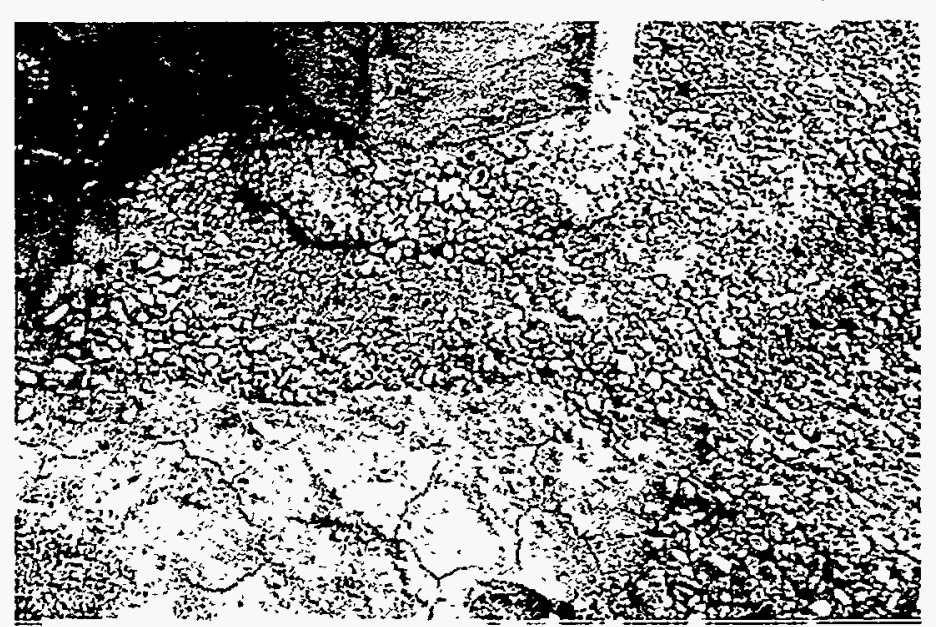

Figure 21 - Excavated Top Gravel Bed, Test 1 pumped into the wellbore. The total volume of the wellbore and the void volume in the gravel beds was approximately 33 barrels.

Temperature data indicated that cement was present in all three gravel beds with the largest amount being in the bottom bed. After the cement was allowed to cure for several days, the test bed was excavated. Excavation began at the top of the test chamber and was completed basically in the 


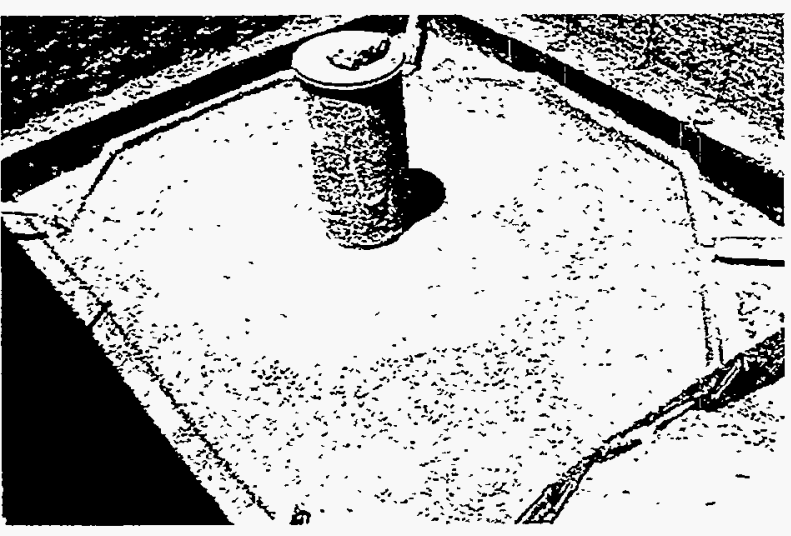

Figure 22 - Excavated Middle Gravel Bed, Test 1

reverse order used during installation. Small sinkholes were found along the test chamber walls where erosion took place during the test. Figure 21 shows some cement infiltration into the top gravel bed. Excavation continued slowly with care being taken to minimize disturbance of the gravel beds. More cement was present in the middle bed, as expected, since this was our simulated loss zone. Figure 22 is a photograph of the middle gravel bed after all loose gravel was removed. Note the colored cement that filled the gravel voids to the complete 12 " bed thickness and flowed out to about an $8^{\prime}$ diameter around the wellbore. This cement completely bonded to the gravel, and the gravel was joined on the bottom over the full 12' diameter of the test bed, as shown by the sloping edge of the cemented gravel. The largest amount of cement was found in the bottom gravel bed and as shown in Figure 23 the cement flowed into the 12 " thick gravel bed over almost the entire test bed. Test

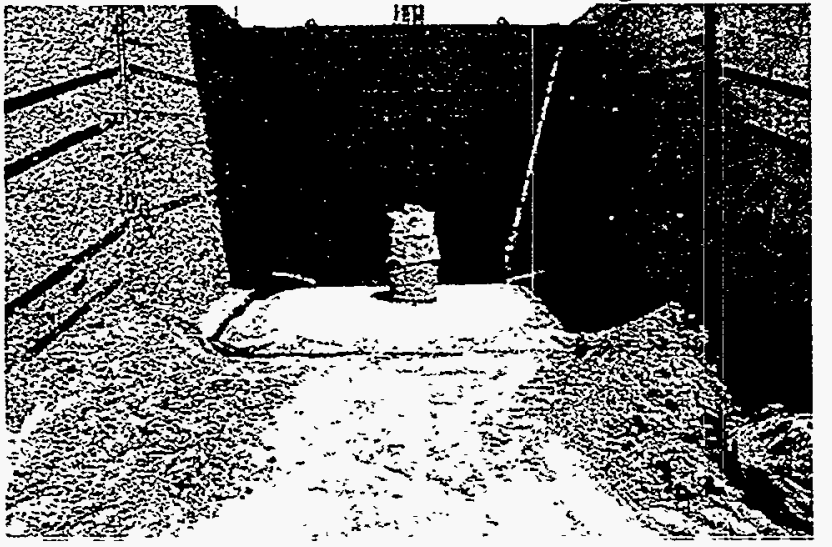

Figure 23 - Excavated Bottom Gravel Bed, Test 1 results indicate that the cement falls to the bottom of the wellbore then fills the well until it can flow into the loss zone. Evidence of a standing balanced plug in this water-filled wellbore could not be found; however, since test bed erosion was considered excessive and may have affected the test results, a repeat of this test was essential to establish our baseline.

To better contain the water in the gravel bed during the second test, flexible plastic containment boxes were produced from commercial polyethylene geomembrane material routinely used to line landfills. This "geo-box" was 12'X 12'X 1'thick and made from .060" thick high density polyethylene. Ports were installed in the geo-box for water pipe and instrumentation feed-through connections and for attachment and sealing to the wellbore concrete pipe. After the geo-box was filled with gravel, a geomembrane cover was installed to provide a water tight seal over the gravel bed. The cover was attached to the geo-box by employing industry standard extrusion welding techniques, that are used to join geomembrane liner materials together in landfills, to provide a water tight seal. Geoboxes were produced for each of the three gravel bed layers. A 2X4 lumber and plywood frame was constructed to support the outside perimeter of the geo-box during gravel installation. 


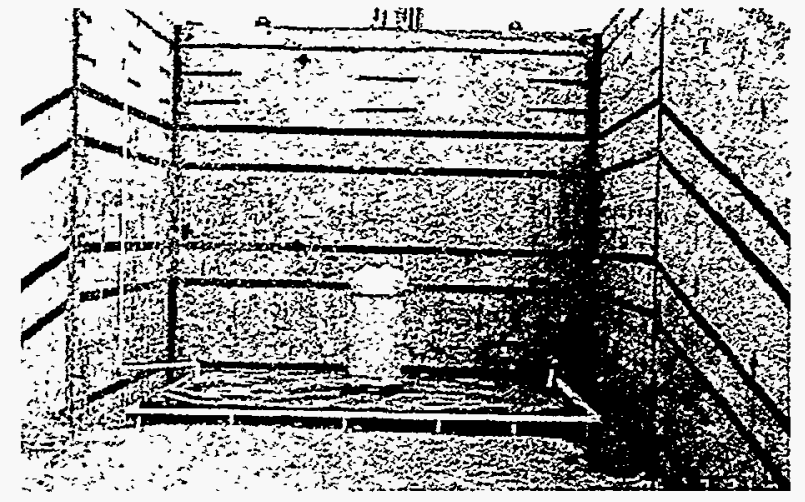

Figure 24 - Bottom Gravel Bed Test 2

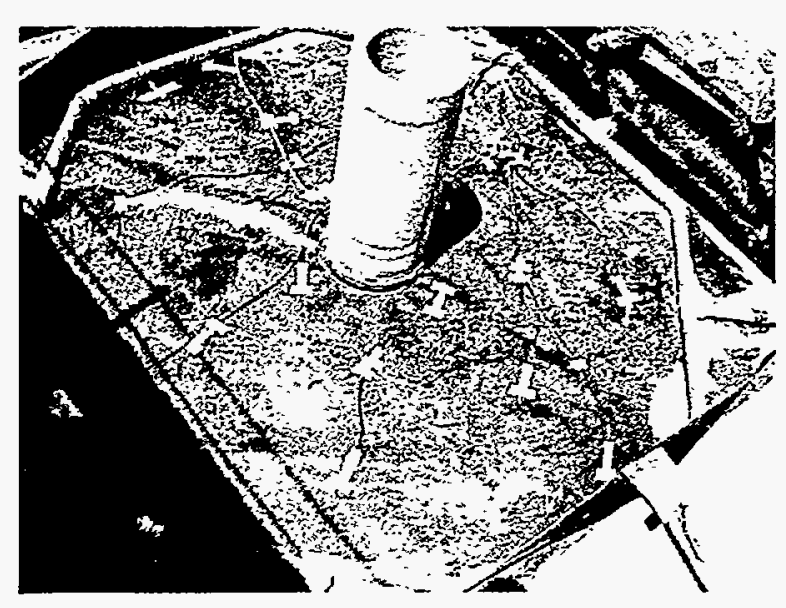

Figure 25a - Middle Gravel Bed Geo-Box Test 2

The test bed was again assembled in the ELTF test chamber. Since the bottom clay layer was not removed during excavation of test 1 , installation began with the bottom gravel bed. Figure 24 shows the bottom gravel bed with the geo-box, wood frame, instrumentation cables, gravel, concrete wellbore pipe, and cover installed. A PVC vent pipe is also visible. They were used in each layer to vent the air from the gravel bed while filling the wellbore with water. The instrumentation cables were routed through a short piece of PVC pipe and through the test chamber wall. Figure 25a is a photograph of the middle layer geo-box with the water distribution manifold and the 20 temperature sensors installed. Both the middle and top layers contained water distribution manifolds.

Figure 25b shows the geomembrane cover being extrusion welded to the middle layer geo-box to seal the gravel bed from the clay. The top layer gravel bed is shown in Figure 26; this photograph was taken prior to installing and welding the cover on the geo-box.

This test was a repeat of the first open end drill pipe test except that the water flow was better contained since the geo-boxes minimized leak and erosion problems. In addition, since the bottom gravel bed was not connected to the ELTF plumbing system, an 8" high gap was installed in the wellbore-to-gravel bed interface. This larger gap (it was .5" in test \#1) more appropriately modeled a deeper well since more of the gravel bed volume was directly open to the wellbore.

The second test was conducted on $12 / 12 / 95$. Water was circulated with the ELTF system pump into the top gravel bed and into the wellbore.

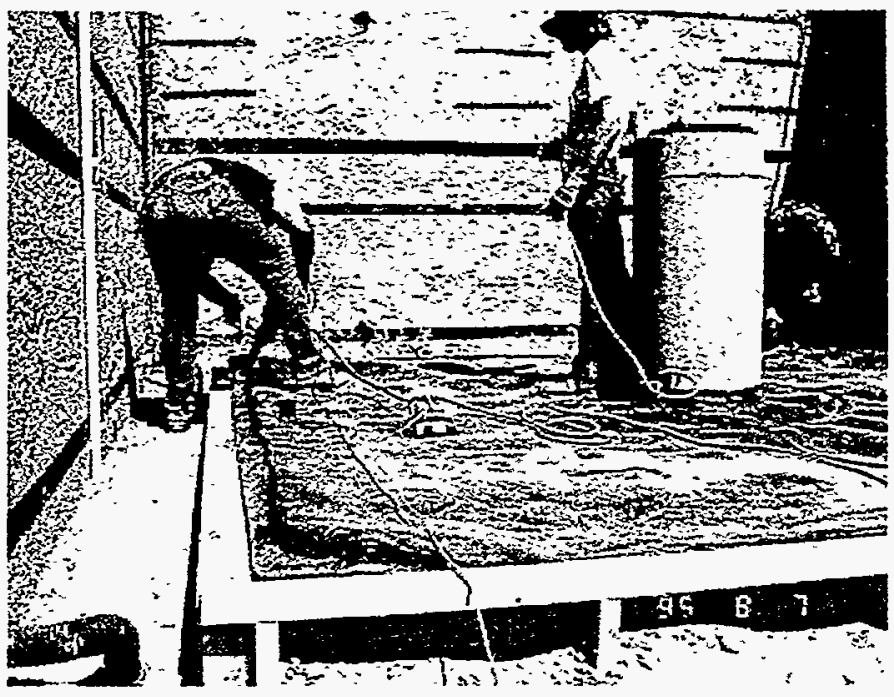

Figure 25b - Middle Gravel Bed Cover Installation Test 2 
After filling the wellbore and bottom gravel bed, water then flowed from the wellbore into the middle gravel bed and returned to the ELTF storage tank. The flow rate recorded during this pre-test circulation was $98 \mathrm{gpm}$. When the Class $\mathrm{G}$ oil well cement was mixed, dyed with a red iron oxide, and ready to be pumped into the wellbore, a calibration sample was again pumped into an empty 55 gallon drum. Water flow into the top gravel bed was then terminated and remained off during the test. To avoid overfilling the gravel beds approximately

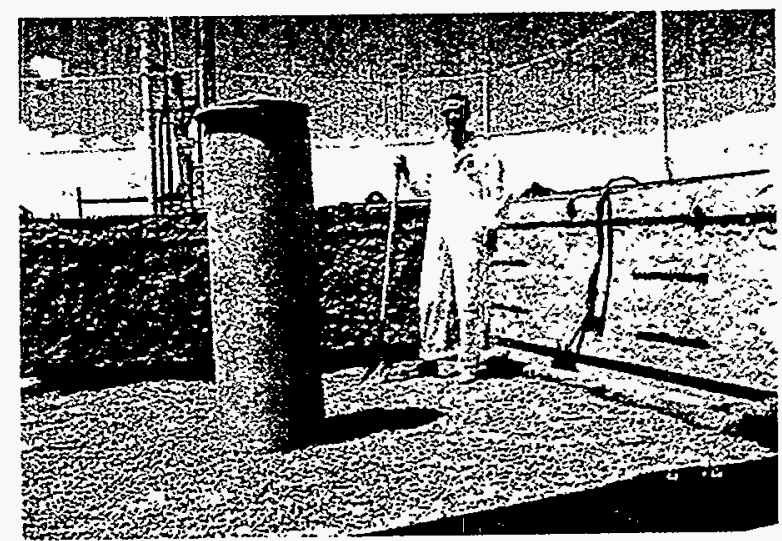

Figure 26 - Top Gravel Bed Test 2 7 barrels of cement were pumped from the Halliburton truck into the wellbore through the 4" PVC open-end-drill-pipe that was again located 12" above the middle gravel bed opening. The cement pumping rate was slowly ramped up to $2.5 \mathrm{bbl} / \mathrm{min}$ then held at this rate until all the cement was pumped.

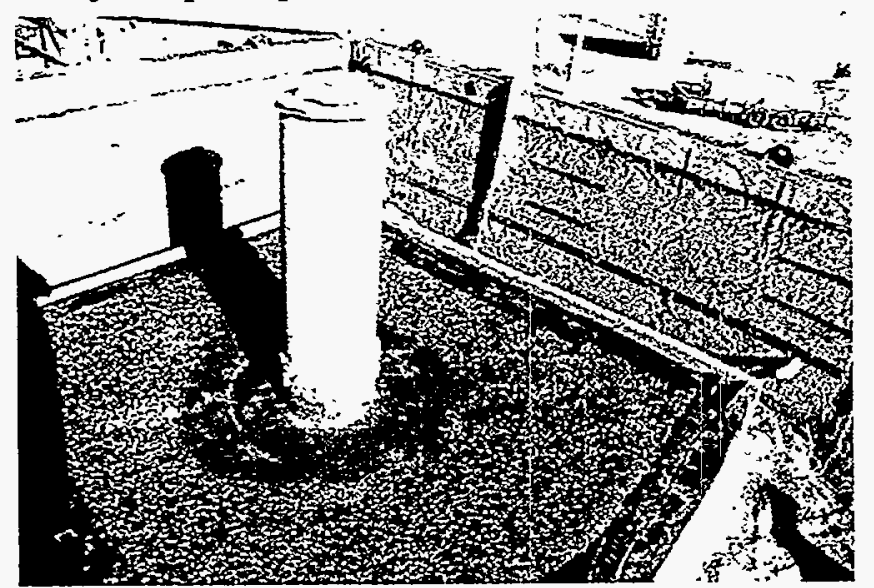

Figure 27 - Excavated Top Gravel Bed Test 2

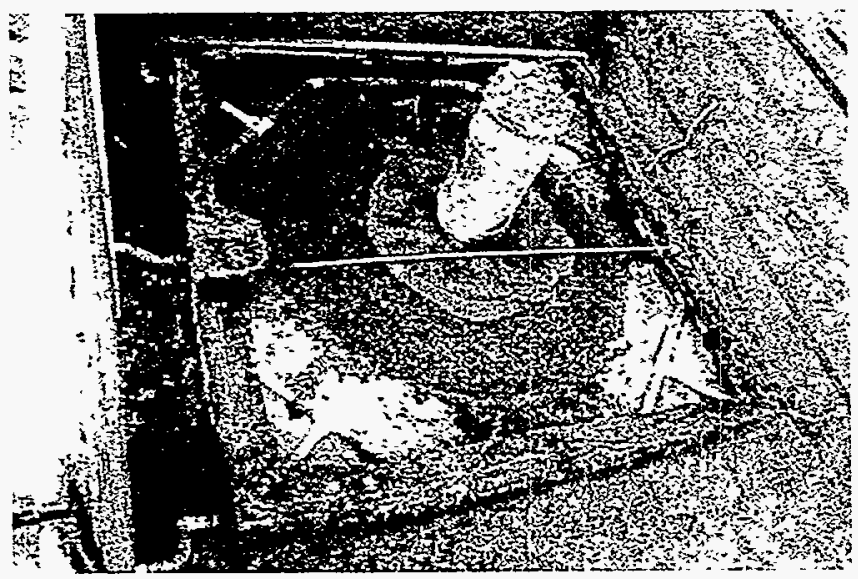

Figure 28 - Excavated Middle Gravel Bed Test 2
Some minor water leakage was again noted around the test chamber during this test.

The data once again indicated that there was cement in all three layers. Excavation began after the cement was allowed to cure. Leakage of water at the connections between the test chamber wall and the geo-boxes was found. Several PVC pipe and flex hose connections were broken, either during clay tamping operations before the test, as a result of high flow rates during the test, or during excavation operations after the test. These broken fittings could have caused the water leakage noted around the test chamber during the test. As shown in Figure 27, cement was found in the top gravel bed when the geo-box cover was removed. The middle box also contained cement as shown in Figure 28. Only slightly more cement was found in this loss zone gravel bed, than in the top static (the water flow was shut off) production zone. When the 
bottom gravel bed was excavated about the same amount of cement found in each of the other two layers as was found in this layer. Figure 29 shows the bottom geo-box after all the loose gravel was removed. Since this gravel bed was only used to increase the

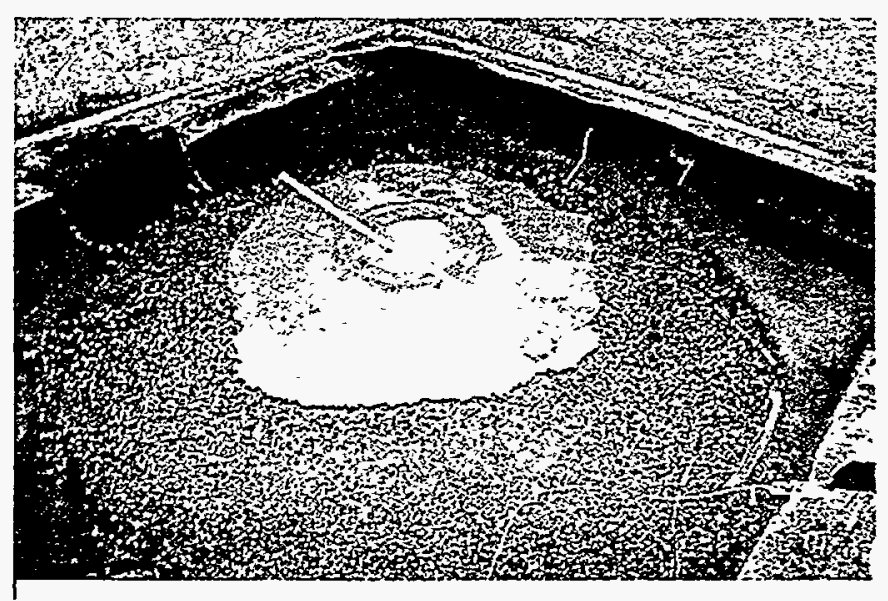

Figure 29 - Excavated Bottom Gravel Bed Test 2 wellbore volume, $\mathrm{PVC}$ manifolds were not installed. Again, as in the first test, evidence of a standing balanced plug in the water filled wellbore could not be found and cement flowed into all three layers indicating that the loss zone is not being preferentially plugged with this method.

\section{B.) $15^{\prime \prime}$ ID Concrete-Pipe Wellbore} Test 3 with DSP:

The third test in the ELTF was performed to test the full scale operation of the drillable straddle packer and compare the results to the two previous tests. The test bed was assembled identically to the previous test, that is: geo-bags were used to contain the gravel and water, the bottom gravel layer was isolated as additional wellbore volume with an 8 " wellbore gap, and temperature and pressure sensors were installed in all three layers.

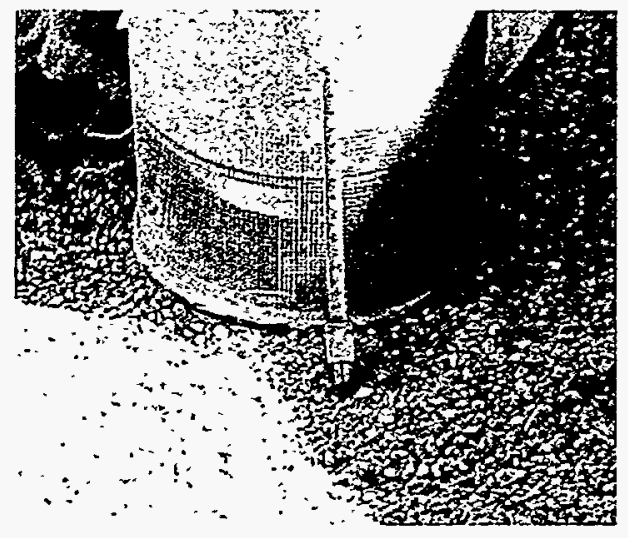

Figure 30 - 8" Wellbore Gap Test 3

Figure 30 shows the 8 " gap in the wellbore in the bottom gravel bed prior to final installation of the gravel in the geo-box. A $3.5^{\prime \prime}$ high X $0.125^{\prime \prime}$ thick steel band was placed inside the 8 " spacer to provide a smooth internal wellbore wall, at the top of the spacer, in the event that the inflated lower DSP bag extends into this region. In order to monitor the differential pressure between the two DSP bags, a copper tube was sealed in a hole through the wall of the simulated

wellbore concrete pipe. This tube was located between the DPS bags, and was connected to a pressure transducer, see Figure 31. The clay in the test chamber was tamped with a gasoline-powered mechanical tamper. Figure 32 shows the clay being tamped between the middle and upper gravel layers. This procedure was used to compact the clay, in 12" high lifts, during the clay filling process for the entire

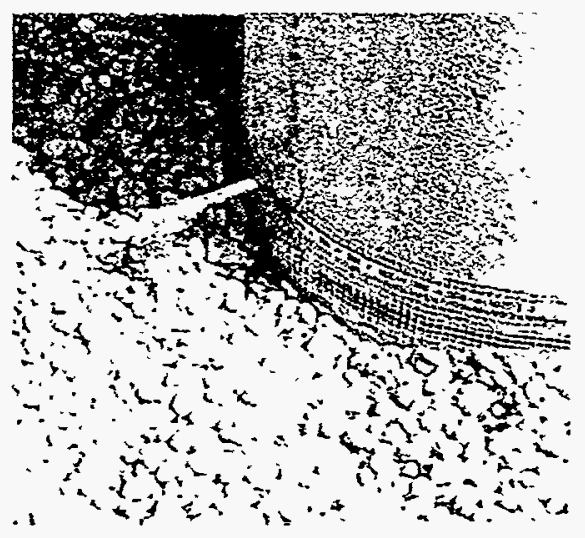

Figure 31 - Pressure Port Test 3 test chamber. The DSP was assembled and attached to 


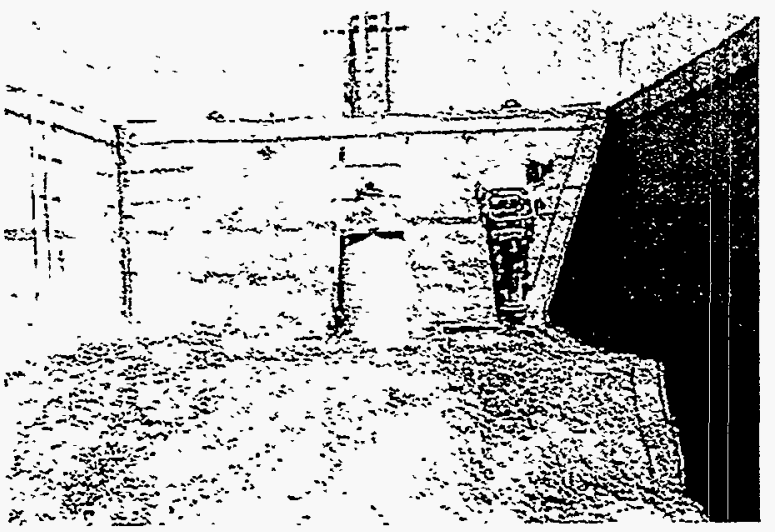

Figure 32- Clay Tamping Procedure Test 3

The third test was conducted on 6/19/96. Water was pumped into the wellbore through the upper gravel layer (production zone) at $50 \mathrm{gpm}$ until returns to the ELTF storage tank through the middle gravel layer (loss zone) were obtained. The water level in the wellbore was steady and remained above the top gravel bed at this $50 \mathrm{gpm}$ flow rate. The water flow was terminated and cement was pumped, by Halliburton, into the DSP bags and out through the injection ports. Water flow was observed returning to the ELTF storage tank during cement pumping, as the cement displaced the water in the loss zone. The cement pumping rate was ramped up to $2 \mathrm{bbl} / \mathrm{min}$ and held steady until a total of $4 \mathrm{bbl}$ of cement was pumped into the wellbore. Care was taken not to pump excessive amounts of cement into the loss zone since this could force cement into the ELTF plumbing system and damage system piping and valves. a steel cover plate containing a feedthrough port for pumping cement into the DSP bags. The cover plate with the DSP was then picked up with a hoist and the DSP was lowered into the wellbore, see Figure 33. The cover plate was then secured to the top of the wellbore pipe and the flexible hose from the Halliburton cement pumping truck was, in turn, attached to the feed-through port in the cover plate.

The data from our instrumentation indicated that cement was in the middle gravel bed, but not in the top or bottom gravel beds. The measured pressure between the DSP bags, while cement was flowing, was 6 psi while the peak pressure recorded in the drill pipe/DSP pipe was $18 \mathrm{psi}$. Based on the wellbore head pressure, this 12 psi differential pressure should have been enough to seal the DSP bags in the wellbore and force cement into the loss zone, while preventing cement from flowing around the bags and into the other sections of the wellbore. After the cement was allowed to cure, the top plate on the wellbore was removed and excavation of the test chamber began. The top gravel bed, or production zone, was completely free of cement. The gravel, PVC distribution manifold, and instrumentation was removed from the top geo-box. The geo-box was removed and clay excavated to the middle or loss zone gravel bed. Cement was found in this layer and the gravel was fully cemented over a large portion of the test bed, as shown in Figure 34 . 


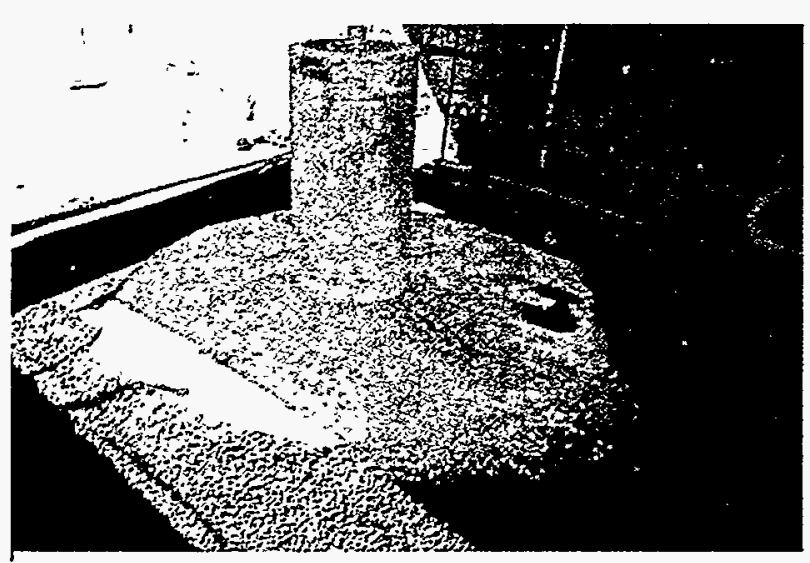

Figure 34 - Excavated Middle Gravel Bed Test 3

In order to verify the quality of the cement job, the cemented gravel bed was sectioned using a large concrete saw. Figure 35 shows this sectioned gravel bed. Cement can be seen throughout the gravel matrix and the radial distribution appears to be uniform from the 0.5 "-high simulated wellbore crack. Excavation continued and the concrete wellbore pipe sections containing the DSP was removed in one piece for additional analysis. The bottom gravel bed, like the top bed, did not contain cement. The concrete wellbore pipe with the DSP was cut along its centerline axis to split the DSP and pipe, as shown in Figure 36. This photograph clearly shows that both DSP bags inflated with cement and that cement was also forced into the void between the two bags and thus into the loss zone. In this series of tests, the DSP lost circulation treatment method was superior to the open-end-drill-pipe method for placing the cement into the desired location. Results of these tests were reviewed and it was determined that more

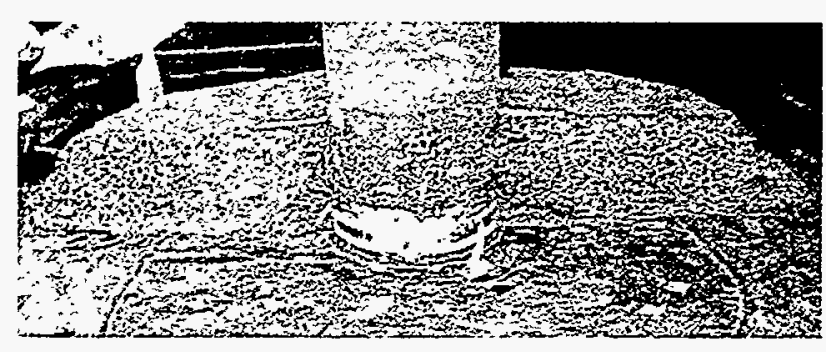

Figure 35 - Sectioned Middle Gravel Bed Test 3

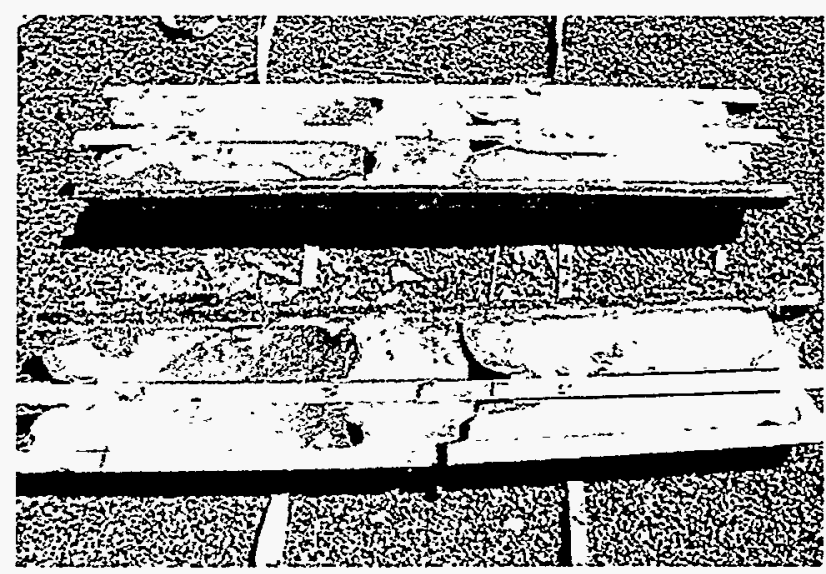

Figure 36 - Sectioned Concrete DSP/Pipe Test 3 information on wellbore flow dynamics was needed to further evaluate the DSP and the open-end-drill-pipe techniques.

\section{C.) ELTF Modifications:}

We felt that the best method to document wellbore cement flow dynamics was to construct a transparent wellbore that could be observed, video taped, and photographed during and after a cementing test. A design concept was prepared to construct a transparent wellbore in the ELTF test chamber. Since there was sufficient space in the test chamber for two sideby-side $15^{\prime \prime}$ wellbores, the test plan was modified to test both the open-enddrill-pipe and the DSP cementing techniques at one time. This plan reduced testing costs by completing two tests with one operation at the ELTF and with one visit by the Halliburton cementing team. This also mandated that the ELTF system

plumbing had to be capable of being quickly disconnected from one wellbore and re- 
connected to the other for a second test. Since these wellbores had to be at least 16 ' high to accommodate the DSP and the various simulated production and loss zones, they required an external support structure. This structure was determined to be a tower, with removable bracing for test bed installation and post test extraction. In order to easily remove and examine a wellbore, after a test, the support towers also had to be capable of being rotated from a vertical orientation for the test, to a horizontal position for wellbore removal and diagnosis after a test. In addition, since wellbore access was required for installation and operations during a test, a two level mezzanine would be required for safe working access to the towers and wellbore assemblies.

Design requirements for the towers and work mezzanine were prepared in parallel. Specifications for the mezzanine were prepared and a commercial pre-engineered structure was purchased and installed in the ELTF test chamber. The tower design with the transparent wellbore and three 36" X 36" X 7" high transparent acrylic boxes to model the three production and loss zones in the original ELTF test bed, was prepared. The acrylic boxes also included six ports for flexible water hose connections as well as the 0.5 "-high simulated wellbore cracks for flow comparisons. This design defined the transparent wellbore material requirements for the test bed. Cast acrylic tubing and acrylic sheet that met our structural requirements were

\section{TRANSPARENT WELLBORE $8^{n}$ TEST FIXTURE}

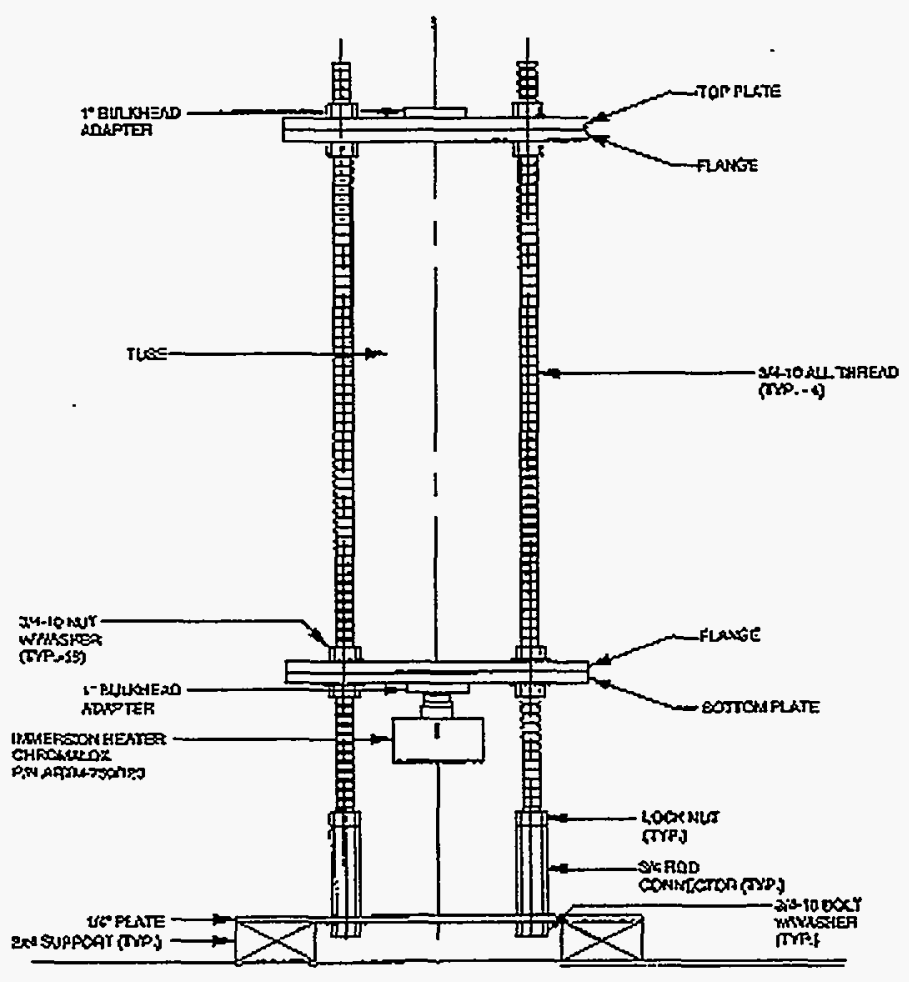

Figure 37 - Transparent Wellbore Material Verification Test Fixture selected. Acrylic, however, has a temperature-dependent structural strength and at elevated temperatures its yield strength became questionable. To assure the integrity of the transparent wellbore material, at the elevated temperatures expected during the cement curing process, we conducted a material verification test.

The acrylic material verification test was designed around 8" cast acrylic tubing, since our test plan was to first test two 8" transparent wellbore configurations followed by four 16 " wellbore tests. The test fixture is shown in Figure 37. The verification test was conducted on $12 / 3 / 96$. The test parameters were to verify the cast acrylic tube integrity at an elevated temperature of 
$160^{\circ} \mathrm{F}$ and at a peak pressure of $40 \mathrm{psi}$. This represented the maximum range of temperatures and pressures expected during our tests in the ELTF. The 8" acrylic tube was filled with water and the test fixture was attached to the system heating and pressure sources. Tests were successfully completed at temperature, pressure, and at combined temperature and pressure. This hydrostatic elevated temperature test provided the necessary verification of material integrity to support the design and safety requirements of the full-scale test bed.

The rotatable towers were procured and installed in the ELTF test chamber. The towers were designed to be used with both the 8 " and 16 " wellbore configurations. Figure 38 is a photograph of the two towers and the mezzanine after installation in the ELTF test chamber. The towers are designed to be rotated forward and rest on the test chamber floor next to the mezzanine access stairways. Some removal of the mezzanine deck and stairways are required for tower rotation.

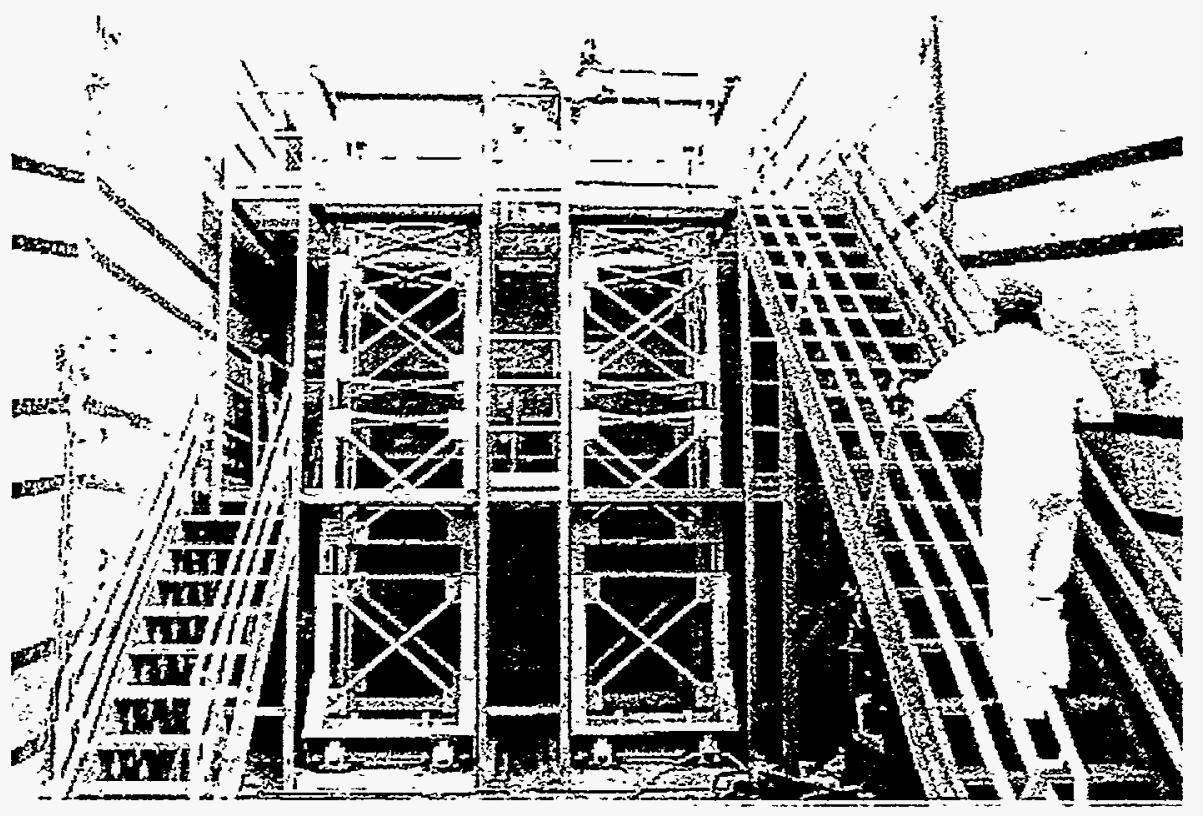

Figure 38 - Transparent Wellbore Towers and Mezzanine

\section{D.) 8" Transparent Wellbore Test without DSP:}

Acrylic tubing and sheet were purchased and machined to produce two 8 " wellbores and six boxes for the first series of transparent wellbore (TW) tests. The acrylic components were assembled in the towers in preparation for the tests. Figure 39 is a photograph of the 8" TW from under the middle level box looking up through the box, with the top box also visible through the middle box. The six round dark ports on the box are the feedthrough ports for the water connections. All joints in the acrylic assemblies were glued with acrylic cement as well as being bolted together with steel fasteners. In addition to the structural bond, the glue in the joints also provided the sealing necessary for a water tight assembly. To connect the ELTF water system to the TW boxes, twelve 2" diameter 


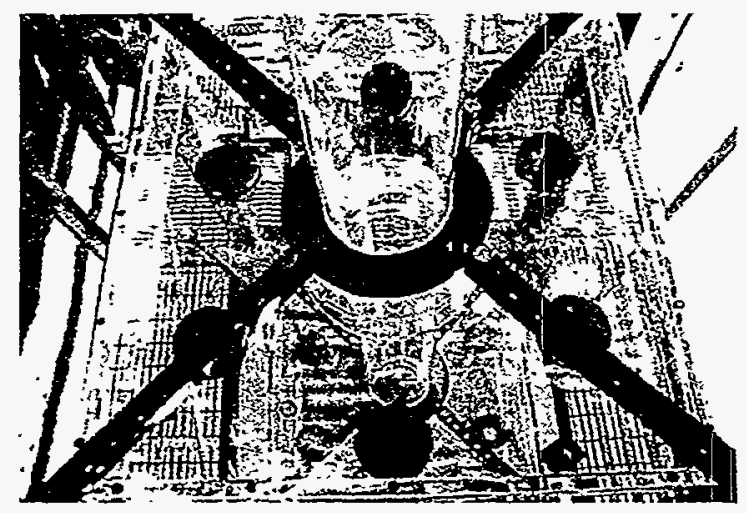

Figure 39 - 8" Transparent Wellbore

flexible hoses with quick connect fittings were employed. The flex hoses were installed between the test chamber wall feed-through ports and the ports on the acrylic boxes. The top box represented the production zone and thus the six inflow hoses were connected to the top box. The six outflow hoses were in turn connected to the middle box that simulated the loss zone. As in the previous tests the bottom box served merely as increased wellbore volume and was not connected to the ELTF water system. In addition to connecting the loss zone (middle) box to the ELTF water system, another PVC pipe manifold was constructed to route water and/or cement from the test chamber to an adjacent plastic lined evaporation pond. To avoid contaminating the ELTF water system with cement during testing, the six loss zone hoses were disconnected at the test chamber wall feedthrough ports and re-connected to the evaporation pond manifold ports. This permitted relatively unrestricted flow from the loss zone acrylic box to the evaporation pond. This connection to the evaporation pond was made after system water flow testing was completed and just prior to actually pumping cement into the wellbore. Water flow into the production zone was also terminated prior to connecting the loss zone hoses to the evaporation pond manifold, and it remained off during these tests.

Both 8 " transparent wellbores were instrumented to measure and record pressure, temperature, and flow. Each box contained one pressure transducer and two thermistors to measure box fluid temperature. There was also one pressure transducer in the simulated drill pipe, and one thermistor at the bottom of the wellbore. In addition, a pressure transducer was installed in the wellbore wall of the DSP test bed to record fluid pressure between the inflated DSP bags. Water flow rates were recorded with the ELTF system flowmeters, while cement flow was recorded with the flowmeter on the Halliburton cement pumping truck. Sandia video services department set up and operated four broadcast-quality video cameras to document the cement flow dynamics during each test. The cameras were focused on various sections of the wellbore where critical cement flows were expected. This included coverage of the middle box, the wellbore between the middle and top box, the wellbore between the middle and bottom box, and the wellbore between the bottom box and the bottom of the wellbore. In addition we also used a tripod-mounted video camera to monitor the entire test bed during each cementing operation.

The 8 "TW tests were completed on 7/23/97. The first test was done in Tower \#1 and was a test of the open-end-drill-pipe (OEDP) technique, see Figure 40. A cement sample was pumped into a 55 gallon drum for flow gage calibration, as was done on previous tests, prior to pumping the cement into the wellbore. Water was circulated through the wellbore and acrylic boxes to fill the wellbore and confirm water-tight seals on the test bed. The system water supply was shut off and the loss zone flex hoses were connected 


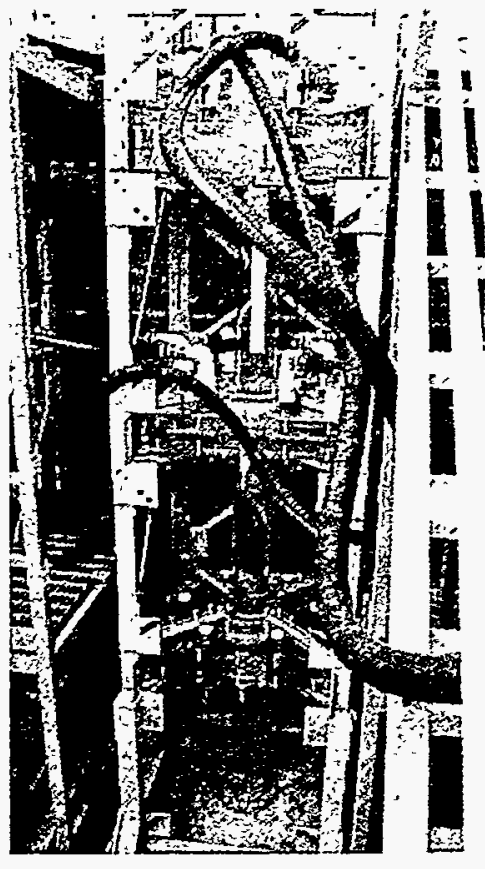

Figure 40 - 8" TW w/ OEDP

to the evaporation pond manifolds. The Class $\mathrm{G}$ red iron oxide dyed cement was then pumped into the wellbore at 2 $\mathrm{bbl} / \mathrm{min}$ and the cement flow was documented with video cameras. The cement fell toward the bottom of the wellbore immediately upon exiting the OEDP. A standing plug in the vicinity of the OEDP was not visible. Most of the cement did flow into the loss zone, however cement also flowed to the bottom of the wellbore and into both the top and bottom box. A total of $2.6 \mathrm{bbls}$ of cement was pumped during this test.

\section{E.) 8" Transparent Wellbore Test with DSP:}

Input from the geothermal industry resulted in several improvements being made to the DSP design. One of these improvements was to add check valves to the cement ports used to inflate the DSP bags. These check valves will prevent unintentional deflation of the bags when the cement stops flowing and/or when the drill pipe is disconnected. Laboratory verification tests on a check valve design were conducted. Test results show that these check valves can contain reverse pressures of $15 \mathrm{psi}$ and still permit forward flow rates up to $100 \mathrm{gpm}^{5}$. The check valves were installed in the 8" DSP bag flow ports during DSP fabrication.

The second 8" TW test was performed in Tower \#2 and was a test of the DSP technique. The flex hoses and video cameras were moved and positioned for use on Tower \#2. Again a cement sample was pumped into a 55 gallon drum for calibration purposes. The DSP assembly was positioned in the wellbore with the two bags straddling the middle box or loss zone. Water flows were established in the wellbore to verify system integrity and then terminated for the test. The 2" diameter flex hoses from the loss zone were again connected to the evaporation pond manifolds. Cement pumping began and was slowly ramped up to $2 \mathrm{bbl} / \mathrm{min}$ over 30 seconds with a total of $2.6 \mathrm{bbl}$ pumped into the wellbore through the DSP assembly. Cement flow dynamics were again recorded with the video cameras. The DSP bags inflated quickly and clearly showed that the cement was forced into the loss zone with only small amounts of cement getting around the bags while they were inflating. The differential pressure measured across the DSP bags while pumping cement was $30 \mathrm{psi}$. Initial temperature measurements indicated cement was only in the middle box. Figure 41 is a post-test photograph of the deployed DSP in the 8 " TW. This photograph clearly shows that the cement was primarily in the middle box with no cement visible in either the top or bottom boxes. After the cement cured the TW towers were rotated, and the test beds were removed. The DSP test bed was then sectioned along its axis to expose the DSP bags and the loss zone acrylic box. Figure 42 shows one-half of this sectioned cemented wellbore, acrylic box, and DSP assembly. Cement is visible in both DSP bags and in the void between the bags, as well as in the loss zone acrylic box. A water-filled void is visible in the wellbore above the box and 


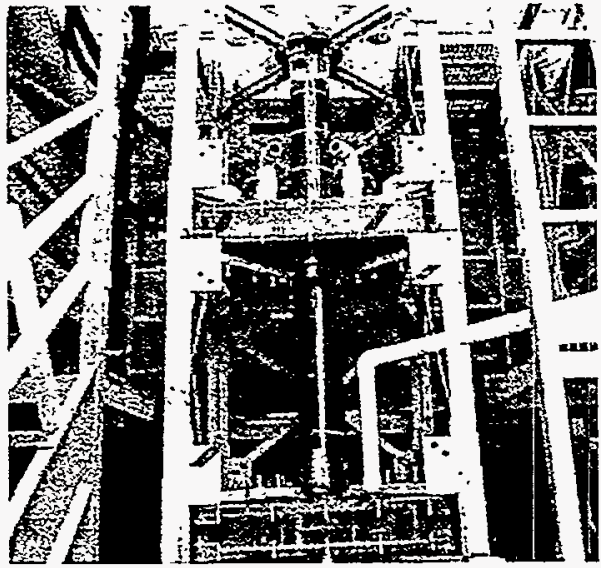

Figure 41 - 8" TW w/ DSP

under the upper DSP bag. The top and bottom boxes were not sectioned since they did not contain cement. The OEDP test bed was also not sectioned since the cement in the wellbore was flushed to the evaporation pond when the water was drained after the test and none of the three boxes contained enough cement to warrant sectioning.

\section{F.) 16" Transparent Wellbore Test without DSP (Static Wellbore):}

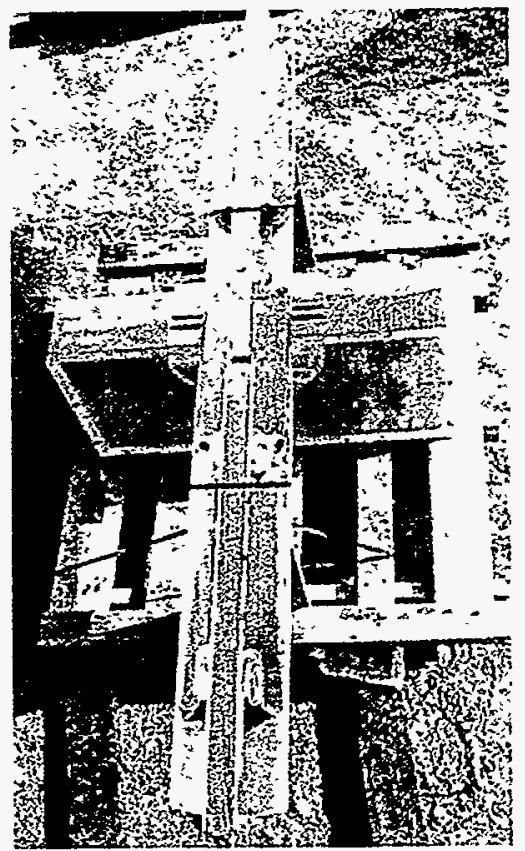

Figure 42 - Sectioned 8" TW

The 16" TW tests were a repeat of the 8 " TW tests to compare any difference in cement flow dynamics due to wellbore size. Acrylic tubing and sheet were purchased and machined to fabricate two 16" TW assemblies. The acrylic components were assembled in the towers for the tests. The external dimensions of the six acrylic boxes were identical to the 8 "TW test bed boxes, only the top and bottom ports for the wellbore were increased to fit the 16" TW tubes. To insure water tight assembly all acrylic joints were again glued with acrylic cement as well as secured with steel fasteners. As was done on the 8" TW tests, the twelve 2" diameter flex hoses were installed between the ELTF test chamber wall feed through ports and the ports on the acrylic boxes. The top box represented the production zone and the middle box again was the loss zone. To prevent cement from entering the ELTF water system, the evaporation pond manifold was again utilized to flow cement from the loss zone box directly to the evaporation pond. This connection to the evaporation pond was made after system water flow testing was completed and prior to actually pumping cement into the wellbore. Water flow into the production zone was also terminated prior to connecting the loss zone hoses to the evaporation pond manifold and it remained off during these tests. To avoid having to manufacture new OEDP acrylic hardware for the next series of 16" TW tests in Tower $\# 1$, we decided to drain the cement in the wellbore and boxes immediately after documenting the test results and before the cement had time to set up. We would then flush the acrylic tubes and boxes with clean water, wipe the insides where possible, and save the test bed for use on the next series of 16" TW OEDP tests.

Both 16" TW towers were instrumented the same as the 8 "tests to record pressure, temperature, and flow. Video coverage of the $16^{\prime \prime}$ test beds was also identical to the 8 " tests. Extra care was taken during the cleaning operation on Tower \#1 to minimize 
damaging any of the instrumentation. Valves were installed in series with the pressure transducers. These valves were closed after the cement was pumped, and the transducers were removed and cleaned before the cement had time to set up and damage the transducer diaphragms.

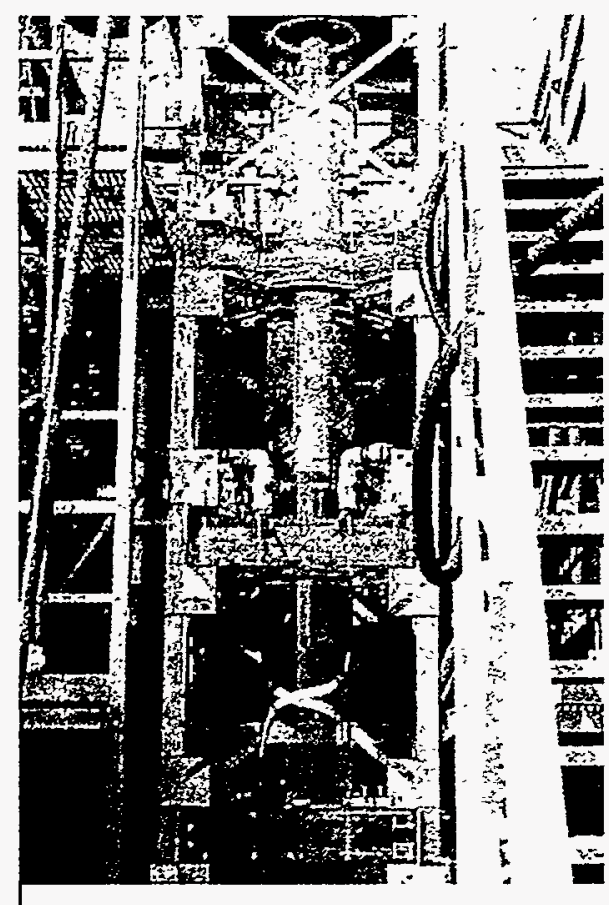

Figure 43 - 16" TW w/ OEDP

The 16" TW tests were completed on 11/20/97. The OEDP test was again done in Tower \# 1 and is shown in Figure 43 prior to pumping the cement. A $4 "$ PVC pipe located 12" above the loss zone was used to model the OEDP. The cement flow gauge on the Halliburton truck was again calibrated by pumping one barrel of cement into an empty 55 gallon drum. Water was circulated through the wellbore and acrylic boxes to fill the wellbore and confirm water tight seals on the test bed. The system water supply was shut off and the loss zone flex hoses were connected to the evaporation pond manifolds. The Class $\mathrm{G}$ red iron oxide dyed cement was then pumped into the wellbore at $2 \mathrm{bbl} / \mathrm{min}$ and the cement flow was documented with video cameras. The cement fell toward the bottom of the wellbore immediately upon exiting the OEDP. A standing balanced plug in the vicinity of the OEDP was again not visible. The majority of the cement flowed into the loss zone; however, cement also flowed to the bottom of the wellbore and into both the top and bottom box. A total of 5 bbls of cement was pumped during this test. Figure 44 shows the 16" wellbore after the cement was pumped through the OEDP. Cement was visible in the wellbore from the bottom to near the top, with cement also visible in both the middle (loss zone) and bottom box.

\section{G.) 16" Transparent Wellbore Test with DSP (Static Wellbore):}

The second 16" TW test was performed in Tower \#2 and was another test of the DSP technique. While the flex hoses and video cameras were being moved and positioned for use on Tower \#2, Tower \#1 was drained, flushed with water, and cleaned. Prior to starting the DSP test, a cement sample was again pumped into a 55 gallon drum for calibration purposes. The DSP assembly was positioned in the wellbore with the two bags straddling the middle box or loss zone. Water flows were established in the wellbore to verify system

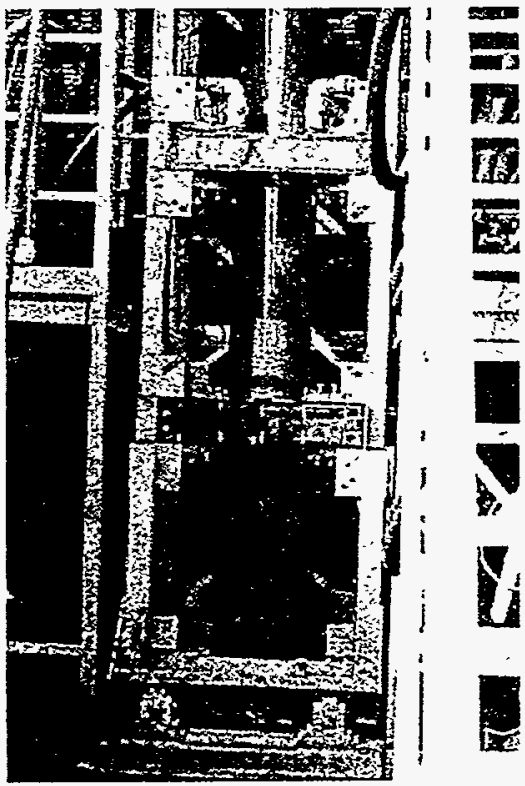

Figure 44 - 16" TW OEDP w/Cement integrity, then terminated for the test. The 2 " diameter 


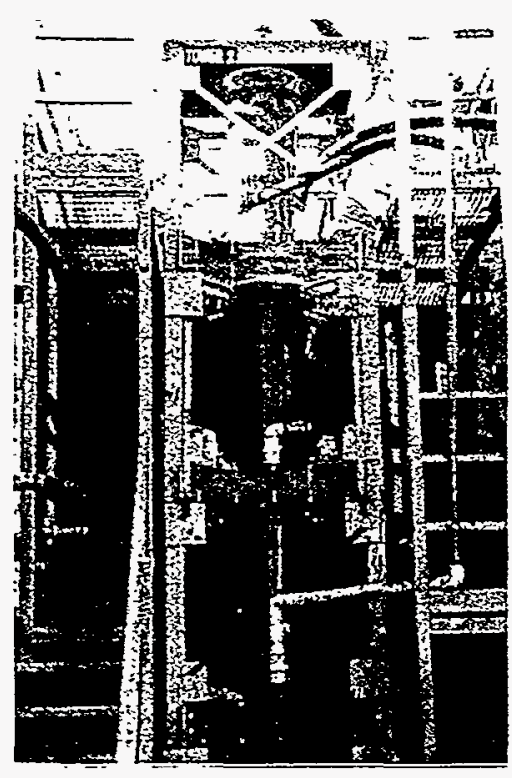

Figure 45 - 16" TW DSP Deployed

flex hoses were again connected to the evaporation pond manifolds. Cement pumping began and was slowly ramped up to $2 \mathrm{bbl} / \mathrm{min}$ over 30 seconds and a total of 5 bbls was pumped into the wellbore through the DSP assembly. Cement flow dynamics were again recorded with the video cameras. The DSP bags inflated quickly and clearly showed that the cement was forced into the loss zone with only small amounts of cement getting around the bags while they were inflating. The differential pressure measured across the DSP bags while pumping cement was 18 psi. Initial temperature measurements indicated cement was only in the middle box. Figure 45 is a post test photograph of the deployed DSP in the 16" TW. This photograph shows that the cement was primarily in the middle box with only cement colored water visible in either the top or bottom boxes.

To test how well the deployed DSP would remain in position in the wellbore, after it was disconnected from a drill pipe in an actual field application, the DSP in our test bed was disconnected from the top plate immediately after cement pumping was completed. This released the deployed DSP from any support and allowed it to slide down the acrylic wellbore, if possible. The smooth walled acrylic wellbore surface was considered a "worse case" condition for comparison of slippage in a rougher-walled drilled wellbore. Some slow sliding was documented, and after 24 hours it had slid down the wellbore approximately 24 " from its original position.

After the cement cured for several days Tower \#2 was rotated to the horizontal position, reference Figure 46, and the 16" DSP test bed was removed, as shown in Figure 47. The

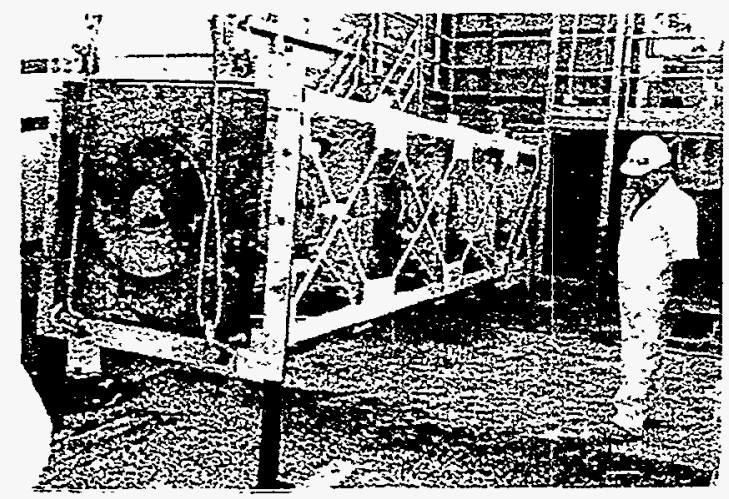

Figure 46 - 16" TW Rotated Tower 2

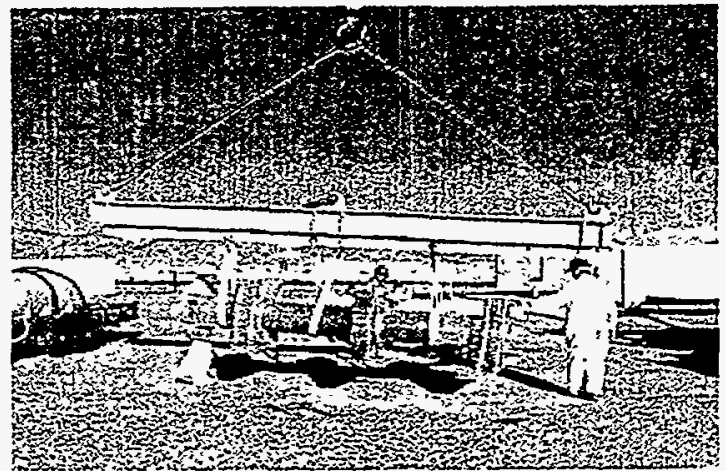

Figure 47 - 16" TW DSP Test Bed

test bed was then sectioned along it's axis to expose the DSP bags and the acrylic boxes. Figure 48 shows one half of this sectioned cemented wellbore, acrylic boxes, and DSP assembly. Cement is visible in both DSP bags, in the void between the bags, and in the loss zone acrylic box. No cement was found in the bottom box. DSP slippage down the 


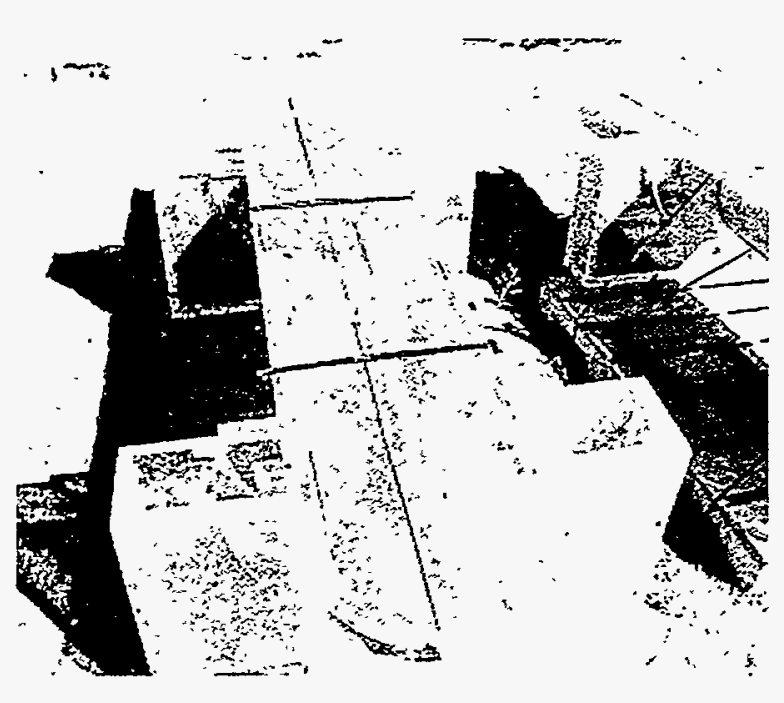

Figure 48 - Sectioned 16" TW DSP wellbore after disconnection from the simulated drill string is visible, however it did not slide all the way to the bottom, indicating that it did retain some mechanical integrity against the wellbore walls. It should be emphasized that this DSP is an older version that was assembled prior to the installation of check valves over the bag cement ports. The check valves should retain the bag inflation pressure and thus further reduce the likelihood of slippage down the wellbore after the DSP is disconnected from the drill string. The OEDP test bed was not sectioned since the cement in the wellbore and boxes was flushed to the

evaporation pond with water and cleaned after the test for re-use on the next series of experiments.

\section{H.) 16" Transparent Wellbore Test without DSP (Flowing Wellbore):}

The final 16" TW experiments were designed to measure cement flow dynamics when water was flowing into and out-of the wellbore while the cement was being pumped. These flowing transparent wellbore (FTW) tests were to document the effect of both OEDP and DSP cementing techniques in a well containing a production zone.

Acrylic tubing and sheet were again purchased and machined to produce one more 16" FTW for the DSP test. The acrylic components were assembled in Tower \#2 as was done on the previous tests. The 16" TW assembly in Tower \#1 was re-used for the OEDP 16" FTW test. The twelve 2" diameter flex hoses were installed between the ELTF test chamber wall feed-through ports and the ports on the acrylic boxes. As before, the top box represented the production zone and the middle box was the loss zone. To prevent cement from entering the ELTF water system during the tests, the evaporation pond manifold was utilized to flow water and/or cement from the loss zone box directly to the evaporation pond, as was done on the previous tests. This connection to the evaporation pond was made after system water flow testing was completed and prior to actually pumping cement into the wellbore. Water flow into the production zone or top box continued during and after cement pumping to document the effect of a production zone on the loss zone treatment technique. Water flowing from the loss zone also flowed to the evaporation pond, but was diverted to a stock tank just prior to pumping cement into the wellbore. A liquid level capacity gauge was installed in the stock tank to document the quantity of water and/or cement pumped into the loss zone during a test.

Both towers were instrumented to document pressure, temperature, and flow, as was done on previous tests. Video coverage was also the same as prior tests. Precautions were 
again employed to recover as many instrument sensors as possible for future use, as well as flushing and cleaning Tower \#1 again for a third 16" TW OEDP test.

The 16" FTW tests were conducted on 4/28/98. As before the OEDP test was done in Tower \#1. The Halliburton truck cement flow gauge was again calibrated by pumping a barrel of cement into an empty 55 gallon drum. Water was again circulated through the wellbore and acrylic boxes to fill the wellbore and confirm water-tight seals. The system water supply was shut off and the loss zone flex hoses were connected to the evaporation pond manifolds. System water flow was then resumed and adjusted to provide a flow rate of approximately $50 \mathrm{gpm}$ into the top box or production zone, with the same flow rate out-of the middle box or loss zone to the evaporation pond. Just prior to pumping cement into the wellbore the water flow to the evaporation pond was diverted to the stock tank. Class $\mathrm{G}$ red iron oxide dyed cement was pumped into the wellbore through the 4" PVC OEDP and, as shown in Figure 49, immediately began to fall to the bottom of the wellbore. Flow measurement data indicated that a balanced standing cement plug was formed in the wellbore and partial plugging of the loss zone was

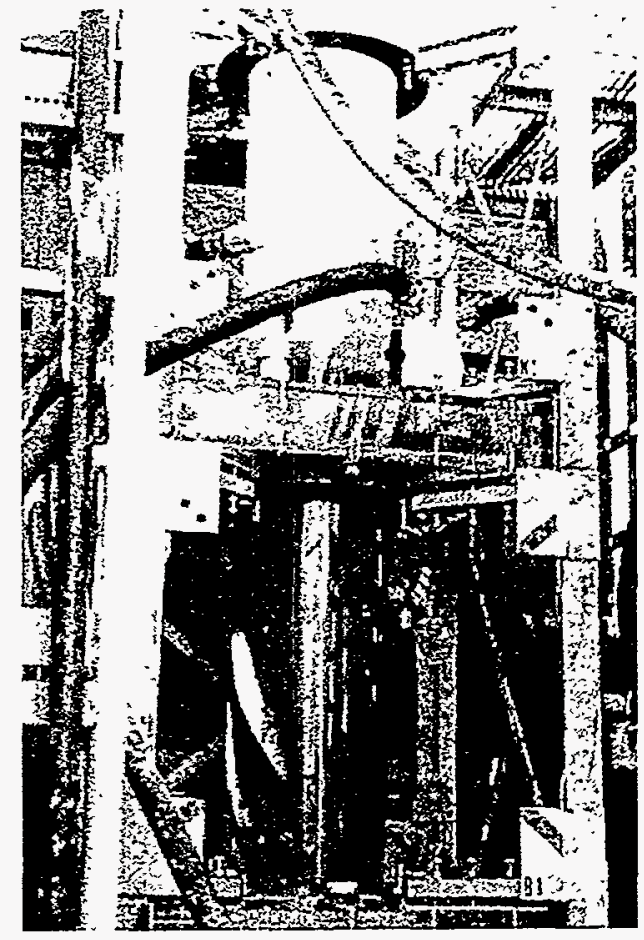

Figure 49 - 16" FTW OEDP w/ Cement Falling During Pumping indicated. However, this partial loss zone plug was easily breached by the production zone flow as soon as cement pumping was terminated. A total of $5 \mathrm{bbls}$ of cement was pumped into the wellbore at a $2 \mathrm{bbl} / \mathrm{min}$ flow rate. When production zone flow indicated that the loss zone was not plugged, system water flow was terminated. The test bed was drained to the evaporation pond, flushed with water, cleaned and prepared for another OEDP test.

\section{I.) 16" Transparent Wellbore with DSP (Flowing Wellbore):}

The normal DSP design package includes a shroud to protect the DSP while it is being lowered into a well. As indicated in Reference 3, the shroud is to be pushed down the wellbore and off the DSP by the cement pumping pressure, prior to inflating the DSP bags. This procedure utilizes a dropped ball and piston/shaft device to push the shroud downward and off the DSP. The mechanism to deploy the shroud was confirmed with a laboratory test using a single DSP bag. Depending on the length of the DSP assembly, this shroud could become long and would require a much deeper test bed than is available at our facility for full-scale testing. Since our tests at the ELTF require two 48" long DSP bags and is limited to a 16' deep test bed, a shroud could not be used or tested. However, to test the function of the shroud piston and ball drop technique in a real cement pumping environment, the DSP for these tests was modified to include a piston, piston housing, 
shear pin, and bottom housing. These components were designed, fabricated, and attached to the DSP for use during the 16" FTW DSP test.

The second 16" FTW test was done in Tower \#2 and was a test of the DSP cementing technique. The DSP assembly included the shroud removal mechanism verification test hardware. The flex hoses and video cameras were moved to Tower \#2 and positioned for the test. The $50 \mathrm{gpm}$ ELTF system water flow was again established into the production zone and out-of the loss zone then through the PVC manifold to the evaporation pond. The outflow from the test bed was once again diverted to the stock tank. Just prior to pumping cement into the wellbore, through the DSP, a 1.5" diameter nylon ball was dropped into the DSP pipe from the top of the wellbore. Figure $\mathbf{5 0}$ shows the DSP bags just before the cement began flowing but after the nylon ball was dropped. Note that the bottom end of the shroud verification test housing is visible in the wellbore below the bottom box and that the DSP bags, though not centered in the wellbore, are positioned above and below the loss zone or middle box. Figure $\mathbf{5 1}$ is a photograph of the DSP just after the cement began to flow. Note here that the DSP shroud piston is now protruding from the bottom of the shroud verification test housing, indicating that the cement pressure did indeed shear the piston pins and force the piston to the bottom of the DSP

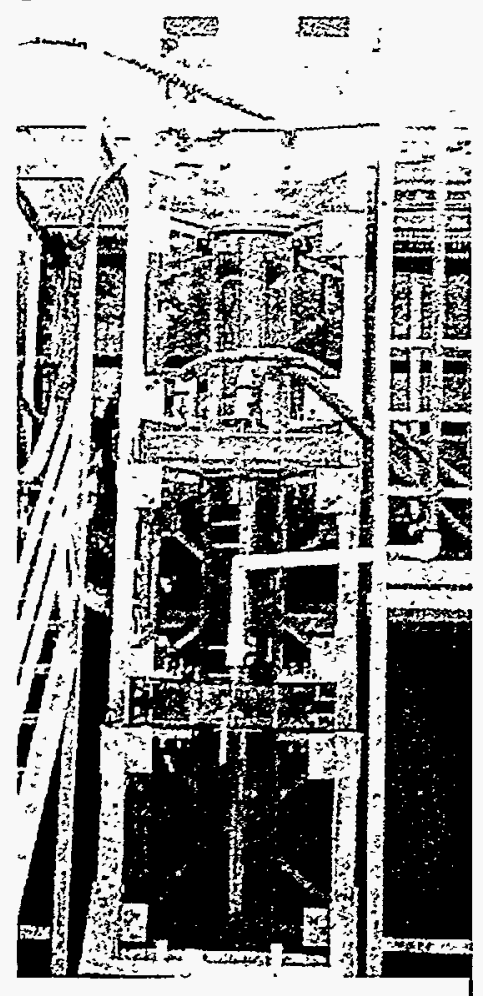

Figure 50 - 16" FTW DSP assembly, as intended. Had a shroud been connected to this piston, it would have been pushed off the DSP bags. The bags are just beginning to inflate and some cement is visible in the middle box as well as in the wellbore below the bottom DSP bag. Small amounts of cement can get around the bags, during the inflation process, especially if the inflation rate is slow. Cement pumping began at a slow rate and was ramped up to the $2 \mathrm{bbl} / \mathrm{min}$ rate within 30 seconds, then held at this rate until the total $5 \mathrm{bbl}$ was pumped through the DSP. Data showed that the shroud shear pins broke at $46 \mathrm{psi}$ and that the differential pressure

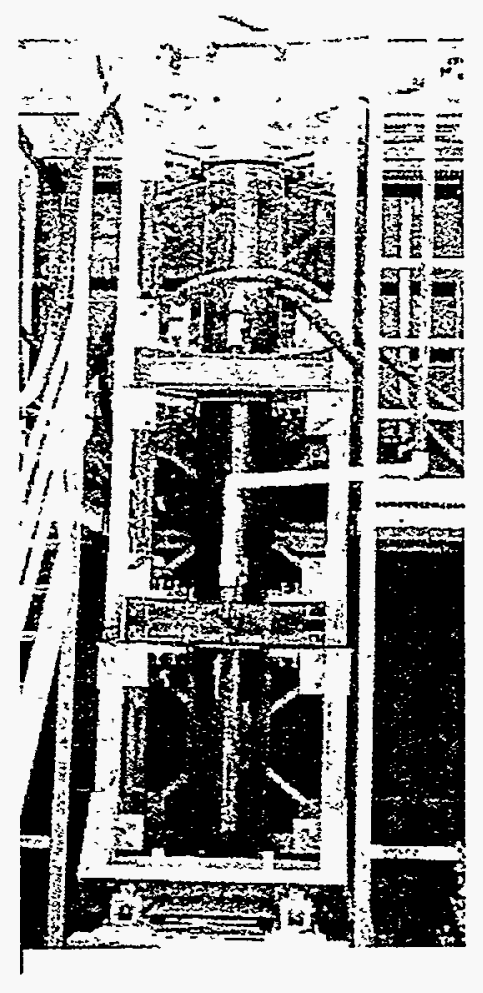

Figure 51 - 16" FTW DSP During Deployment across the DSP bags was 23 psi. Water flow from the production zone was blocked by the inflated DSP bags during the time the cement was being pumped. After the cement pumping was terminated, the production zone flow was slowly increased in an attempt to collapse the DSP bags. This flow did cause slow collapse of the upper bag, however, as stated previously the 16" DSP assemblies did not contain the check valves that probably would have prevented or minimized this collapse. 
Overall the DSP did isolate the loss zone and the majority of the cement was forced into the loss zone with only small amounts flowing around the bags during inflation.

The cement was again allowed to properly cure, then the tower was rotated and the test bed removed. The test bed was once more sectioned along the wellbore axis for further analysis. Figure $\mathbf{5 2}$ shows one-half of this sectioned test bed. Cement is visible in the

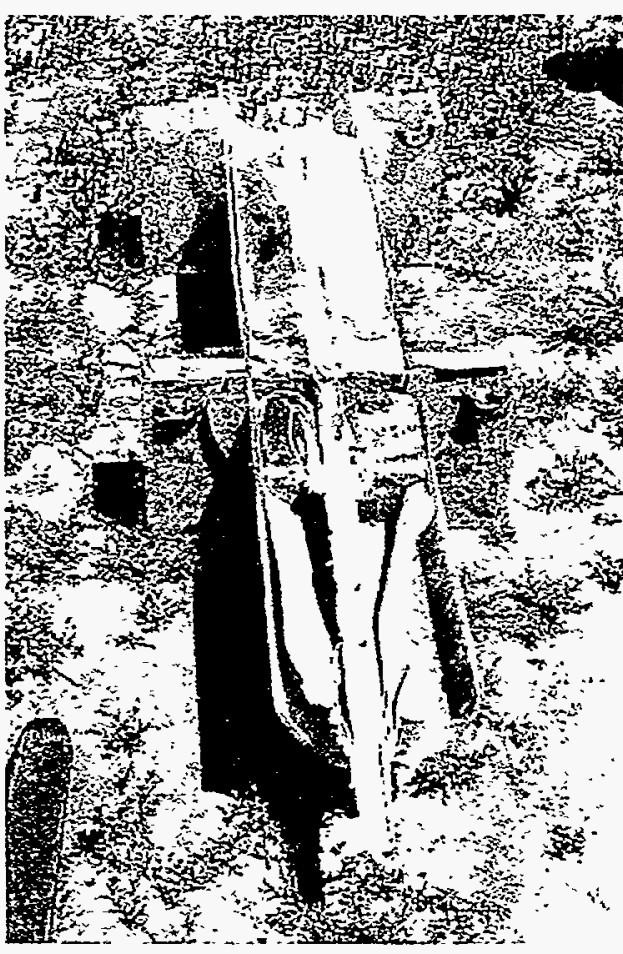

Figure 52 - 16" FTW Sectioned middle box, and the bottom DSP bag, with some in the void between the bags and in the DSP top bag. Water may have been forced into the top bag and/or into the void between the bags from the DSP pipe, since water was in the pipe when the nylon ball was dropped prior to pumping cement. The production zone water flow during and after the test may also have forced cement out of the top bag and thus contributed to this visible void area in the bag. Whatever caused the void in the top bag may very well have been eliminated, or at least minimized, if the check valves had been installed in the DSP assembly. In addition, if a shroud had been around the bags prior to pumping the cement, the bags would have remained uninflated while the shroud was being pushed off and would not have trapped air or water. Cement was not visible in the bottom box or in the wellbore above or below the DSP.

\section{J.) 16" Transparent Wellbore Test without DSP (Mud-Filled Wellbore):}

The third and final OEDP test in Tower \#1 was conducted on 4/29/98. This 16" TW test was done to document cement flow dynamics in a drilling mud-filled wellbore. Due to the fact that drilling mud is opaque, the TW is only of minimal value. However, since this test bed had been salvaged during the previous 16"FTW OEDP test, and since no additional OEDP tests were planned, this was considered a cost effective way to obtain this data. The test bed was filled with water from the ELTF water system, and flow was established to the evaporation pond and/or stock tank. The water system was then turned off and the top box isolated from the system plumbing. The middle box or loss zone was left open to the stock tank. The water was drained from the 16" TW and boxes and replaced with an $8.5 \mathrm{lb} / \mathrm{gal}$ bentonite drilling mud. The drilling mud was mixed in our laboratory facility and transported to the ELTF in 55 gallon drums for pumping into the wellbore. The drilling mud had an apparent viscosity of 25.5 Centipoise and after being pumped into the wellbore was allowed to set long enough to develop the full 10-minute gel strength.

The 4" PVC OEDP was positioned in the wellbore. Instrumentation was identical to the previous OEDP tests executed in this test bed. The video cameras were again set up to 
record flow dynamics, if the cement could be seen through the drilling mud. To distinguish this cement from any residual red iron oxide colored cement used on previous tests, this Class $\mathrm{G}$ cement was dyed with a black iron oxide. It was felt that the black color would also be more visible in the drilling mud. The cement flow gauge on the Halliburton truck was again calibrated by pumping one barrel of cement into an empty 55 gallon drum. Cement was pumped into the wellbore through the 4" PVC OEDP at 2 $\mathrm{bbl} / \mathrm{min}$. Figure $\mathbf{5 3}$ shows the black cement falling in the wellbore and flowing out the loss zone or middle box. A standing balanced plug seemed to form in the wellbore below the loss zone and the mud did not dilute the cement as severely as the water did on previous tests. A total of 5 bbls of cement was pumped and flow from the loss zone to the stock tank was visible.

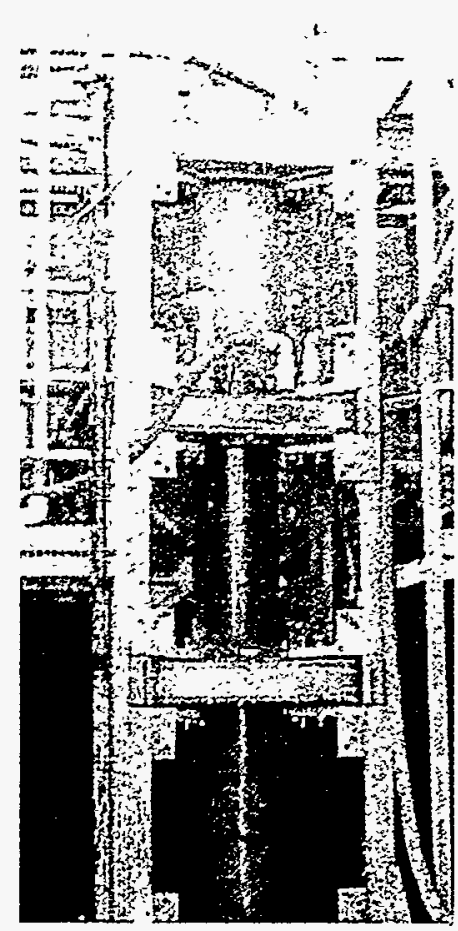

Figure 53 - 16" TW w/ Mud, OEDP, \& Cement
The cement was allowed to cure, and the tower was rotated so the test bed could be removed. This OEDP test bed was sectioned along the tube axis, like the previous DSP test beds, and is shown in Figure 54. A short (14") piece of cut-off and sectioned 4" PVC pipe that modeled the OEDP is visible where the cement began flowing into the mud. The cement can also be seen in the loss zone box and in the wellbore between the loss zone box and the bottom of the wellbore. No cement entered the bottom box and seemed to diffuse as it flowed down the wellbore. No cement appeared to flow above the

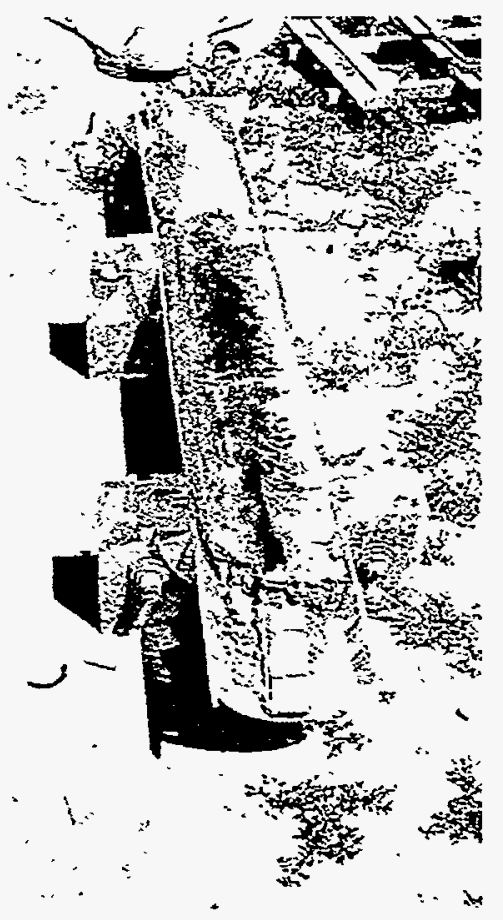

Figure 54 - Sectioned 16" TW w/ Mud in Test Bed

OEDP exit. Cement primarily flowed downward and into the loss zone from the 4" PVC drill pipe indicating that a balanced plug was easier to form in the gelled mud environment than in water.

Table I, shown below, is a summary of test bed conditions for the full scale tests conducted at the ELTF.

Video documentation of the 8 " TW, 16" TW, and the 16" FTW tests, including the mud filled wellbore, have been reviewed and analyzed. Short duration (12-15 minute) videotapes of each of the three test series have been prepared. These videotapes are stored in the Sandia Geothermal Research Department files, and are available for viewing upon request. 


\begin{tabular}{|c|c|c|c|c|}
\hline \multicolumn{5}{|c|}{$\begin{array}{l}\text { TABLE I } \\
\text { Overview of Full Scale Test Conditions at the ELTF }\end{array}$} \\
\hline $\begin{array}{l}\text { FULL SCALE } \\
\text { TEST \# / NAME }\end{array}$ & WELLBORE TYPE & $\begin{array}{l}\text { CEMENTING } \\
\text { TECHNIQUE }\end{array}$ & $\begin{array}{l}\text { WELLBORE } \\
\text { FLUID }\end{array}$ & $\begin{array}{l}\text { WELLBORE } \\
\text { ZONES / TYPE }\end{array}$ \\
\hline 1 & $\begin{array}{l}15 " \text { I.D. Concrete } \\
\text { Pipe }\end{array}$ & OEDP & Water, Static & $\begin{array}{l}\text { Loss / Gravel Bed, Flow } \\
\text { to ELTF Tank }\end{array}$ \\
\hline 2 & $\begin{array}{l}\text { 15" I.D. Concrete } \\
\text { Pipe }\end{array}$ & OEDP & Water, Static & $\begin{array}{c}\text { Loss / Gravel Bed, Flow } \\
\text { to ELTF Tank }\end{array}$ \\
\hline 3 & $\begin{array}{l}\text { 15" I.D. Concrete } \\
\text { Pipe }\end{array}$ & DSP & Water, Static & $\begin{array}{l}\text { Loss / Gravel Bed, Flow } \\
\text { to ELTF Tank }\end{array}$ \\
\hline $4 / 8^{\prime \prime} \mathrm{TW}$ & $\begin{array}{l}\text { 8" (7.5" I.D.) Acrylic } \\
\text { Tube }\end{array}$ & OEDP & Water, Static & $\begin{array}{l}\text { Loss / Box, Flow to } \\
\text { Pond }\end{array}$ \\
\hline $5 / 8^{\prime \prime} \mathrm{TW}$ & $\begin{array}{l}\text { 8" (7.5" I.D.) Acrylic } \\
\text { Tube }\end{array}$ & DSP & Water, Static & $\begin{array}{l}\text { Loss / Box, Flow to } \\
\text { Pond }\end{array}$ \\
\hline $6 / 16^{\prime \prime} \mathrm{TW}$ & $\begin{array}{l}16^{\prime \prime} \text { (15" I.D.) Acrylic } \\
\text { Tube }\end{array}$ & OEDP & Water, Static & $\begin{array}{l}\text { Loss / Box, Flow to } \\
\text { Pond }\end{array}$ \\
\hline $7 / 16 " \mathrm{TW}$ & $\begin{array}{l}\text { 16" (15" I.D.) Acrylic } \\
\text { Tube }\end{array}$ & DSP & Water, Static & $\begin{array}{l}\text { Loss / Box, Flow to } \\
\text { Pond }\end{array}$ \\
\hline $8 / 16 "$ FTW & $\begin{array}{l}\text { 16" (15" I.D.) Acrylic } \\
\text { Tube }\end{array}$ & OEDP & Water, Flowing & $\begin{array}{l}\text { Production and Loss / } \\
\text { Box, Flow to Pond }\end{array}$ \\
\hline $9 / 16 "$ FTW & $\begin{array}{c}6^{\prime \prime} \text { (15" I.D.) Acrylic } \\
\text { Tube }\end{array}$ & DSP & Water, Flowing & $\begin{array}{l}\text { Production and Loss / } \\
\text { Box, Flow to Pond }\end{array}$ \\
\hline $10 / 16^{\prime \prime} \mathrm{TW}$ & $\begin{array}{l}16^{\prime \prime}\left(15^{n} \text { I.D.) Acrylic }\right. \\
\text { Tube }\end{array}$ & OEDP & $\begin{array}{l}\text { Drilling Mud, } \\
\text { Static }\end{array}$ & $\begin{array}{l}\text { Loss / Box, Flow to } \\
\text { Pond }\end{array}$ \\
\hline
\end{tabular}




\section{Conclusion}

The DSP concept has been verified through this development and testing program and the data is available to transfer this technology to the geothermal industry.

Testing of the DSP operation at geothermal well temperatures has not been done. However, since all components are, or can be made from, materials with $450^{\circ} \mathrm{F}$ or higher temperature ratings use in geothermal well environments should not affect DSP operation. A basic prototype design drawing package of the 8" and 16" DSP is provided in Appendix C. Sewing and fabrication procedures used to produce the DSP bags are provided in Appendix D.

Prototype DSP assemblies have been primarily fabricated and assembled at Sandia by Sandia employees. Using costs based on estimated time and material requirements and using current shop rates, a prototype DSP with two bags and a PVC shroud should cost less than $\$ 2000$. This is somewhat higher than our initial low cost goal, however costs should be lower when the DSP is produced in larger quantity production run numbers.

Plots of data taken during testing are provided in Appendix E. The ELTF data was used to document wellbore hydraulic pressure and flow conditions as well as cement movement and location during tests. 


\section{References}

1. D. A. Glowka, 1990 "Lost Circulation Technology Development Projects," Geothermal Program Review VIII, U. S. Department of Energy, April 18-20, 1990, San Francisco, CA.

2. D. A. Glowka, D. M. Schafer, E. K. Wright, G. L. Whitlow, and C. W. Bates, 1993 "Status of Lost Circulation Research," Geothermal Program Review XI, U. S. Department of Energy, April 27-28, 1993, Berkeley, CA.

3. D. A. Glowka, 1995 "Lost Circulation Technology Development: Status of the Drillable Straddle Packer," Geothermal Program Review XIII, U. S. Department of Energy, March 13-16, 1995, San Francisco, CA.

4. D. A. Glowka, 1995 "A Drillable Straddle Packer for Lost Circulation Control in Geothermal Drilling," Proceedings of the World Geothermal Congress, Vol. 2, pp 1433-1438, May 18-31, Florence, Italy.

5. Memo to Carlos Escudero, Unocal Corporation from J. L. Wise and E. K. Wright, Sandia National Laboratories Geothermal Research Department, dated December 19,1996 "Straddle-Packer Check Valve Demonstration at Sandia National Laboratories". 


\section{Appendix A}

\section{SUMMARY OF FABRIC TESTING DATA}

NOTE: The data presented in this appendix is a chronological log of the tests conducted to select the fabric for the DSP bag. This data is not intended, as shown, to confirm the material choice, but is a summary of the detailed steps used in making the fabric selection. Complete information may be found in the Geothermal Research Department files.

\section{Fabric Stress Tester Log}

Test ID: FST02052.A. -

$$
\mathrm{R}_{2}=\frac{0.625^{\prime \prime}}{2}, \mathrm{~d}=0.1^{\prime \prime} \text { on both clamps. Test fabric placed against } 0.625^{\prime \prime} \text { groove }
$$

with two thicknesses between test fabric and O-ring. Bottom clamp failed first, but top clamp had started to fail. Failure was due to tearing at the $\mathrm{O}$-ring contact line -- preceded by scraping the silicone off the fibers. Failure occurred at $144 \mathrm{lbs}$.

Test ID: FST02052.B -

$$
\mathrm{R}_{2}=\frac{0.625^{\prime \prime}}{2} \text { on both clamps; } \mathrm{d}=0.1 \text { " on lower clamp; } \mathrm{d}=0.25^{\prime \prime} \text { on upper clamp. }
$$

Test fabric placed against $\mathrm{O}$-ring in this case, with two thicknesses between the test fabric and the $0.625^{\prime \prime}$ groove. Bottom clamp failed at $102 \mathrm{lb}$. Failure was due to tearing at the bolt hole. Upon examination, it was found that the O-ring prevents the plates (from the O-ring out to the edge) from contacting the fabric -- i.e., contact is only in the O-ring groove and between the groove and the bolt. By contrast, $d=0.25$ " causes the plates to squeeze the fabric, but the O-ring is essentially uncompressed.

Test D: FST02052.C -

Repeat of FST02052.B, except that test fabric was placed between the $0.625^{\prime \prime} / 2$ groove and the two thicknesses of fabric. Edge of $0.625^{\prime \prime} / 2$ groove was filed off. Bottom clamp ( $d=0.1$ in.) failed at $106 \mathrm{lb}$. Lower failure load as compared with FST02052.A. Probably due to edge of $0.625^{\prime \prime}$ groove being filed off.

\section{Test ID: FST02052.D -}

Repeat of FST02052.C, except only one thickness of fabric was used. Bottom clamp $(\mathrm{d}=0.1 \mathrm{in})$ again failed first, this time at $118 \mathrm{lb}$. Top clamp $(\mathrm{d}=0.25 \mathrm{in}$.) probably near the breaking point - differential stretching was beginning. 


\section{Test D: FST02062.A -}

I plate $-R_{2}=3 / 8^{\prime \prime} ; d=0.163^{\prime \prime}$ (center squeeze); three fabric thicknesses; fail on bottom plate $-\mathrm{R}_{2}=7 / 32^{\prime \prime} ; \mathrm{d}=0.217^{\prime \prime}$ (side squeeze); three fabric thicknesses; fabric slipped out of plates - failure @ 138 lbs.; tearing initiated @ bolt; stretching occurred @ top plate also (differential) with tearing initiated @ bite point.

* Where fabric failed, fabric was mistakenly placed toward the O-ring.

\section{Test ID: FST02062.B -}

Three fabric thicknesses; fabric against groove. Failure on bottom plate @ 125 lbs. $-R_{2}=7 / 32^{\prime \prime} ; d=0.217^{\prime \prime}$ (side squeeze). Fabric tore @ pinch point in rapid failure clean tear. Top plate $-\mathrm{R}_{2}=3 / 8^{\prime \prime} ; \mathrm{d}=0.163^{\prime \prime}$ (center squeeze); abrasion @ pinch point, but no stretching or tearing.

\section{Test ID: FST02062.C -}

Three fabric thicknesses; fabric toward groove. Repeat of FST02062.B except orientation of clamps is reversed - testing to see if clamps always failed when loaded on bottom. Failure@ @op plate - $\mathrm{R}_{2}=7 / 32^{\prime \prime} ; \mathrm{d}=0.217^{\prime \prime}$ (side squeeze) - fairly clean tear @ pinch point @142 lbs.

Bottom plate- $\mathrm{R}_{2}=3 / 8^{\prime \prime} ; \mathrm{d}=0.163^{\prime \prime}$; tearing @ bolt \& pinch point (center squeeze) with stretching occurring@bolt also.

\section{Test ID: FST02062.D -}

Single fabric test; fabric toward groove. Top plate $-\mathrm{R}_{2}=3 / 16^{\prime \prime} ; \mathrm{d}=0.207^{\prime \prime}$ (side squeeze) - failure@ 82 lbs. Clean tear @ pinch point - no knocked edge. Bottom plate $\mathrm{R}_{2}=3 / 8^{\prime \prime}, \mathrm{d}=0.157^{\prime \prime}$ (center squeeze) - no stretching, tearing or abrasion.

\section{Test ID: FST02062.E-}

Single fabric repeat of FST02062.D. Repeat with knocked edges @ $\mathrm{R}_{2}=3 / 16^{\prime \prime}$; $\mathrm{d}=0.207$ " (side squeeze). Bottom plate (center squeeze) failed @ 146.5 lbs. - "radial" tear@ unknocked center. Top plate (side squeeze) began tearing@ pinch points with some stretching.

\section{Test ID: FST02062.F -}

Repeat of FST02062.E with knocked edges on center squeeze plate. Top plate (center squeeze) failed@142 lbs. - catastrophic tear@bolt as fabric slid past O-ring; stretching in center@tearing where load was supported by bolt. Bottom plate (side squeeze) - tearing initiated@ pinch points with stretching. 
Test ID: FST02062.G -

Top plate - triple fabric (center squeeze) - $\left(R_{2}=3 / 8^{\prime \prime} ; d=.163\right)$

Bottom plate - single fabric (side squeeze) - ) $R_{2}=3 / 8^{\prime \prime} ; d=.207$ )

Bottom plate failed at $147 \mathrm{lbs}$. Tear started at pinch point, then ripped out, leaving thread strands. Some stretching at bolt hole. Top plate started to rip at pinch point, but not yet torn.

\section{Test D: FST02072.A -}

Flat surfaces top \& bottom. Bolt torque - 100 in-lb (all previous were $\sim 40$ in-lb) Broke at $120 \mathrm{lb}$. (top). Tear initiated at bolt hole.

\section{Test ID: FST02072.B -}

$\mathrm{d}=0.157^{\prime \prime} ; \mathrm{R}=3 / 8^{\prime \prime}$ (center squeeze single) on top; $\mathrm{d}=0.163^{\prime \prime} ; \mathrm{R}=3 / 8^{\prime \prime}$ (center squeeze triple) on bottom. Bottom broke at $148 \mathrm{lbs}$. Top starting to tear at bolt. Bottom broke at pinch point. Bolt torque $=100 \mathrm{in}-\mathrm{lb}$.

Test ID: FST02072.C -

Top: $d=0.142, R=7 / 32$ full squeeze single)

Bottom: $d=0.163, R=7 / 32$ (full squeeze triple) broke @ 168 lbs.

Tear on top in silicone, but not in threads.

Tear on bottom through the silicone and threads.

Bolt torque $=100$ in-lb.

\section{Test D: FST02072.D -}

*Note: Bolt torque - 100 in-lb. unless stated otherwise

Top: $d=0.142, R=7 / 32$ (full squeeze single)

Bottom: $d=0.157, R=3 / 8$ (center squeeze single)

Top broke at $147 \mathrm{lbs}$.

Test D: FST02072.E -

Top: $d=0.157, R=3 / 8$ (center squeeze single)

Bottom: $d=0.163, R=7 / 32$ (full squeeze single)

Top broke@133 lbs. Tore at bolt heads.

Bottom silicone barely deformed at pinch point. 


\section{Test ID: FST02072.F -}

*Note: Weave was oriented $90^{\circ}$ from previous tests; plastic was not removed from silicone

Top: $d=0.163^{\prime \prime}, R=7 / 32^{\prime \prime}$ (full squeeze single)

Bottom: $d=0.163^{\prime \prime}, R=3 / 8^{\prime \prime}$ (three fabric thicknesses)

Failure on bottom at $169 \mathrm{lbs}$ - stretched \& tore at corner

Top clamp experienced stretching at nearest pinch point and stretching \& tearing at other pinch point.

Test ID: FST02072.G -

Repeat of FST02072.F with plastic liner removed from silicone

Top: $d=0.163^{\prime \prime}, R=7 / 32^{\prime \prime}$ (full squeeze single)

Bottom: $d=0.163 ", R=3 / 8^{\prime \prime}$ (three fabric thicknesses)

Bottom tore at $176 \mathrm{lbs}$. at pinch point.

Top experienced stretching \& tearing at farthest pinch point.

Test ID: FST02072.H -

Top: $d=0.163^{\prime \prime}, R=7 / 32^{\prime \prime}$ (full squeeze single)

Bottom: $d=0.153^{\prime \prime}, R=7 / 16^{\prime \prime}$ (center squeeze triple)

Top broke at $169 \mathrm{lbs}$., tearing at pinch point.

Very little tearing at pinch point on lower.

Test ID: FST02102.A -

Top: $R_{2}=7 / 32, d=0.163$ " (triple full squeeze)

Bottom: $R_{2}=7 / 16, d=0.153$ (triple center squeeze)

Bottom broke at $185 \mathrm{lbs}$. - "radial" tear.

Top starting to tear at both pinch points.

Test ID: FST02102.B -

Top: $R_{2}=3 / 8, d=0.163$ (triple center squeeze)

Bottom: $R_{2}=7 / 32, d=0.163$ (triple full squeeze)

Top broke at $180 \mathrm{lb}$. Strange, uneven pulls prior to breaking.

"Radial" tear. Bottom starting to tear at both pinch points.

Test ID: FST02102.C -

Top: $7 / 32, \mathrm{~d}=0.163$ (triple full squeeze)

Bottom: $7 / 16, d=0.153$ (triple center squeeze)

Repeat of FST02102.A, except fabric against O-ring. 
Top broke at $174 \mathrm{lb}$.

Test ID: FST02172.A -

Top: $R_{2}=7 / 16, d=0.153$ (triple center squeeze)

Bottom: $\mathrm{R}_{2}=7 / 16, \mathrm{~d}=0.153$ (" " ")

Top \& bottom broke simultaneously at $186 \mathrm{lb}$.

Tears initiated at pinch points.

\section{Test ID: FST02172.B -}

One-inch wide stitched loop. Double-stitched, then single top-stitched.

Broke at stitches at $107 \mathrm{lb}$. A lot of stretching and breaking of silicone before that point.

Test D: FST02172.C -

Repeat of FST02172.B. Same results - broke at $107 \mathrm{lb}$.

Fabric started to show holes in the silicone at $70 \mathrm{lb}$; threads still intact.

Test D: FST02172.D -

Repeat of FST02171.B. Broke at $112 \mathrm{lb}$.

Test D: FST02192.A -

Top and bottom $7 / 16-\mathrm{R}_{2} ; 0.153$ - $\mathrm{d}$ (single squeeze)

Bottom pulled out at $174 \mathrm{lbs}$. Fabric against the groove.

Test DD: FST02192.B -

Top \& bottom $\mathrm{R}_{2}=7 / 16, \mathrm{~d}=.153$ (triple squeeze)

New fabric - \#4032 .032" thick; burst 600 , tear 100/90 breaking 450 x 400; gray in color

Bottom tore straight across at $217.5 \mathrm{lbs}$. and it had another tear just below bolt hole.

Fabric was against the groove.

Test ID: FST02192.D -

Top \& bottom $R_{2}=7 / 16, d=.153$ (single squeeze); same fabric

Top tore at $193 \mathrm{lbs}$. with a tear at the bolt hole 
Test ID: FST02192.E -

One-inch wide stitched loop, double-stitched; was not top-stitched.

Broke at stitches at $85 \mathrm{lbs}$.

Fabric is \#1032, white silicon-reinforced fiberglass.

\section{Test ID: FST02191.F -}

Same fabric as FST02192.E.

Broke at $78 \mathrm{lbs}$. in the same fashion as before.

Test ID: FST02192.G -

Same fabric as FST02192.E.

Broke at $80 \mathrm{lbs}$. with more damage to the other side of the loop, almost tore it in two - on both sides.

Test D: FST02192.H -

One-inch wide stitched loop; double-stitched; was not top-stitched.

Fabric is \#4032 silicon-reinforced fiberglass, gray in color

Ripped in two at $133 \mathrm{lbs}$.

Test ID: FST02192.I -

Same as FST02192.H

It ripped to two at $121 \mathrm{lbs}$.

Test D: FST02192.J -

Same as FST02191.H

Also ripped to two at $123 \mathrm{lbs}$. Just snapped.

Test ID: FST02262.A -

Top \& bottom: $\mathrm{R}_{2}=7 / 16, \mathrm{~d}=0.153$

Triple white fabric with $3 / 8$ " bolt torqued near 300 in-lb (one of them started to strip).

Broke at $167 \mathrm{lb}$; tear initiated at O-ring.

\section{Test D: FST02262.B -}

Repeat of FST02262.A, except plastic back-up threads and only 175 in-lb.

Broke at $172 \mathrm{lb}$; tear initiated at O-ring. 
Test ID: FST02262.C -

Repeat of FST02262.B, except with gray fabric. Tore at $176 \mathrm{lb}$; tear initiated at $\mathrm{O}$-ring.

Test ID: FST03032.A - NEW SEWING MACHINE

One-inch wide gray fabric strips. Double-stitched but not top-stitched. Thread slipped out at $86 \mathrm{lb}$.

Test W: FST03032.B -

Repeat of FST030321.A. Thread slipped out at $59 \mathrm{lb}$.

Test D: FST03032.C -

Repeat of FST03032.A. Thread slipped out at $84 \mathrm{lb}$.

Test ID: FST03032.D -

Repeat of FST03032.A, except "hand-sewn" with square-knot ends. Broke at $119 \mathrm{lb}$; knot on one end came loose.

Test D; FST03032.E -

Repeat of FST03032.D. Broke at $133 \mathrm{lb}$; ripped through fabric in middle, then broke thread.

Test ID: FST03032.F -

Repeat of FST03032.D. Broke at $120 \mathrm{lb}$; ripped through fabric in middle, then broke thread. (First seam ripped (came untied) at $\sim 60 \mathrm{lb}$. Second seam broke at $120 \mathrm{lb}$.).

Test W: FST03032.G -

Repeat of FST03032.D, except "machine-sewn" back, then forth.

Test D: FST03032.H -

Repeat of FST03032.d, except "hand-sewn" with double seam, then top seam. Broke at $192 \mathrm{lb}$. Ripped at first single seam; then pulled top seam out. 


\section{Test ID: FST03032.I -}

Repeat of FST03032.H. Broke at $192 \mathrm{lb}$. again. Same failure mode.

Test D: FST03232.J -

Repeat of FST03032.H. Broke at $191 \mathrm{lb}$. Same failure mode.

\section{Test ID: FST03032.K -}

Repeat of FST03032.H, except two top seams. Broke at 201 lb. @ first top seam.

\section{Test ID: FST03032.L -}

Repeat of FST03032.K, except first single seam was crooked and stitches were too close together (machine-sewn). Broke at $131 \mathrm{lb}$. at first seam.

\section{Test ID: FST03172.A -}

Top plate: 1" PVC with groove - nut and bolt @ 400 in-lb.

Bottom plate: 1" PVC with groove - nutsert installed from far side in 19/32' hole. Torqued to 35 in-lb. Gray fabric.

Bottom plate: Fabric tore at O-ring (clean tear) at $220+\mathrm{lb}$. (scale bottomed out).

Test D: FST05292.A -

Both plates: Gland L design

Three fabric thicknesses

Red fabric (1584 from Fabricoat - Satin Weave)

200 in-lb. torque on never-seezed Al bolts

At $200 \mathrm{lb}$., fabric slowed, pulled through clamp. No damage to fabric.

\section{Test ID: FST05292 -}

Repeat of FST05292.A, except clamps placed to prevent longitudinal extrusion of O-ring. Did not break or slip at over $200 \mathrm{lb}$. Need to re-design tester to add more weight.

\section{Test ID: FST06012.A -}

New tester: Wood frame, fabric clamps, C-clamps, and three sand bags (weight $=$ $184 \mathrm{lbs}$.) Plastic water barrel weighs 9 lbs.

Both plates $=$ Glad L design

Three fabric thicknesses; test fabric against 0 -ring 
Red fabric

200 in-lb. on never-seezed Al bolts

Fabric slipped out of clamp suddenly at $301 \mathrm{lb}$.

Test ID: FST06012.B -

Repeat of FST06012.A. Fabric slipped out of clamp slowly at $249 \mathrm{lb}$.

Test D: FST06012.C -

Repeat of FST06012.A. Fabric slipped out of clamp slowly at $291 \mathrm{lb}$.

Test D: FST06012.D -

Repeat of FST0612.A, except test fabric was placed against the outer PVC surfaces of the gland instead of the O-ring (i.e., pad fabric placed against $\mathrm{O}$ ring). Fabric from a previous test was used. Fabric tore at gland edge at $256 \mathrm{lb}$.

Test ID: FST06012.E -

Repeat of FST06012.D. Fabric tore at gland edge at $337 \mathrm{lb}$.

\section{Test D: FST06022.A -}

Repeat of FST06012.D, except bolt torque reduced to $150 \mathrm{in}-\mathrm{lb}$. Fabric tore at gland edge at $317 \mathrm{lb}$.

Test I: FST06022.B -

Repeat of FST06012.D, except bolt torque reduced to 100in-lb. Fabric tore at gland edge at $282 \mathrm{lb}$.

Test ID: FST06022.C -

Repeat of FST06012.D, except new fabric sample used.

Both plates: Gland $\mathrm{L}$ design

Three fabric thicknesses; test fabric against outer gland PVC surfaces, not

O-ring

Red fabric (new sample)

100 in-lb. torque on $\mathrm{Al}$ never-seezed bolts

Fabric tore at gland edge at $410 \mathrm{lb}$. 
Test ID: FST06022.D -

Repeat of FST06022.C. Fabric tore at gland edge at $410 \mathrm{lb}$.

Test ID: FST06022.E -

Repeat of FST06022.C. Fabric tore at gland edge at $410 \mathrm{lb}$. 


\section{Appendix B}

\section{SUMMARY OF BAG TESTING DATA}

NOTE: The data presented in this appendix is a chronological log of tests conducted to evaluate and finalize the design of the DSP bag. This data, without detailed test setup information, is not intended to present all the necessary analysis to confirm the design, but is an overview of the detailed steps undertaken during development of the DSP bags. Complete information may be found in the Geothermal Research Department files.

\section{DRILLABLE STRADDLE PACKER LABORATORY PROTOTYPES}

LABORATORY PROTOTYPE 1 (first design, steel band clamp) - Used solid steel bands to fasten the 16-inch diameter fabric tube to the 10-inch bulkheads. Foam tape was placed between the bands and the fabric to help prevent tearing caused by the edge of the bands. Test ID PT12171.A. Bands allowed fabric to slip along bottom bulkhead, pulling the tube out of the bands and "bursting" the packer at 2.5 psi. Fabric tube itself was unharmed.

LABORATORY PROTOTYPE 1A (ends folded radially, screwed to flange, band clamp also used) - Packer tube was cut between bulkheads, shortened by 2.75 inches, and coupled together with a PVC coupler. This allowed 1.375 inches of excess tube length on each end. These excess lengths were folded $90^{\prime}$ radially inward and screwed to the outer face of each bulkhead with 8 each \#1 0 X 1 " flathead wood screws and fender washers. Slotted steel bands were also used together with foam tape. Test ID PT01222.A. Stress concentration at steel band edges tore through the foam tape and fabric, allowing it to rip open, bursting at $36 \mathrm{psi}$.

LABORATORY PROTOTYPE 1B (split bulkhead with 0-ring, arbitrary gland design, new radial fold) - About 5.5 inches of the fabric tube from $1 \mathrm{~A}$ were cut off, and the bag was re-used (total fabric tube length $=34$ inches). A fold pattern was developed to take the 16-inch radius fabric tube down to a 5.0-inch radius on each end. A split bulkhead design was developed that uses an 0-ring and 12 each 1/4-inch aluminum screws to clamp the folded part of the fabric tube. An entirely new packer tube was assembled. Evidently, poor-quality PVC cleaner was used, and an incomplete bond developed in a tube fitting. During test PT01312.A, the bond failed (at about $13 \mathrm{psi}$ ), propelling the inflated assembly down the casing. The edge of the lower bulkhead and the bag abraded against the side of the casing on the way down. The sharp edge of the simulated loss zone tore the bag at one point and badly abraded it over a length of about 10 inches. The bag plugged the loss zone outlet, causing pressure in the casing to build to the point where both production zone unions at the turbine flow meters blew apart.

Re-Test ID test PT02042.A after cutting off torn part of fabric tube and refastening to the lower bulkhead. The bag tore through the bolts on the upper bulkhead at about 27 psi. Lower bulkhead held OK. 
LABORATORY PROTOTYPE 1C (ends sewn on fabric tube, optimized 0-ring gland design) - This design uses a 37.5-inch-long, 16-inch-diameter fabric tube with fabric ends that have 5 -inch holes in their centers. Since ends were not folded, 2 fabric spacers were used in each end to allow the bulkheads from $1 \mathrm{~B}$ to be used without modification. Fabric glands optimized by fabric stress tests to $R_{2}=7 / 16 ", d=0.153$ " on both bulkheads. Bulkhead bolts torqued to 100 in-lb.

Test ID PT02242.A. Top circumferential seam broke at 26 psi; otherwise, the fabric was undamaged. Fabric glands held $\mathrm{OK}$.

LABORATORY PROTOTYPE 1D (radial fold with optimized 0-ring glands) Shortened tube from $1 \mathrm{C}$ by 3 inches by cutting the ends off. Folded ends as in Prototype 1B. Used same bulkheads as in Prototype 1C. Upper bulkhead bolts torqued to 100 in$\mathrm{lb}$; however, 1 bolt broke and was augmented by new bolts on each side of it. Lower bulkhead bolts were torqued to only $75 \mathrm{in}-\mathrm{lb}$, because two broke and one stripped the plastic threads. Each of these three bolt failures were also augmented by new bolt holes on the side.

Test ID PT'02252.A. Fabric tore out of lower bulkhead at 22 psi. Fabric slipped past 0ring and tore out the bolt holes. It was later found that the bolt holes in question were substandard, having interfered with previous holes in the bulkhead.

LABORATORY PROTOTYPE 1E (increased bolt size on one end from $1 / 4^{\prime \prime}$ to $3 / 8$ ", increased bolt torque to $175 \mathrm{in}-\mathrm{lb}$ ) - Shortened tube from $1 \mathrm{D}$ by 1 inch and replaced lower bulkhead bolts with $3 / 8$ " bolts. Previous bolts were all $1 / 4$ ". Conducted fabric stress tests and found that 175 in-lb with the larger bolts gives about the same results as 100 in$\mathrm{lb}$ with $1 / 4$ " bolts. Top bulkhead still used $1 / 4$ " bolts with $100 \mathrm{in}-1 \mathrm{~b}$ torque, since that bulkhead was previously successfully assembled and survived the previous test.

Test ID PT'02262.A. Bottom flange allowed fabric to slip past 0 -ring at $24 \mathrm{psi}$, tearing at the bolt holes. Apparently, 175 in-lb is not adequate, in the circular configuration used in the bulkheads.

LABORATORY PROTOTYPE 1F (changed from white to gray fabric, increased other bolts to $3 / 8$ " diameter, increased bolt torque to $250 \mathrm{in}-\mathrm{lb}$ ) - Replaced upper bulkhead bolts with 3/8" bolts to match the lower bulkhead. Gray fabric used. Ends folded as in 1B. Fabric silicone-sealed to bulkhead groove. Bolts torqued to $250 \mathrm{in}-\mathrm{lb}$.

Test ID PT02282.A. Longitudinal seam tore near lower end at 22 psi. This seam had only one top stitch, not two as the others had. More importantly, the bag was full of air when it was inserted into the casing. Air entrapped in the top of the bag prevented the lower part of the bag from assuming a circular configuration. Thus, hoop stresses that would tear the seam were imposed on the lower part of the bag near the casing wall. 
Re-test ID PT'03052. A with a new gray-fabric bag (the first seam with our new machine). Two screws on the lower bulkhead started to strip. These were augmented with $1 / 4$ " and $3 / 8^{\prime \prime}$ holes on each side. All of the new $3 / 8^{\prime \prime}$ holes, however, intersected previous holes in the inner flange, so they were epoxied, then re-drilled and re-tapped. They held at least $100 \mathrm{in}-\mathrm{lb}$, which is what they were torqued to. The stripped $3 / 8^{\prime \prime}$ hole was also epoxied, re-drilled, re-tapped, then torqued to $100 \mathrm{in}-1 \mathrm{~b}$. The $1 / 4^{\prime \prime}$ bolts were torqued to $85 \mathrm{in}-\mathrm{lb}$. All other flange bolts on the bottom flange were torqued to $190 \mathrm{in}-\mathrm{lb}$. All (3/8 ") bolts on the top flange were torqued to $250 \mathrm{in}-\mathrm{lb}$. Evidently, the top end of the bag never assumed a circular shape. The bag was too long for the bulkhead separation, and the top end could not drag all the excess fabric up so it could assume its circular shape. As a result, the top end was placed in a catenary shape. Evidence of this came from the fact that the lower half-flange (which had not been radiused) tore the bag. The fabric also slipped through the top flanges near the tear point. Failure occurred at 24 psi.

LABORATORY PROTOTYPE $1 \mathrm{G}$ (increased inner flange thickness from $1 / 2$ " to 1 " to improve torque reliability) - Gray fabric, 1 " inner flanges, $3 / 8$ " bolts. Threaded couplings were used to allow the re-use of the stinger tube without cutting off slip couplings. One of the bolts on the top flange stripped at $175 \mathrm{in}-1 \mathrm{~b}$, was epoxied, redrilled, and re-threaded.

Test ID PT03162.A to test sealing capability. Top end tore loose at the bad bolt at about $16 \mathrm{psi}$.

LABORATORY PROTOTYPE $1 \mathrm{H}$ (used 3/8" aluminum nutserts to improve torque capability and self-tapping screws to provide back-up clamping) - Cut off $3 / 4$ " of fabric tube at the torn end from PT03162.A. Made new inner bulkheads from 1" PVC plate. Used 3/8" aluminum nutserts (drilled 9/16" holes " deep, pressed in from backside, backwards with flange ground off). Torqued all $3 / 8$ " bolts to $350 \mathrm{in}-\mathrm{lb}$. Also, put a $\# 10$ $\mathrm{X} 1 / 2$ " aluminum screw with a steel fender washer between each bolt, holding the fabric against the inner flange. (Outer flange had clearance spaces milled out for the screw heads and fender washers.)

Test ID PT03182.A in a sealing test. Top end tore loose from beneath the 0 -ring at 11 psi. PI-P3 may have been higher because P3 was being reduced to zero when the bag broke; however, the P3 transducer went haywire, so good P3 data were not obtained.

LABORATORY PROTOTYPE 11 (new fabric clamp design; reduced size of bag inflation ports from $3 / 4$ " to $3 / 8$ ") - Made new bulkheads (3/4" thick for outer flange, 1 " thick for inner flange) with new fabric clamp design. Reduced size of backup rings and made them a single, slip-over piece. Added 3 tabs to each flange to secure flange to back-up ring through a $1 / 4^{\prime \prime}$ nylon screw ( $90^{\circ}$ flange secured with flange bolt head.) Sewed a new bag. Again used 3/8" nutserts (inserted backwards with flanges ground off) and torqued to $350 \mathrm{in}-\mathrm{lb}$. Reduced size of bag inflation ports from $3 / 4$ " to $3 / 8$ ". 
Test ID PT04132.A. Bottom backup ring came unglued, causing flanges to separate and fabric to pull out of lower flange at 13 psi. Split backup rings to give them a smaller ID. $\mathrm{Re}$-assembled as in previous test (same undamaged bag used).

Re-Test ID PT04142.A. This time, the top backup ring came unglued, causing the top flange to move. The fabric tube tore along the bottom outer edge of the lower flange at 37 psi. The tear appeared to be a tensile failure without evidence of cutting. Upon disassembly, however, several tears were found that resulted from pinching at the "corner" between the two flanges. Care must be taken when assembling the flanges to prevent this pinching.

Re-Test ID PT04152.B after increasing length of back-up ring to 2". This time, the bag tore along the bottom outer flange edge at approximately $40 \mathrm{psi}$. Originally thought that the bag had withstood over 80 psi; however, it was determined that $3 / 8$ " bag inflation ports did not allow the pressure drop (PI-P2) to drop sharply when the bag burst.

LABORATORY PROTOTYPE $1 \mathrm{~J}$ (increased length of back-up rings to 2"; reduced size of ejection ports to $1 / 2^{\prime \prime}$; increased bag inflation ports back to $3 / 4^{\prime \prime}$ ) - Returned to a 2 -inch length on the back-up rings. Cut off 4 inches from the fabric tube used in PT04142.A. This necessitated moving the flanges in from 17 to 13 inches separation. Plugged the $3 / 4$ " ejection ports and re-drilled to $1 / 2$ ". This should reduce by $56 \%$ the flow rate required for a given bag inflation pressure. Care was taken assembling the flanges to prevent pinching. All other parameters the same as with Lab Prototype $1 \mathrm{I}$.

Test ID PT04172.D. Bag tore along bottom outer flange edge at $26 \mathrm{psi}$. This appears to be about the limit for this gray fabric.

LABORATORY PROTOTYPE 1K (modified gland design) - Modified gland design in case prototype $1 \mathrm{~J}$ did not work Never actually built or tested because gray fabric was found to be too weak.

LABORATORY PROTOTYPE 1L (modified gland design for red fabric) - Modified gland design to accommodate thicker red fabric. Still 3/4" bag inflation ports and 1/2" ejection ports.

Test ID PT06192.B. Bag tore along bottom outer flange edge at 43 psi. No slipping of red fabric. Appears that design goal has been met.

Re-Test ID PT02233.A after re-building bag according to existing design. Reused all other hardware. This test was intended to be a repeat of PT06192.B to test repeatability. Again, bag tore along bottom outer flange edge with no slipping, this time at $41 \mathrm{psi}$. Design goal of $40 \mathrm{psi}$ has been confirmed.

Flowby Test ID PT02253.A. This time, the bag tore near the top flange at $34 \mathrm{psi}$, probably due to uneven pleating of the fabric, because it also tore near the bottom flange in line with the top tear. 
Flowby Test ID PT03123.A. However, the bag was unintentionally fabricated from a different, weaker material. Packer tore near top flange at only 11 psi. We did not hear the tear, so we increased pressure to about 33 psi, at which point the packer tube broke, probably because of fatigue from so many tests.

Flowby Test ID PT03293.A and B, this time with correct fabric and entirely new tube assembly. Use steel Tee-nuts instead of aluminum nutserts so that packer flanges can be re-used many times. Puzzling flow from region 2 to region 3, even though P3 $>$ P2. Postulated that this is due to a wall jet forming when the ejection jets hit the wall, with Pstagnation $=\mathrm{Pl}$.

Flowby Test ID PT03303.A. $90^{\circ}$ elbows added to ejection ports to deflect flow downward. Again, we got negative FM3 with P3 $>$ P2. However, this was probably due to leakage at the 2 "X3" reducing bushing, because this bushing was not properly cemented and broke at $35 \mathrm{psi}$. Bag still OK.

Flowby test ID PT04023.A. Ran test with open casing, packer at top of casing. Before start of data storage, charge pump was started, but FM1 valve was wide openprobably broke bag near top flange because once the test was started, the bag leaked through two holes near the top flange.

Flowby test ID PT04023.B. First test of Petersen Stopper Bag with 0.75" orifice in the bottom (closed casing). Bag held up okay to $35 \mathrm{psi}$, but when the flow rate was decreased to lower the bag pressure (for safety), siphoning started. This resulted in pressure going negative---test aborted.

PTCALTEST. 4/2/93. Calibration test without orifice on FM1 outlet.

PTCALTEST.2. 4/2/93. Calibration test with 0.75 " orifice on FM1 outlet.

PTCALTEST.3. 4/2/93. Calibration test with 0.93 " orifice on FM1 outlet.

Stopper bag test ID PT04023.C. Second test of Petersen stopper bag. 0.93" orifice in bottom of bag (closed casing).

Stopper bag test ID PT04063.A. Third test of Petersen stopper bag. 0.93" orifice in bottom of bag with closed casing.

Stopper bag test ID PT04093.A. Modified Packer Test facility to prevent siphoning. Fourth test of Petersen stopper bag. 0-350: FM3 closed; FM3 bypass open.

Stopper bag test ID PT04124.A. Fifth test of Petersen stopper bag. Added an 8' long half-round protrusion in the wellbore consisting of a half-round $5 / 8^{\prime \prime}$ wood molding glued to magnet strips. 
PTCALTEST.1. 4/12/93. Packer Test Facility flow calibration test to test FMI. FMII apparently o.k.

PTCALTEST.1. 8/16/93. Packer Test Facility flow calibration test. All flow meters working well (FMA not tested). P1, P2, and P3 also taken down and tested against pressure standard. P1 read about $1 \mathrm{psi}$ high; otherwise, all tested o.k.

(Petersen) DSP Bag \#1 test ID PT08163.A. First test of Peterson DSP Bag \#1 (Ref. 6/7/93 memo for design). 0-100: Adjusting FM3 to 12gpm, with FM1=0.

(Petersen) DSP Bag \#1 test ID PT08173.a. Second test of Petersen DSP Bag \# 1. During this test, it became apparent that the bag was torn. Data not plotted, but may be useful for demonstrating the effects of a torn bag later.

Coupler test ID PT10073.A. First test of drillstring coupler after reducing ID of piston-pintle $\mathrm{O}$-ring gland to reduce $\mathrm{O}$-ring squeeze. This test done without ball in place. (FM3 $=$ FM4 $=0$ throughout test).

Coupler test ID PT10073.B. First test of drillstring coupler after modifying as stated above. This test done with ball in place.

Shroud mechanism test ID PT11013.A. First shroud piston test of Design \#1 without shroud and without ball. FM1 not working - plot everything against FM2. Flow rate increased from 0 to $\sim 250 \mathrm{gpm}$. P1-P2+3.2 increased to $52 \mathrm{psi}$ with no shearing of shear screws. Good test of flow-through capability, without ball in place.

Shroud mechanism test ID PT11013.B. First shroud piston test of Design \#1 with ball in place (no shroud). FM1 not working-plot against FM2. Mud pump speed slowly increased until P1-P2+3.2 = 190psi, when the shear screws broke. Flow then increased to $\sim 105 \mathrm{gpm}$. Top vent left open and started to flow, spraying P1 pressure transducer connector and causing erroneous P1 readings. When piston pulled out, $\mathrm{O}-$ rings were torn apart.

Shroud mechanism test ID PT11013.C. Second shroud piston test of Design \#1 with ball in place (no shroud). FM1 still not working-plot against FM2. Mud pump speed slowly increased until P1-P1+3.2 = 134 psi; when the shear screws broke. Flow then increased to $105 \mathrm{gpm}$. Good test. Bottom seal tested before removing piston. Seal leaked very slowly. Piston was removed and O-rings were torn apart.

Shroud mechanism test ID PT11043.A. First test of Design \#2 of shroud mechanism with ball in place and without shroud itself. Pressure P1 gage connector was inadvertently placed on the 1000-psi transducer - P1 pressures are erroneous. Not corrected in plot, but could be corrected later if necessary. FM1 was fixed, but FM1 and FM2 do not always agree. FM1 is probably closer, agreeing better with magmeter in line.

Shroud mechanism test ID PT11043.B. First test of Design \#2 of shroud mechanism with ball in place and without shroud itself. FM1 used (see above). P1- 
$\mathrm{P} 2+3.2 \approx 190$ psi when shear pins broke. This design o.k. since 0-ring seals survived the mechanism movement.

Shroud mechanism test ID PT11043.C. Repeat of PT11043.A. P1-P2 + 3.2 $\rightarrow 40$ psi @ FM1 =FM2 = 220 gpm. FM1 working well.

Shroud mechanism test ID PT11043.D. Repeat of PT11043.B. FM1 working well. Shear screws broke at 215 psi.

Shroud mechanism test ID PT11053.A. Third test of Design \#2, shroud mechanism without shroud, with ball. Ran with ball in place and centrifugal pump only for awhile, to test long-term integrity of shear screws. Screws survived for over 20 minutes. Pressure then increased to $250 \mathrm{psi}$ (slowly) to break screws. Good test. Shear pins broke at $254 \mathrm{psi}$.

Petersen Bag \#2 in clear tube test ID PT11093.A. Rubber bands, 2 ea. @ 1.5 and 5 inches from end of folded bag. Bag inflated as desired, with top bands rolling off first, then bottom bands. Air and water flowed through bag at $\sim 5 \mathrm{gpm}$ when fully inflated with $($ Pimax $)=16$ psi. In clear tube, $F M 1=$ magmeter flow rate. $\mathrm{P} 1=\mathrm{P} 1$.

Petersen Bag \#2 in clear tube test ID PT11093.B. Repeat of PT11093.A. Flow rate increased to $\max$ with pressure $\mathrm{P} 1 \rightarrow 22$ psi at pump stagnation. FM1 down to $\sim 8$ gpm.

PTCALTEST 11/11/93. Flowmeter calibration test. FM3 transducer not working. FM1 \& FM2 work well.

Petersen Bag \#2 test ID PT11113.A. Intended flowby test, but upon flowing, it was found that FM2 was not working. Test aborted, but only after bag already filled. No high P1 pressure noted during test, but bas was town along several lower pleats. May still seal--will run test in clear tube. New flowmeters to be ordered for FM2, 3, \& 4 .

Petersen Bag \#2 in clear tube test ID PT11153.A. Pressurized with tap water $\rightarrow$ no flow rate measurements available. Bag burst at 31 psi along top \& bottom. Thereafter, could not sustain high pressure with tap water hose--pressure drops too much at high leakage rate. New paddlemeters installed after PT11153.A on FM2, Fm3, FM4 to replace turbine flowmeters. New turbine flowmeter pickups ordered. Added magmeter as backup for FM1.

Petersen Bag \#2 Calibration test ID PTCAL3. (1/4/94) (with shroud - flowthrough only for this test). PTCAL 7 PTCAL2 run on same date (not listed above) showed that pulse width on FM2 was too large to allow flow rates $>150 \mathrm{gpm}$ to be measured. Reduced pulse width for PTCAL3. With PTCAL3, FM2 was recorded in units (gpm using old [approximate] calibration \{FM2 (gpm or "units") $=$ Vfm2-1/0.032\}. Data had to be reconverted to volts prior to calculating the new calibration:

FM2 $(\mathrm{gpm})=0.454+45.86(\mathrm{Vfm} 2-1)=0.454+\mathrm{Vfm} 2-1 / 0.0218$ or 
FM2 $(\mathrm{gpm})=-45.404+45.858 \mathrm{Vfm} 2$

Petersen Bag \#2 test ID PTCAL4. (1/4/94) (with shroud, flow-through only). Calibration check using new FM2 calibration. FM1 was acting up at low flows. FM2 checks out good in comparison with magmeter. FM2 calibrated o.k.

Petersen Bag \#2 Calibration test ID PTCAL5. (1/4/94) (with shroud - flowthrough only). Calibration check using new FM2 calibration and also flow FM3 \& FM4 to check their operation with new paddlemeters. Calibrations o.k. (FM1 seems unsteady).

Petersen Bag \#2 (with shroud) test ID PT01044.A. First shroud test. Shroud appeared to deploy normally, but upon pressurization of the bag, the male connector between the packer assembly and the flange nipple broke. The packer fell down to the bottom of the casing, the fabric plugged the "loss zone," the pressure in the casing rose to $140 \mathrm{psi}$, and the production zone plumbing blew apart.

Petersen Bag \#2 (with shroud) test ID PT01064.A. Second test of shroud on Petersen \#2. 500-psi transducer on P1 died, so we are using the 1000-psi transducer (recalibrated it 1/6/94). Shear screws broke at $250 \mathrm{psi}$. Then increased flow rate to inflate bag. Bag inflated to 46 psi before massive rupture (bag was torn top \& bottom prior to this test.) Successful test of shroud assembly using pre-torn bag!

Petersen Bag \#3 (with shroud, no ball) test ID PT01134.A. No ball in place-simple flow through. FM2 was o.k. for a while, then showed low flow. (Note that magmeter agrees with FM1).

At $\sim 370$ seconds, opened FM3 drain so that FM1 = FM2 + FM3. All seems o.k. for ball test, but FM2 needs recalibration.

P1- P2 +3.2 went to $\sim 24$ psi at 140 gpm. Shear pins held fine. Good test.

Petersen Bag \#3 with shroud, with ball test ID PT01134.B. First test of shroud with new bag. Shear pins broke at 235 psi. Shroud deployed successfully. Increased flow rate to $\sim 52 \mathrm{gpm}$, and P1- P2 +3.2 went to $\sim 25$ psi. Held for several minutes. Bag survived with only small (1/3-inch) tears in top clamp. Shroud deployed but came off piston pipe lower end cap. Successful test. FM3 drain was open; bag sealed well.

PTCAL1.4/26/94 Calibration test. FM2 calibration test and system checkout. $3 / 4^{\prime \prime \prime}$ pipe orifice in PTF in place of packer. FMK2 was recorded in volts. FM2 worked well. Test run at $\sim 3: 30$ p.m.

PTCAL1.4/28/94 Calibration check. Repeat of PTCAL1.4/26/94 with the FM2 calibrations from that test in place. FM2 now reading consistently low by about $8 \%$ effects of colder water (at 9:00 a.m.)? The FM2 data can be "corrected" according to the data recorded in this test. 
PTCAL2.4/28/94 Calibration check. Increased flow to $\sim 67 \mathrm{gpm}$, then turned on production pump to increase FM3 to $\sim 20 \mathrm{gpm}$. FM1 + FM3 = FM2----o.k.

Petersen Bag \#3 test ID PT04284.A. Burst test; FM3 opened after bag inflated with charge pump. Bag was leaking through previous small holes in top. Bag burst at 62 psi! FM3 maxed out in negative direction. (3 ea. 1/2" orifices). Ripped out bottom and top both, particularly the bottom. Also looks like it could have burst at $25 \mathrm{psi}$, or at least enlarged the existing small rips.

Petersen Bag \#4 test ID PT04284.B. Burst test; FM3 not open at start, opened later. (1 ea. 3/4" pipe orifice). Bag burst at 31 psi. Never did seal completely. Upon inspection, it was found that this bag was constructed of only one fabric tube instead of two like it was supposed to be. Ripped top \& bottom. Also looks like the single fabric tube initially tore at $\sim 12$ psi when the FM3 valve was suddenly opened.

Petersen Bag \#5 test ID PT04284.C. Burst test. FM3 open at start (1 ea. 3/4" pipe orifice). Bag burst at $46 \mathrm{psi}$, after completely sealing (FM3=0). Upon inspection, it was found that this bag was constructed of two fabric tubes instead of one like it was supposed to be. Rip was in top only, and this hole was fairly well sealed because we went to 58 psi subsequently with increase in Q and no blow-out. Great test!

Petersen Bag \#6 test ID PT04294.A. Burst test; FM3 open at start (1 ea. 11/16" orifice). Bag burst at 38 psi after perfect sealing. Top swage moved and fabric pulled out - fabric still o.k. Swage moved because of annealed Al tube? Maybe, but see next test.

Petersen Bag \#8 test ID PT0429.B. Burst test; FM3 open at start (1 ea. 11/16" orifice). Bag burst at 52 psi after perfect sealing. Bottom swage moved and fabric pulled out -- fabric still o.k.! Need more consistent quality on swages, perhaps. FM3 still zero after bag failure because no hole in top of bag.

Petersen Bag \#7 test ID PT04294.C. Burst test; FM3 open at start (1 ea. 11/16" orifice). Bag burst at $66 \mathrm{psi}$ after fairly good sealing. Outer canvas bag o.k.; inner bag obviously tore. Perhaps it was torn to start with since FM3 never went to zero.

Petersen Stopper Bag (same bag as tested 4/2/93) test ID PT04294.D. Burst test; FM3 open at start ( 1 ea. 11/16" orifice). Bag burst at 84 psi after perfect sealing. Bag tore along bottom swage, as usual with fiberglass bags. Even after bag burst, FM3=0.

PTCAL1.6/15/94. Calibration test. $11 / 16^{\prime \prime}$ orifice in place; good test, although FM2 does not wholly agree with FM1 and magmeter --plot with magmeter; pressure drop data is proportional to $\mathrm{Q}^{2}$.

Petersen bag \#9 test ID PT06154.A. Burst test; 11/16" orifice in place. Did not have FM3 valve properly opened until after sealing occurred; however, this caused no problem. Bag (fabric) broke at $36 \mathrm{psi}$ (presumably along top). With further increase in 
FM1, massive rupture occurred at $57 \mathrm{psi}$ (at bottom). Swages held fine. Lower rubber band did not come off(?).

PTCAL1.7/1/94. Calibration test. 11/16" orifice in place. Good calibration test; all three inflow meters agree. $\triangle \mathrm{P}$ is proportional to $\mathrm{Q}^{2} . \Delta \mathrm{P}$ data agrees well with PTCAL1.6/15/94.

Petersen bag \#10 test ID PT07014.A. Same design as Petersen bag \#9. Bag broke along top (fabric tore) at P1 - P2 + $3.2=49$ psi; P1- P3 $+0.4=51$ psi; swages held fine. Bag sealed well prior to bursting (FM3 0). Great test! Prior to this test, bag was inflated with air to $15 \mathrm{psi}$ in clear tube. Rubber bands came off like they were supposed to, and bag inflated into a pumpkin shape properly. 


\section{Appendix C}

DRAWING PACKAGE

\section{TOP DRAWING 8" DSPASSEMBLY}

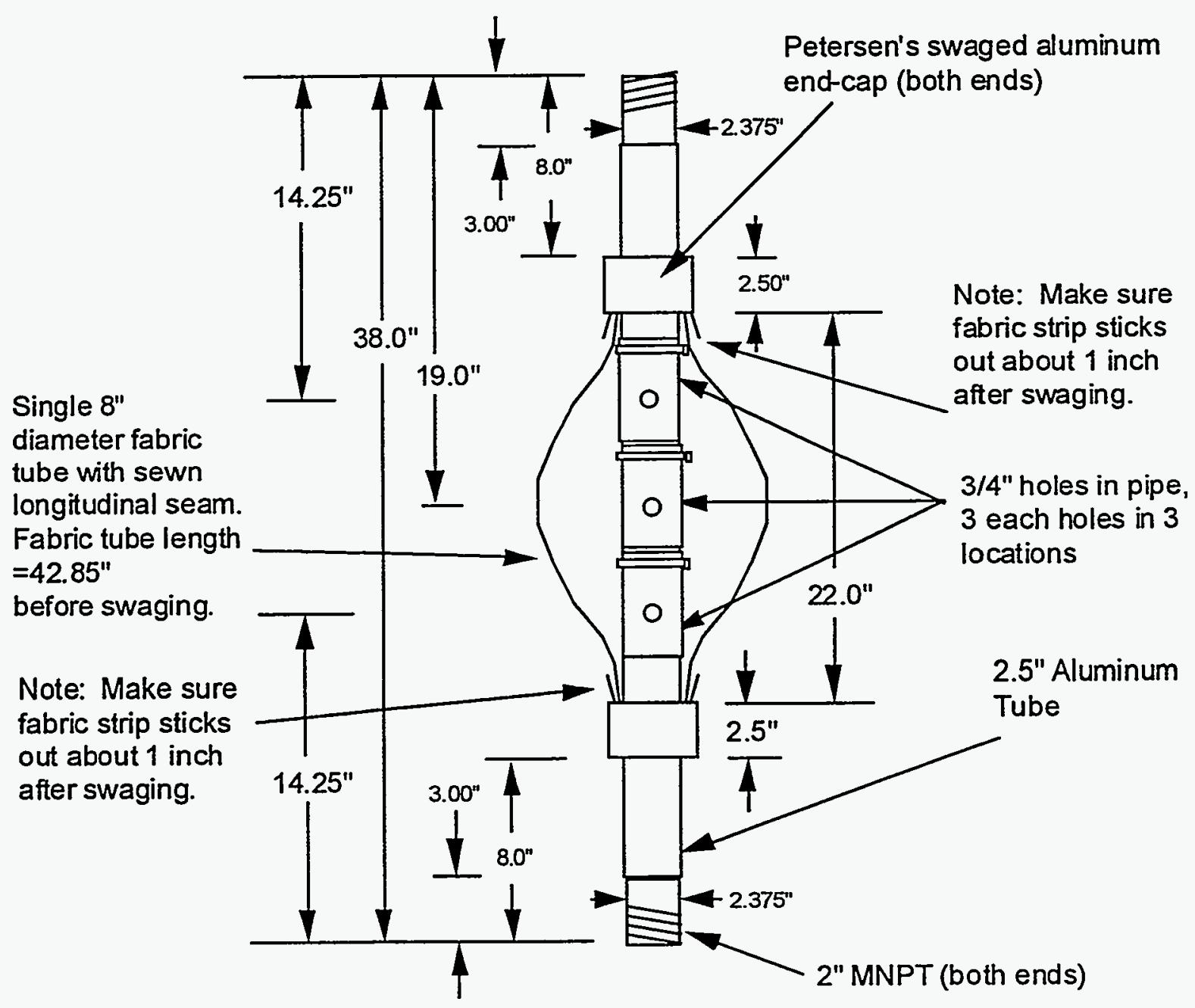




\section{FABRIC ANALYSIS FOR 8" DSP ASSEMBLY}

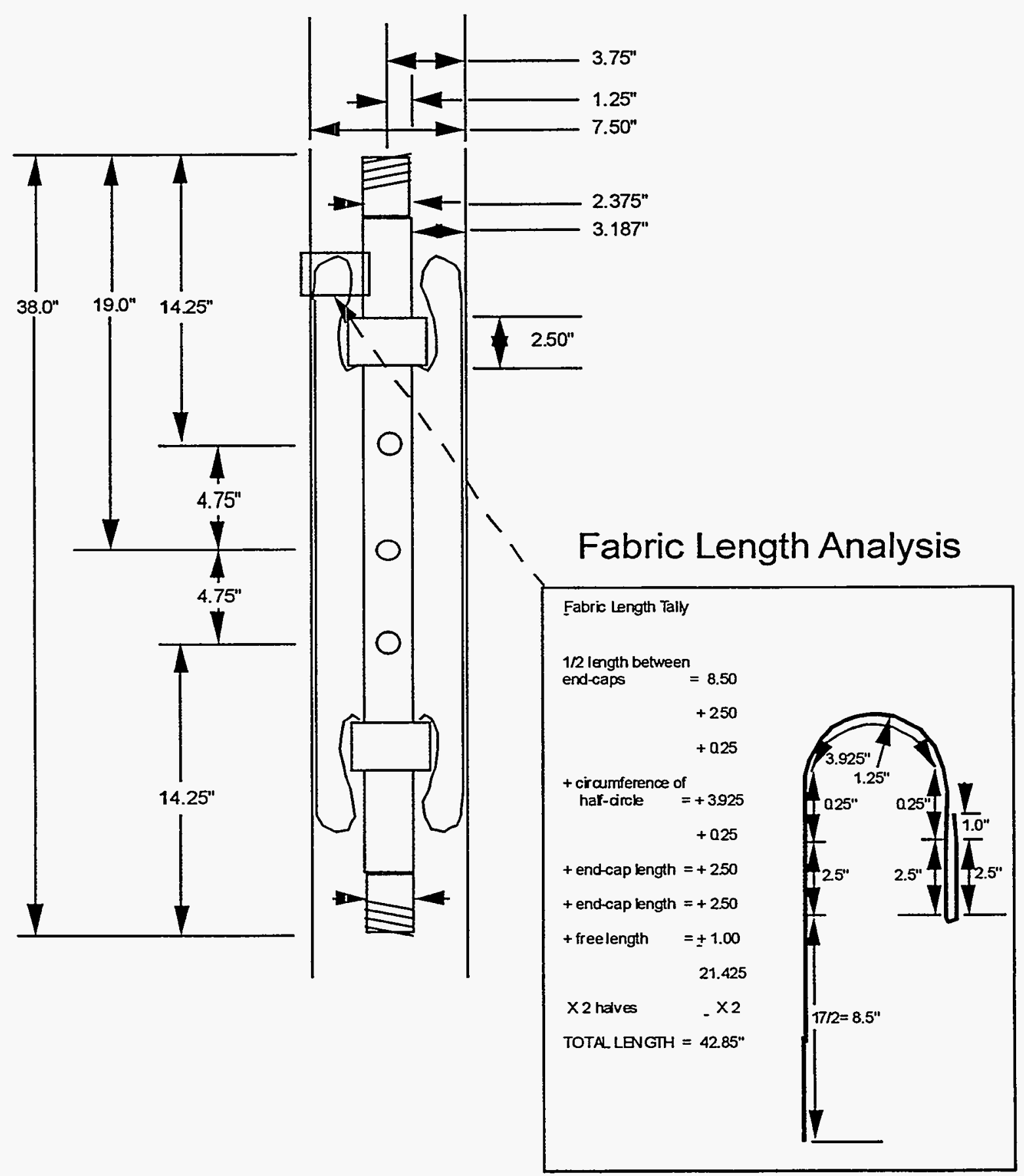




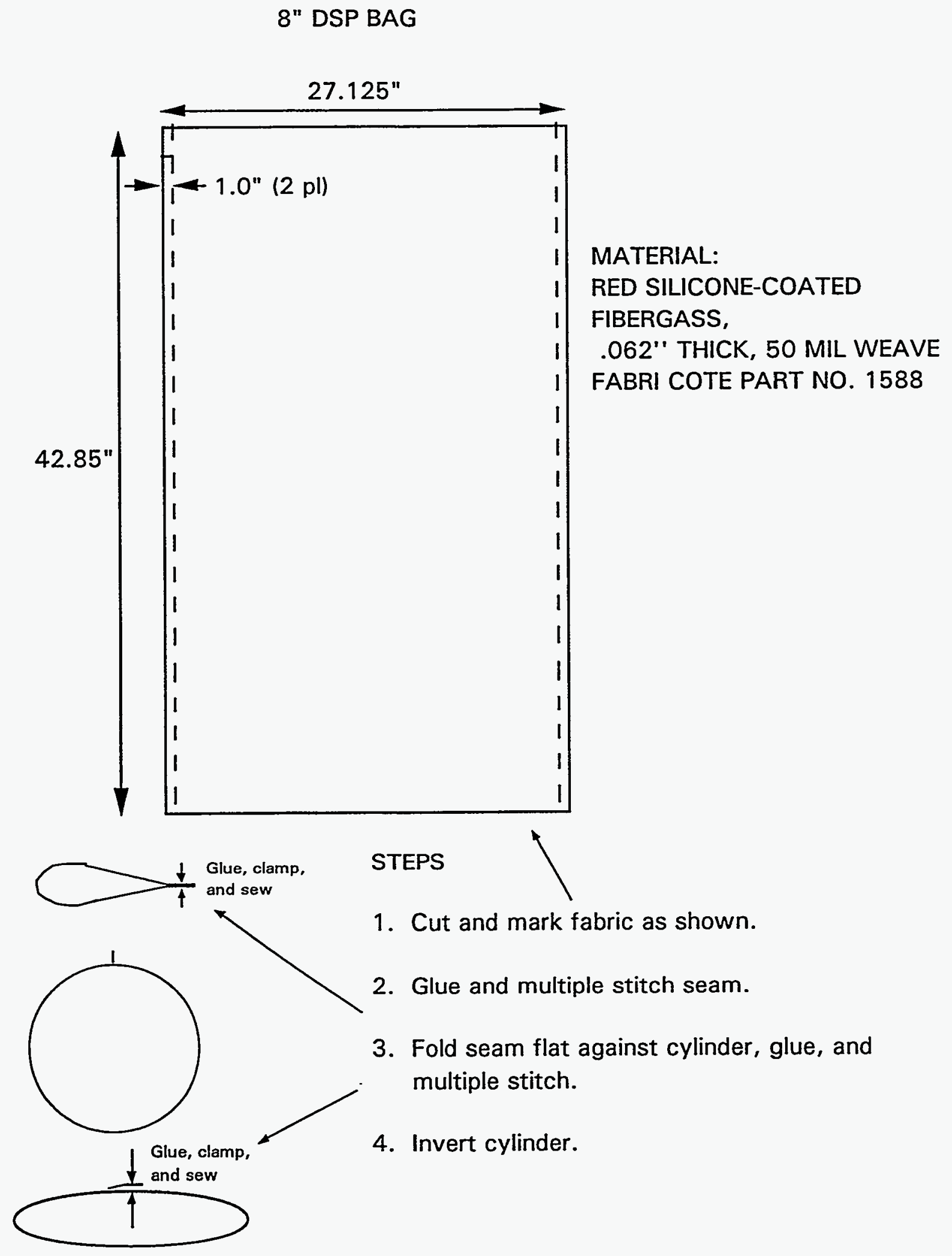




\section{8" DSP ALUMINUM TUBE LAYOUT}

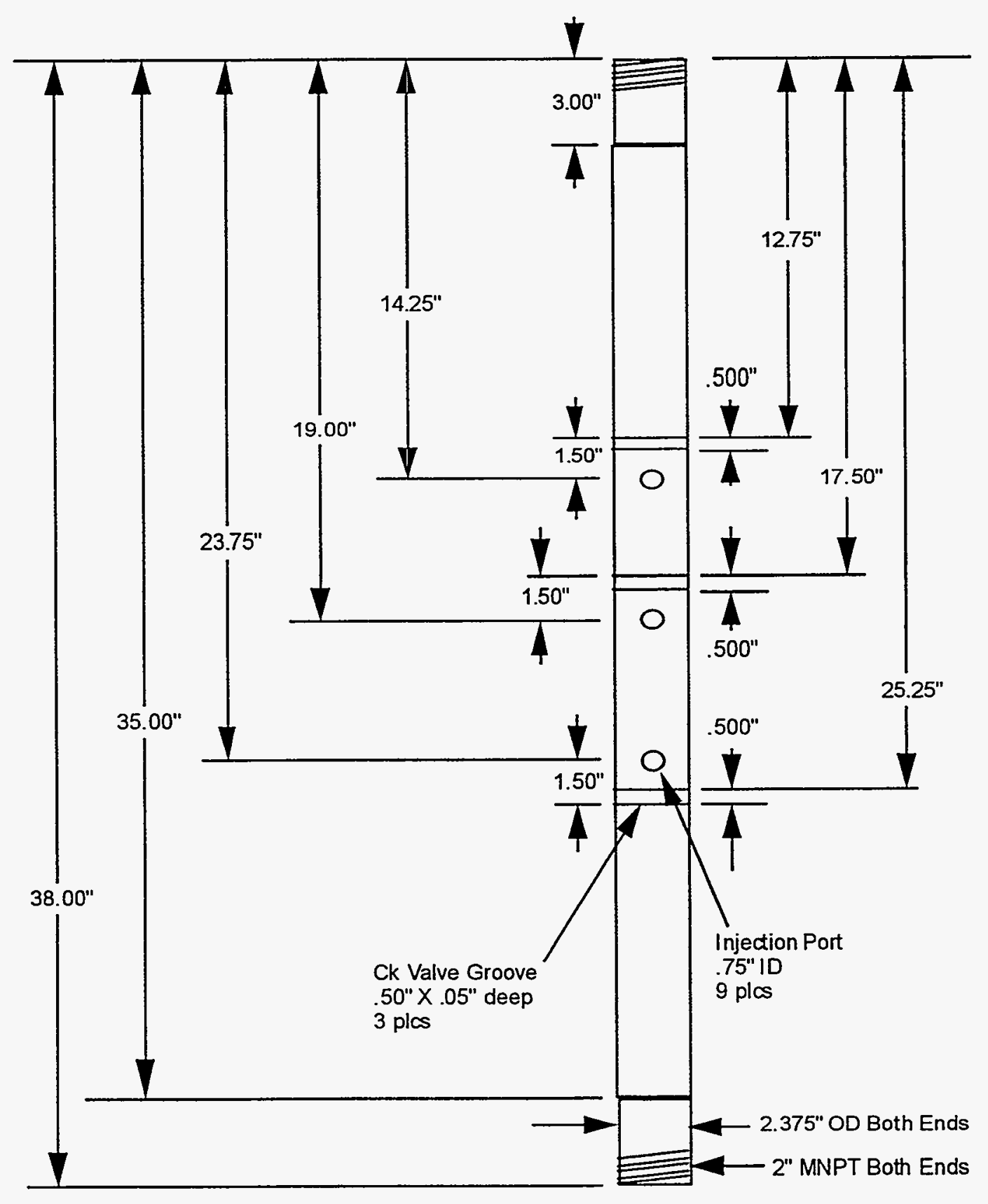




\section{8" DSP CHECK VALVE LAYOUT}
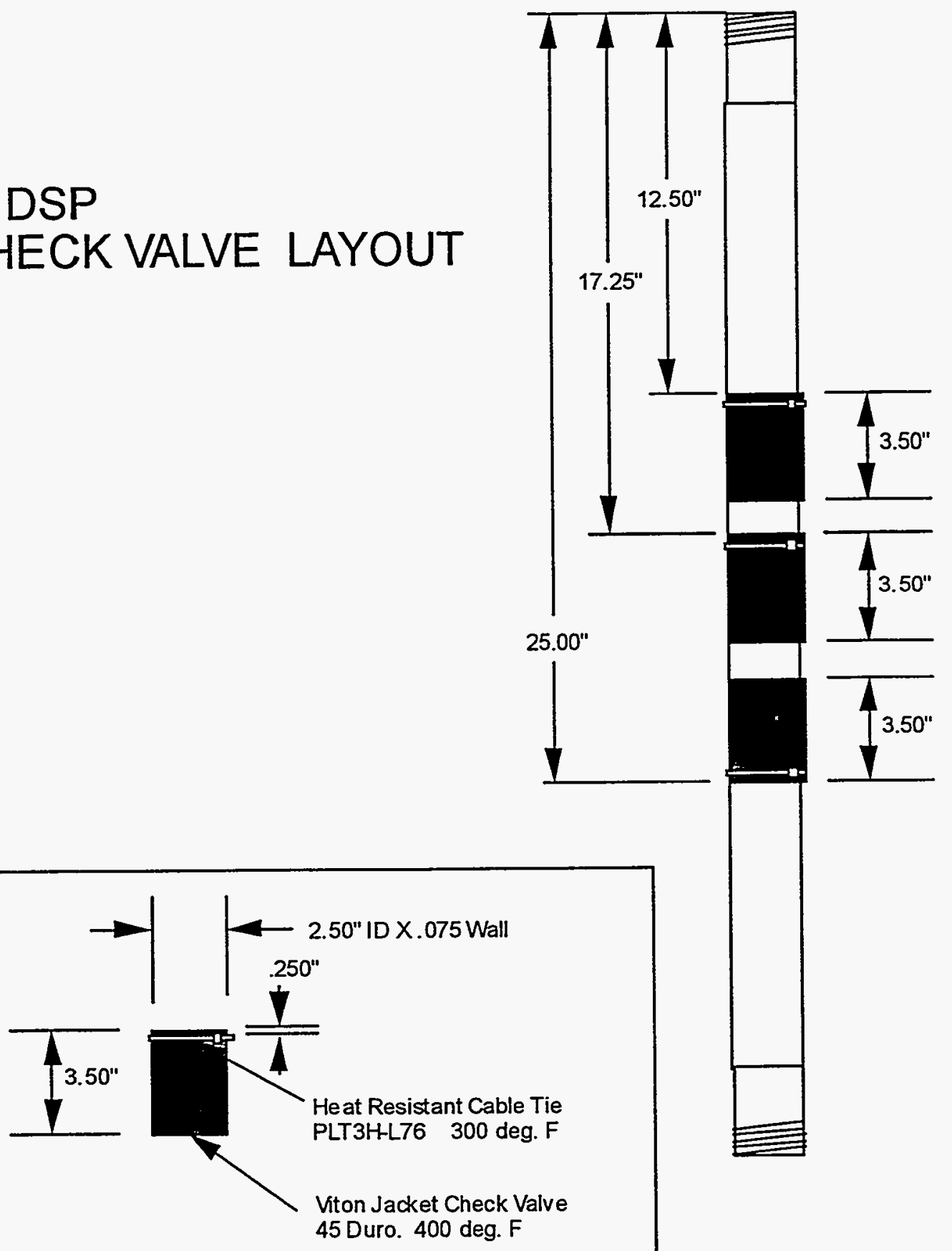

C 5 


\section{TOP DRAWING}

\section{6" DSPASSEMBLY}

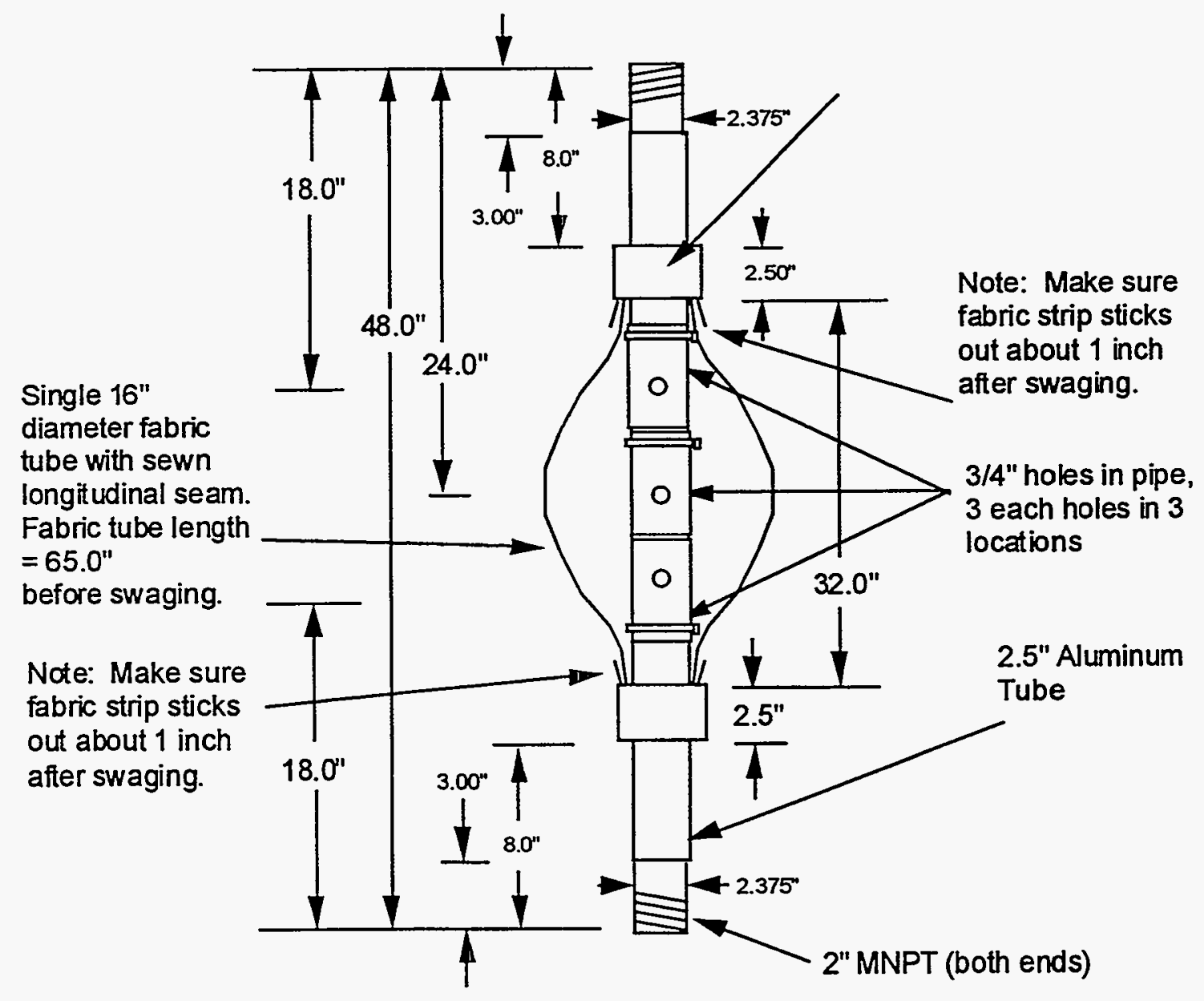




\section{FABRIC ANALYSIS FOR 16" DSP ASSEMBLY}

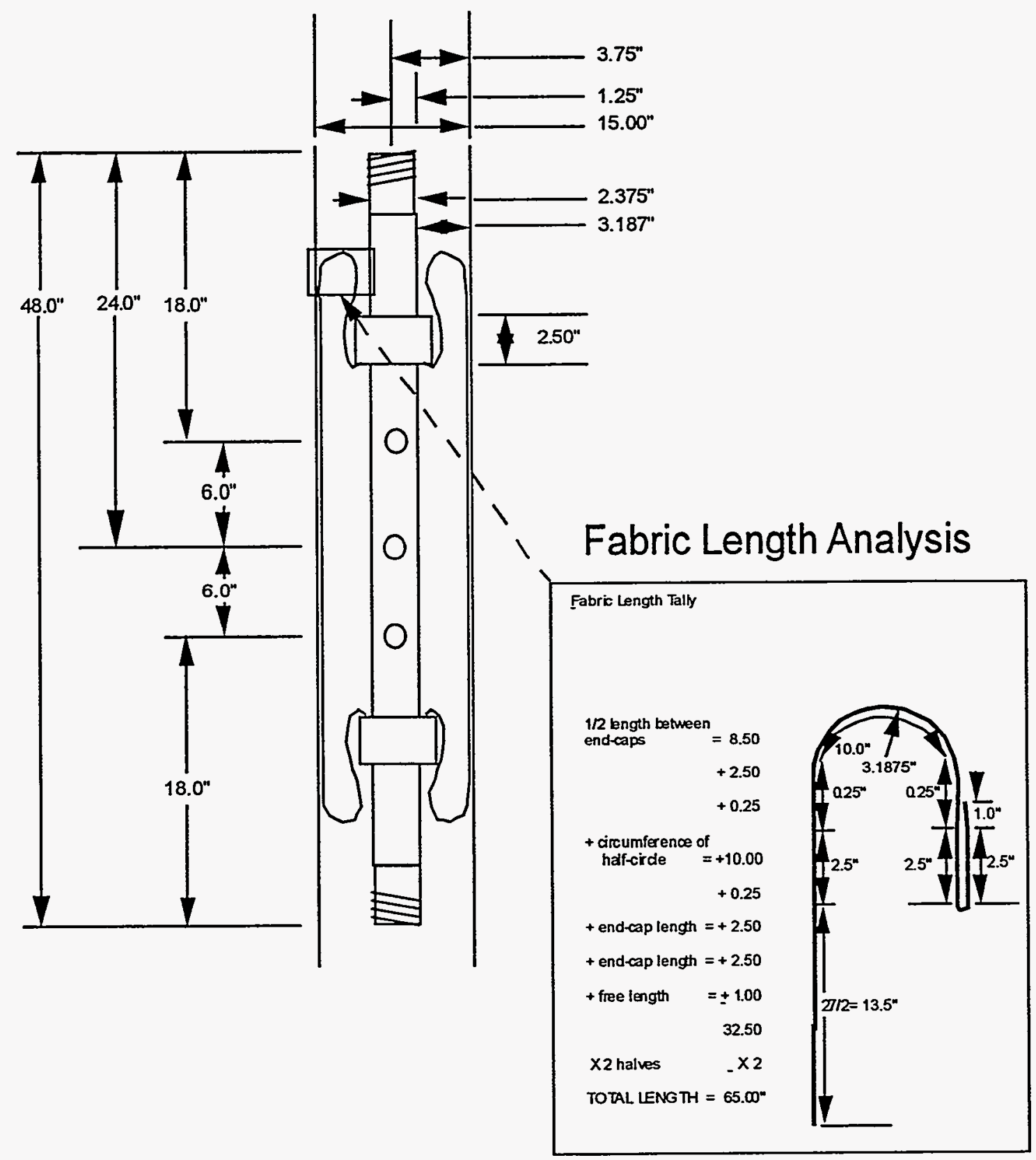




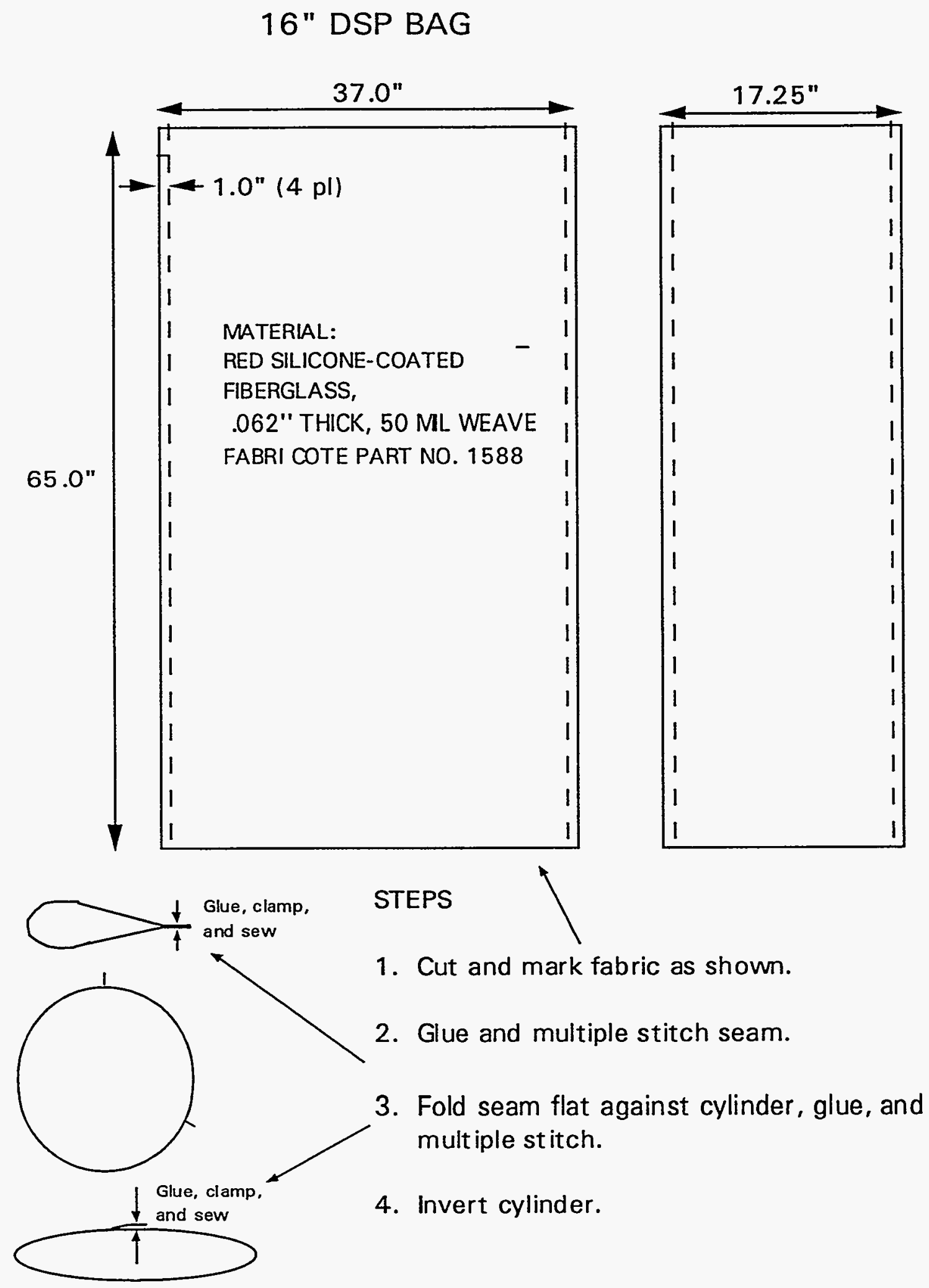




\section{6" DSP ALUMINUM TUBE LAYOUT}

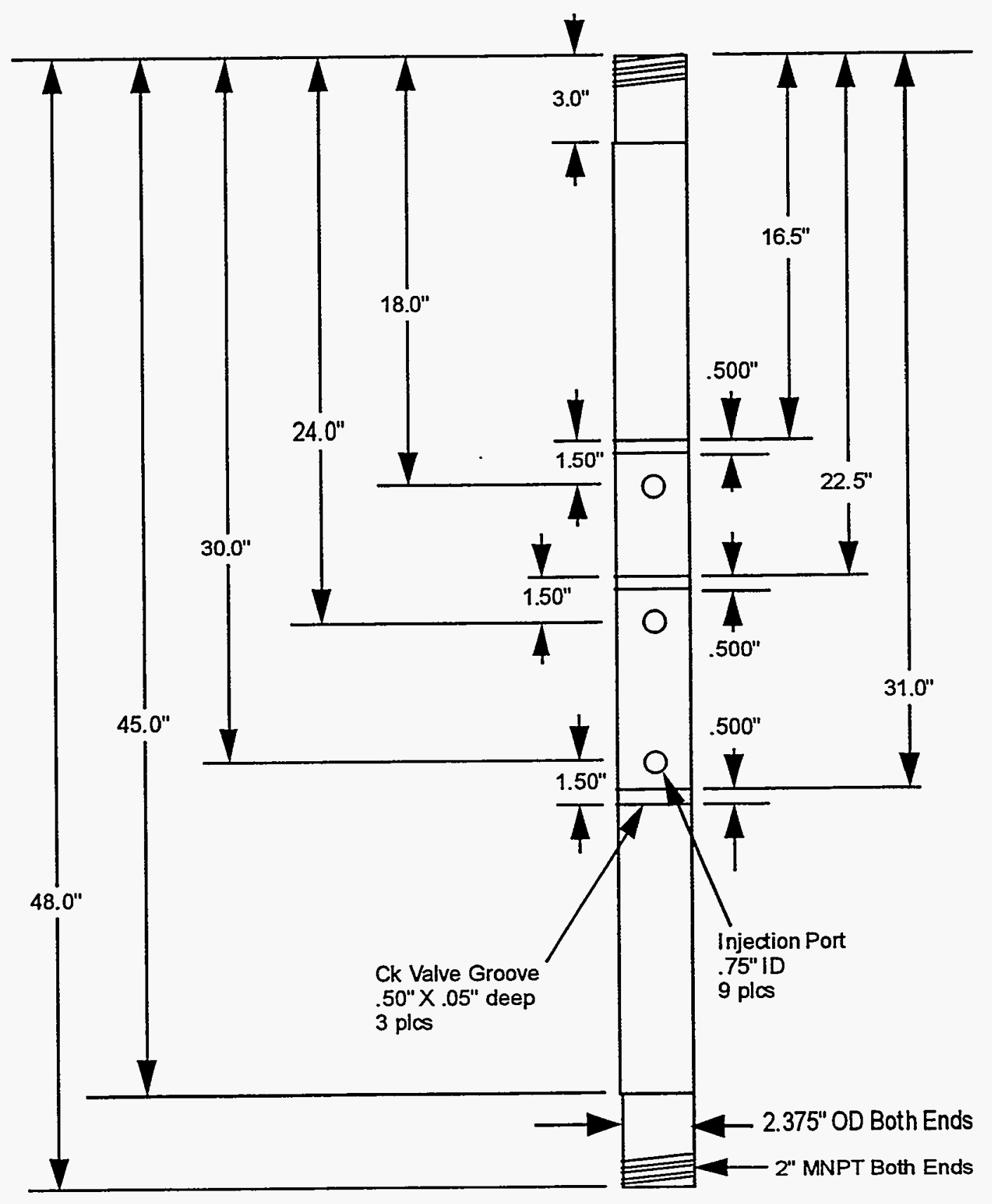




\section{6" DSP}

CHECK VALVE LAYOUT
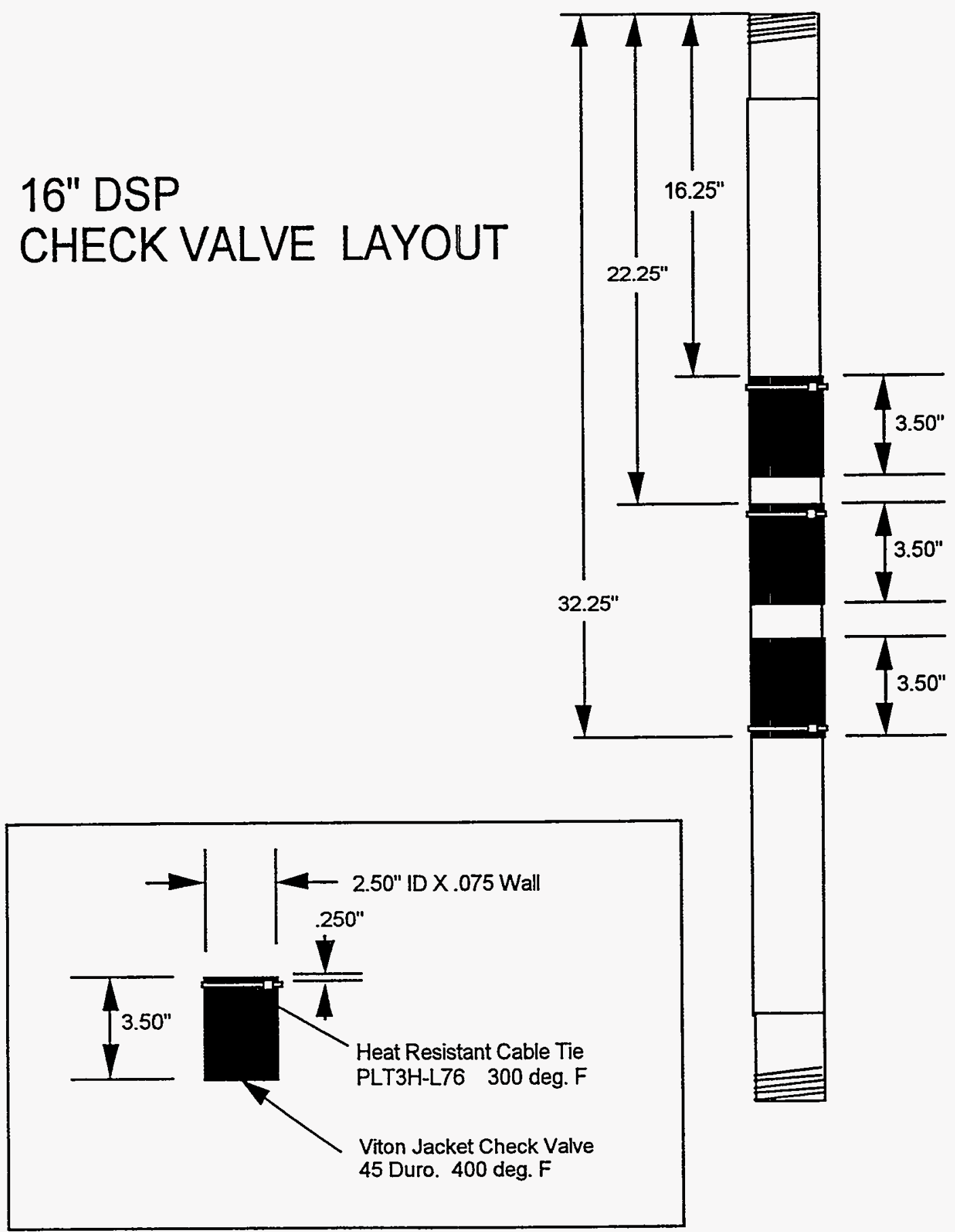


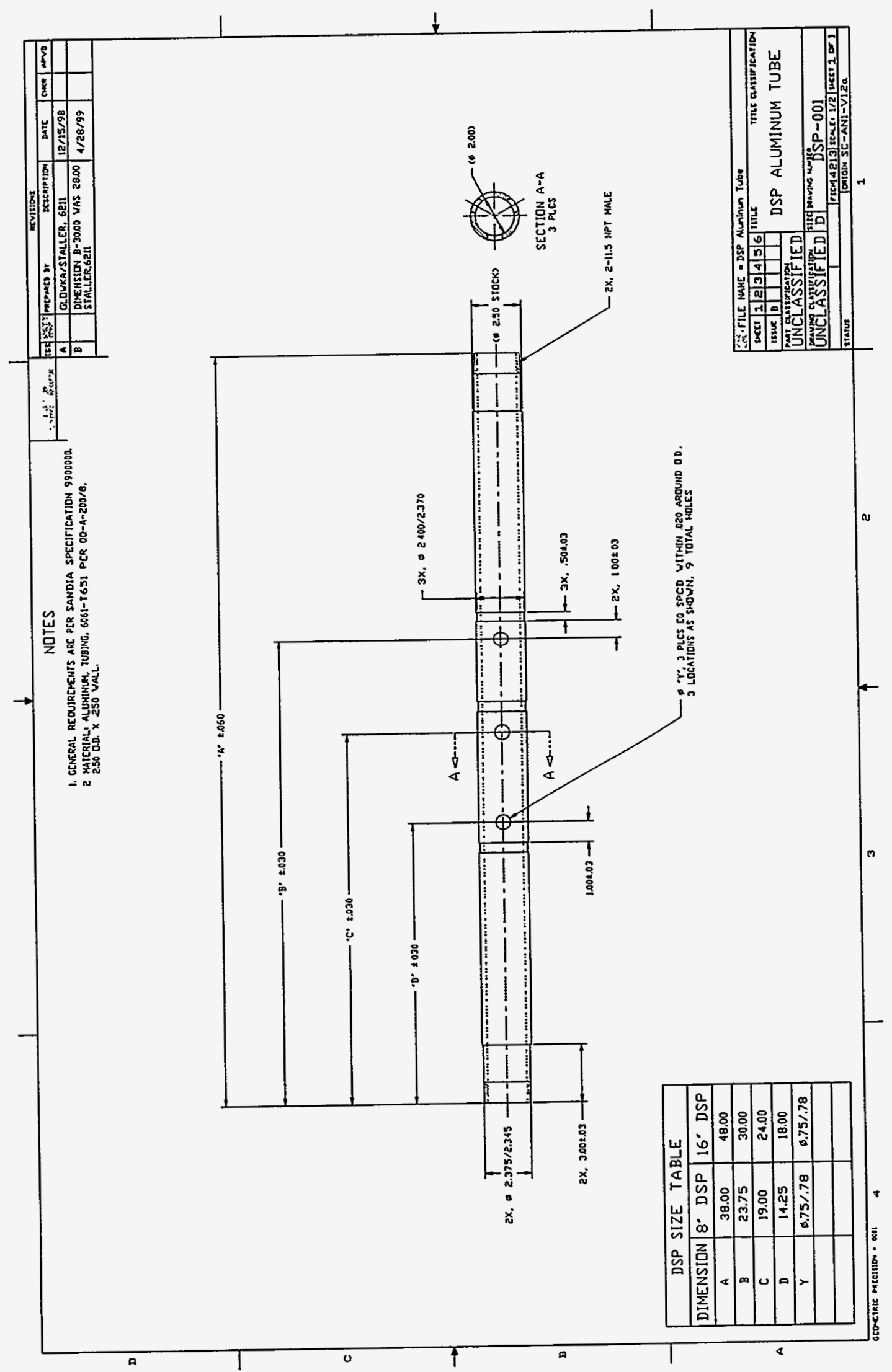

C11 


\section{Appendix D}

\section{BAG FABRICATION PROCEDURES}

This is the process used by Sandia to assemble the DSP bag material into a cylinder for attachment to the aluminum support tube, reference DSP Aluminum Tube drawing number DSP-001 in Appendix C. The packer bag material is the Fabri Cote 1588 red silicone coated fiberglass fabric, .062 " thick, as shown on the DSP Bag drawings in Appendix C. Seams are bonded and stitched then folded and bonded and stitched a second time to form a double bonded and stitched seam. When the finished bag diameter exceeds 11 " (the maximum diameter permitted when using the standard $39.5^{\prime \prime}$ width material), an additional seam is required to produce a wide enough piece of material to fabricate the larger cylinder. This procedure applies to a 16" diameter packer bag and thus contains the instructions for the extra seam.

Tools required:

1. 1" $\times 6^{\prime}$ thin (16-18 gage) strip of steel sheet for use as a gage block.

2. $1 / 4^{\prime \prime} \times 2^{\prime \prime} \times 6^{\prime}$ aluminum flat stock for use as a straight edge and a clamping fixture.

3. 1/4" $\times 2 " \times 36^{\prime \prime}$ aluminum flat stock for use as a straight edge.

4. Retractable blade utility knife.

5. Permanent marking pen.

6. Ten to twelve 6" C-clamps.

7. Dow Corning 736 Heat Resistant Silicone Sealant.

8. Wooden tongue depressors or popsicle sticks for spreading the sealant.

9. A heavy duty sewing machine and nylon thread (Polymatic V125).

10. A suitable work bench.

Procedures:

Step 1. From the drawings obtain the fabric size for both pieces. Cut the fabric, keeping it square, so the rolled tube will form a cylinder and not a truncated cone.

Step 2. Using the permanent marking pen, mark a line one inch from the edge of the fabric. Mark both edges of both pieces of fabric.

Step 3. Place the gage block along the inside edge of the mark to control the silicone sealant during application, compression, and curing. The sealant will not adhere to the gage block.

Step 4. Spread a thin coat of the silicone sealant on the fabric between the edge and the one inch mark/gage block.

Step 5. Place the other piece of fabric over the silicone sealant and line up the edges of the fabric with the edge of the work bench.

Step 6. Place the aluminum straight edge along the edge of fabric over lapping the fabric and gage block.

Step 7. Place the C-clamps ( 6-8" apart) loosely on the straight edge until all clamps are in place.

Step 8. Starting in the middle tighten the C-clamps in steps working out towards the ends until all the clamps have been tightened.

Step 9. Allow the silicone sealant to cure for at least four hours.

Step 10. After the silicone has cured, remove the C-clamps, straight edge and gage block.

Step 11. Sew two seams down the length of the fabric/bond, one about $1 / 4$ " from the one inch mark, and one $1 / 4^{\prime \prime}$ from the edge of the fabric. This stitching is through the two layers of fabric and the silicone sealant bond.

Step 12. Again using the pen, mark two lines at one inch and two inches from the edge of the bonded/sewed fabric.

Step 13. Spread another thin coat of the silicone sealant on the fabric between the two marks.

Step 14. Align the fabric so about two or three inches hangs over the edge of the work bench so it can be looped back enough to form a second 1 " bond under the initial stitched bond, reference Figure 1 .

Step 15. Fold the fabric over and place the aluminum straight edge on the fold as shown in Figure 2.

Step 16 Start placing the C-clamps on the straight edge until all clamps are loosely in place.

Step 17. Hold the bottom fabric and pull the top fabric in the direction of the arrow until the fabric is pulled back in place and the seam is only one inch wide, reference Figure 3. 
Step 18. Starting in the middle tighten the C-clamps in steps working out toward the ends until all the clamps have been tightened.

Step 19. Allow the silicone sealant to cure for at least four hours.

Step 20. After the silicone has cured remove the clamps and the aluminum straight edge.

Step 21. Sew two seams down the length of the fold in the fabric, one about $1 / 4$ " from the one inch mark, and one $1 / 4$ " from the edge of the fabric. This stitch is through four layers of fabric and two silicone sealant bonds.

Note: At this time you should have one seam completely bonded and sewn to produce a large enough piece of fabric to make the $16^{\prime \prime}$ diameter cylinder.

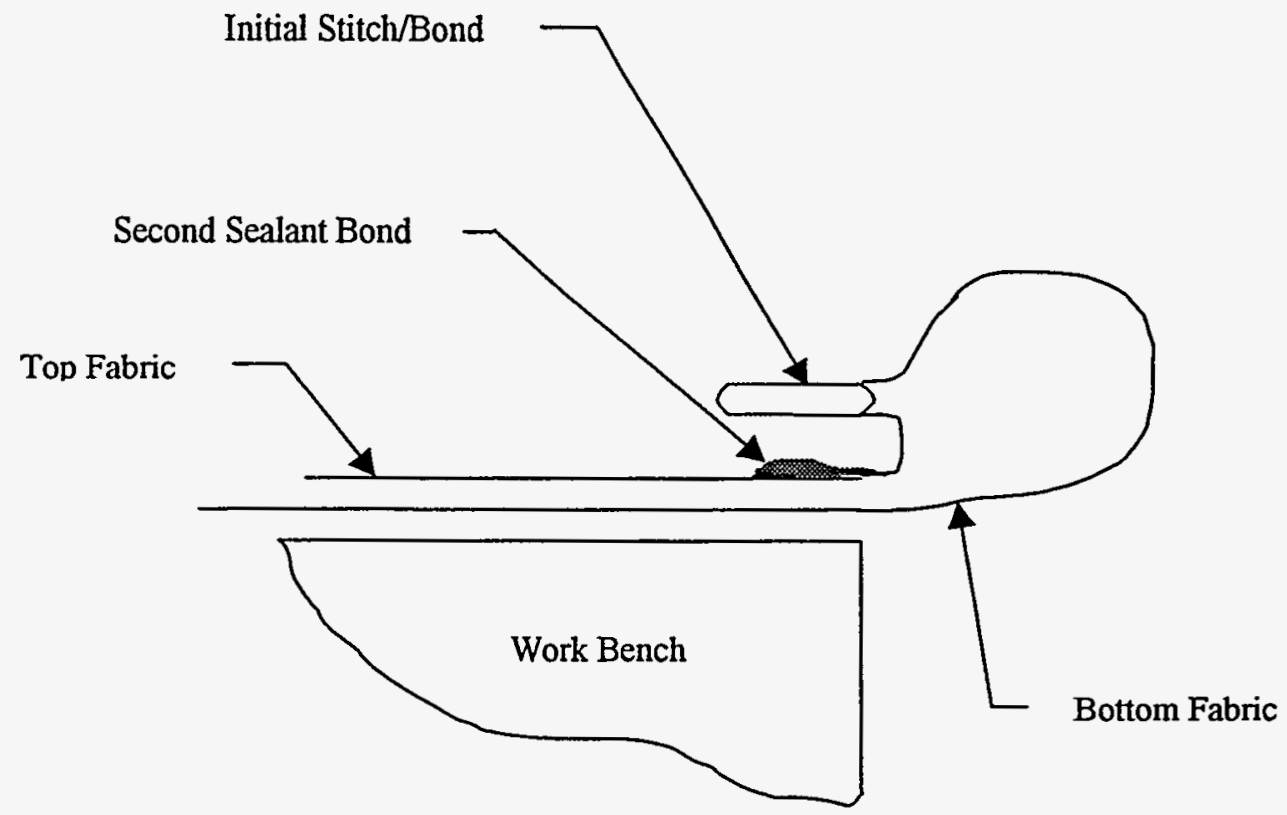

Figure 1

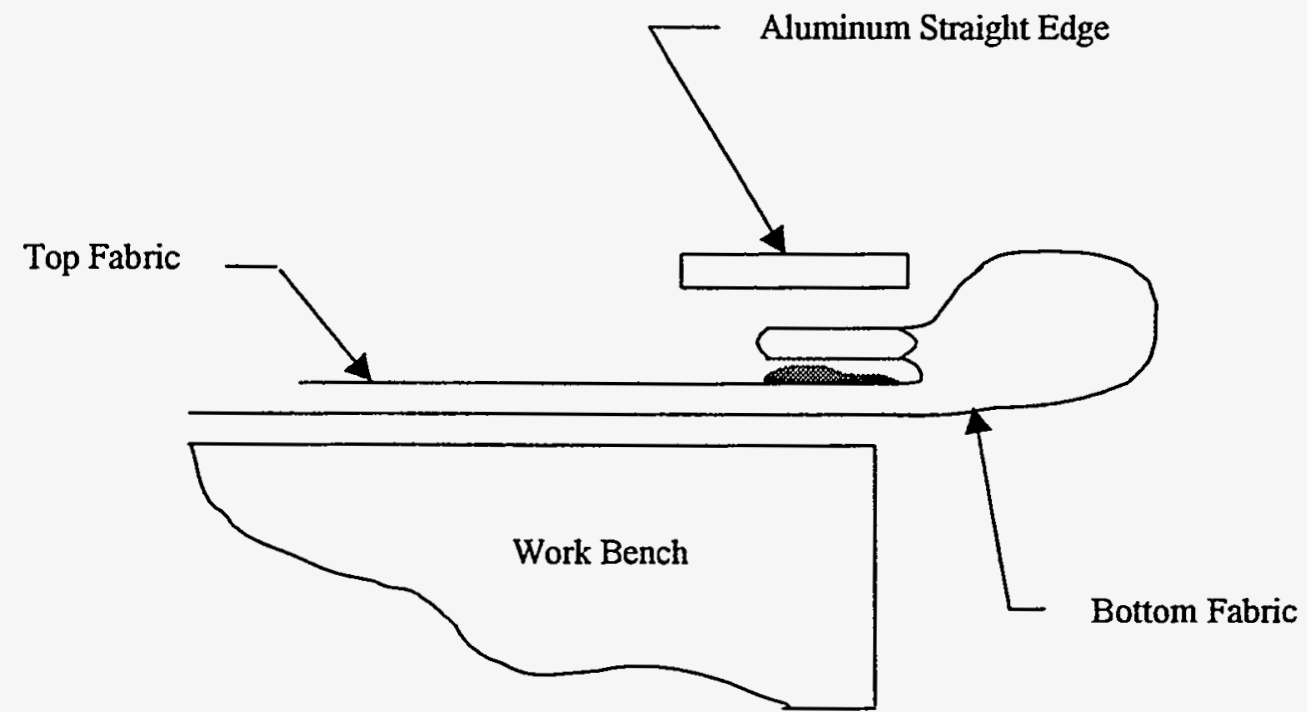

Figure 2 


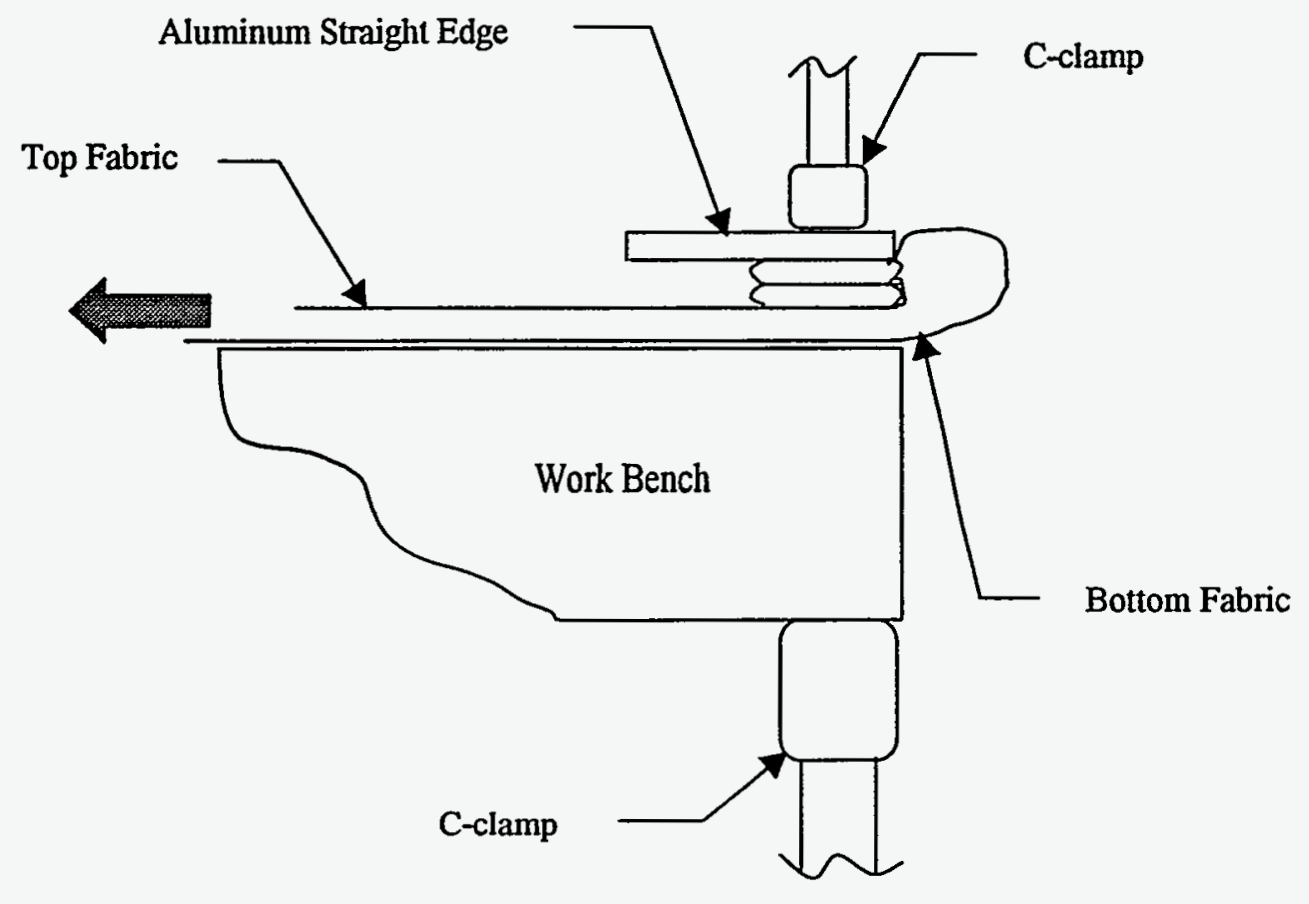

Figure 3

Step 22. Using the one inch mark already along the edge of the fabric, place the gage block along the inside edge of this mark to control the silicone sealant during application, compression, and curing as done previously in step 3 above.

Step 23. Again spread a thin coat of the silicone sealant on the fabric between the edge and the one inch mark/gage block.

Step 24. Place the other piece of fabric over the silicone sealant and line up the edges of the two pieces of fabric with the edge of the work bench. This now forms the cylinder.

Step 25. Place the aluminum straight edge along the edge of fabric over lapping the fabric and gage block.

Step 26. Place the C-clamps loosely on the straight edge until all clamps are in place.

Step 27. Again starting in the middle tighten the C-clamps in steps working out toward the ends until all the clamps have been tightened.

Step 28. Allow the silicone sealant to cure for at least four hours.

Step 29. After the silicone has cured remove the C-clamps, straight edge and gage block.

Step 30. Again sew two seams down the length of the fabric, one about $1 / 4^{\prime \prime}$ from the one inch mark, and one $1 / 4$ " from the edge of the fabric. As before this stitching is through two layers of fabric and the silicone bond.

Step 31. Mark the two lines at one inch and two inches from the edge of the fabric.

Step 32. Spread the second thin coat of the silicone sealant on the fabric between the two marks.

Step 33. Again align the fabric so about two or three inches hangs over the edge of the work bench and it can be looped back to form the second bond as shown in Figure 1 .

Step 34. Fold the fabric over and place the aluminum straight edge on the fold, reference Figure 2.

Step 35 As before start placing the C-clamps on the straight edge until all clamps are loosely in place.

Step 36. Again hold the bottom fabric and pull the top fabric in the direction of the arrow until the fabric is pulled back in place and the seam is only one inch wide, reference Figure 3. 
Step 37. Once more, starting in the middle tighten the C-clamps in steps working out toward the ends until all the clamps have been tightened.

Step 38. Allow the silicone sealant to cure for at least four hours.

Step 39. After the silicone has cured remove the clamps and the aluminum straight edge.

Note: Sandia's sewing machine does not have free arm capability, therefore the last stitches on the inside of the cylinder required some folding of the fabric to enable us to complete the seam with the four fabric layers and two bonds. This is difficult to visualize, but without a free arm machine it can be sewn as described in the following steps.

Step 40. The fabric cylinder was folded along its axis into three equal lengths. One end of the cylinder is folded down over the outside about $1 / 3$ of the cylinder length. The other end is tucked inside the cylinder about $1 / 3$ its length. This forms the three folded sections for sewing the seam.

Step 41. With the seam on the bottom feed the folded fabric under the foot of the sewing machine until about half the tube is through the foot. Pull the bottom layer of fabric (outside fold) out from under the foot.

Step 42. Sew in lengths of about four to six inches at time, making sure the bottom layer is not getting under the foot. Push the inside fold out as you sew, stitching all the way out to the edge of the fabric. Two seams are required over the length of this fabric/bond seam as well, so the cylinder must be re-folded and the sewing process repeated to complete the second parallel seam.

Step 43. After sewing the two seams in one half of the cylinder, refold the fabric tube, switching ends for the outside and inside folds, to be able to stitch the two seams in the other half of the cylinder.

Step 44. Sew the other half of the seam, as above, to complete the cylinder. 


\section{Appendix E}

\section{PACKER BAG TEST DATA}

MAGMETER/GPM = Water flow into DSP bag in GPM, P1-P3 + 0.4 = DSP bag inflation pressure in psi

Packer Bag Burst Test

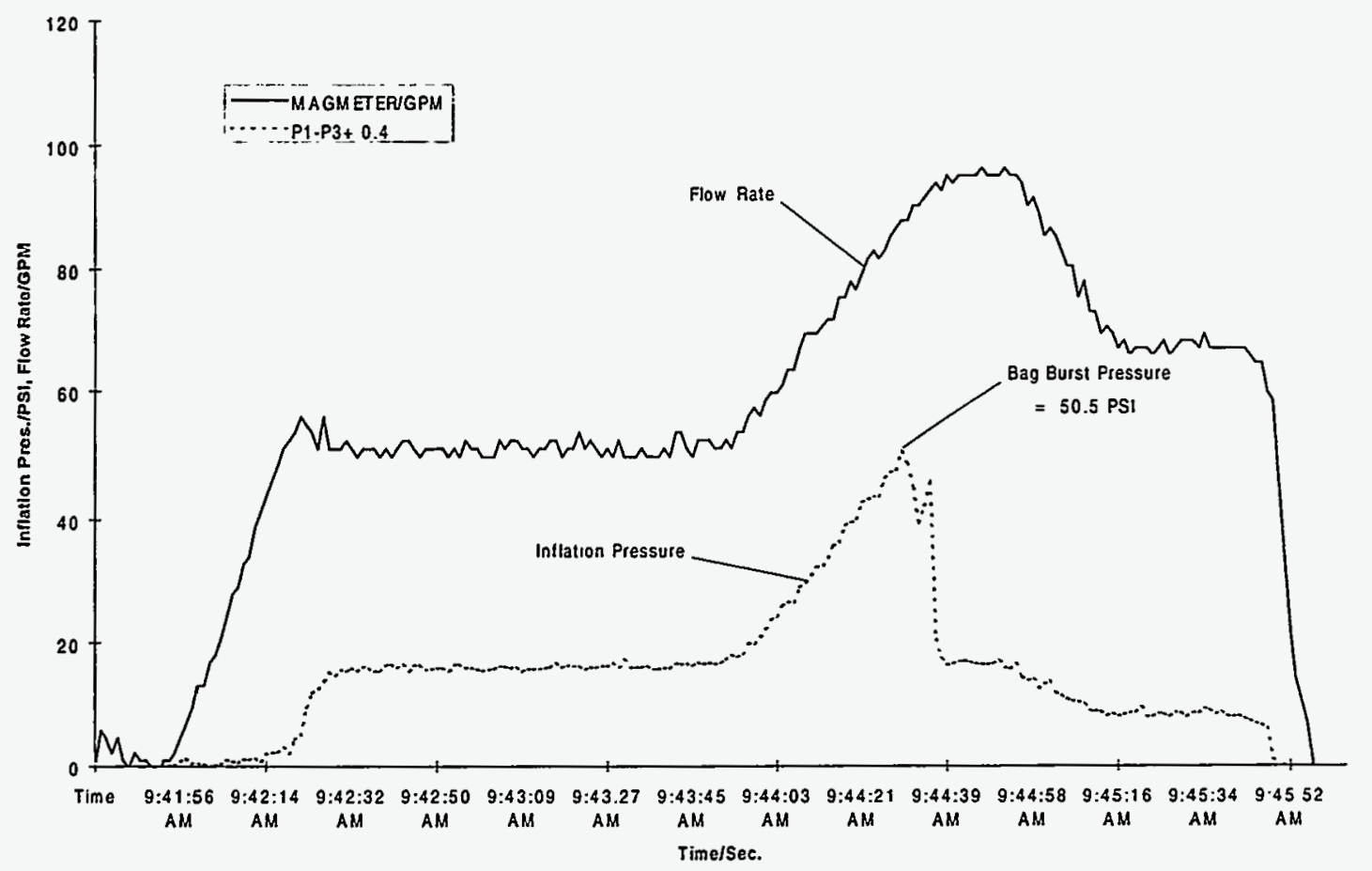




\section{DATA PLOTS FROM ELTF TESTS}

\section{8" TW OEDP}

$\mathrm{P} 1=$ Cement pump pressure, $\mathrm{P} 7=$ Top box pressure, $\mathrm{P} 8=$ Middle loss zone pressure, $\mathrm{P} 9=$ Bottom box pressure, $\mathrm{P} 10=$ Wellbore pressure just above middle loss zone

8" OEDP Test 7/24/97

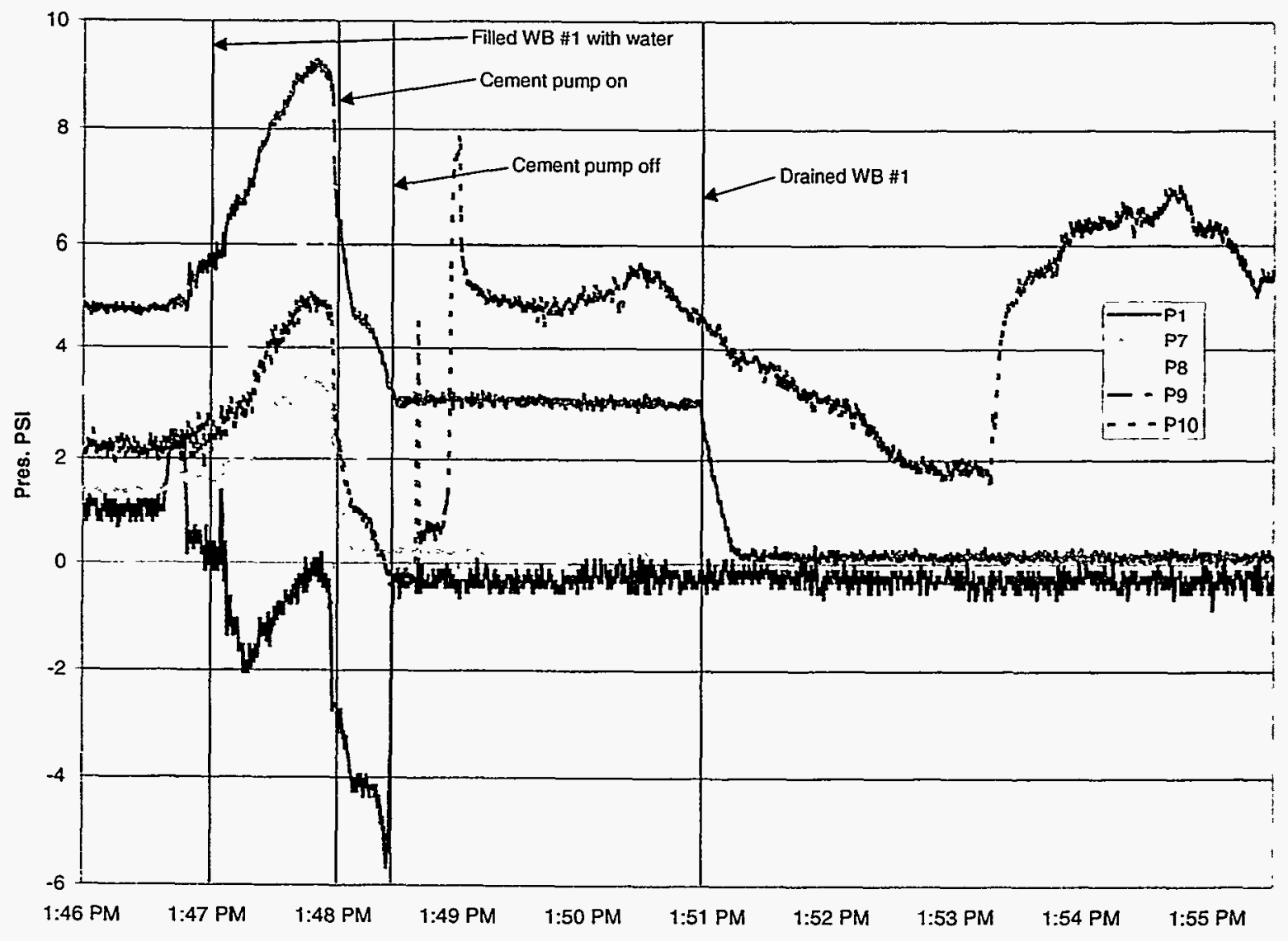




\section{8" TW DSP}

$\mathrm{P} 1=$ Cement pump pressure, $\mathrm{P} 2=$ Top box pressure, $\mathrm{P} 3=$ Middle loss zone pressure, P4 $=$ Bottom box pressure, P5 = Wellbore pressure between DSP bags, Diff Packer Pres $=\mathrm{P} 1-\mathrm{P} 5+\mathrm{L} * .433, \mathrm{~L}=$ distance between $\mathrm{P} 1$ and $\mathrm{P} 5$

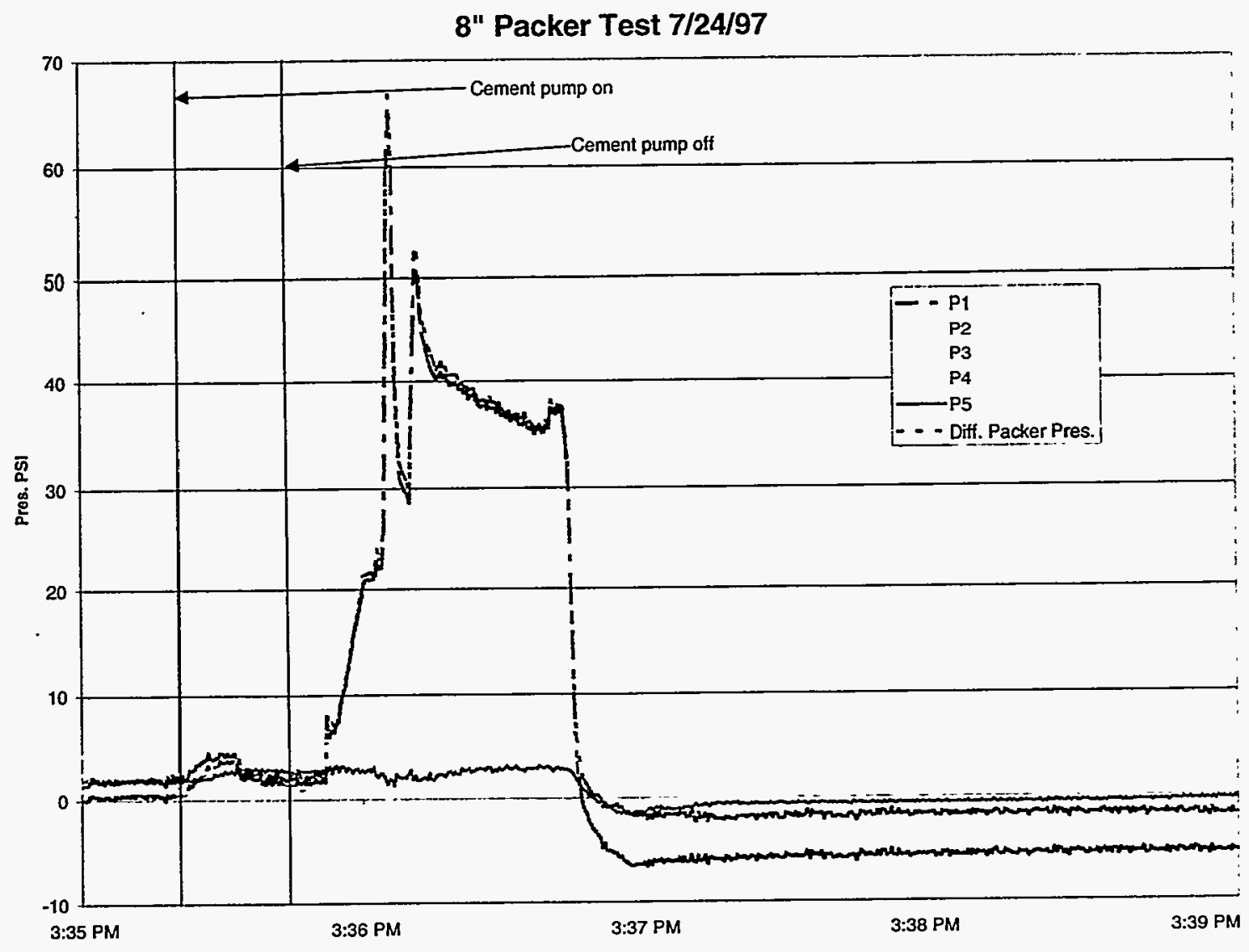




\section{6" TW OEDP}

Pump-O = Cement pump pressure, $\mathrm{O}-\mathrm{Top}=$ Top box pressure, $\mathrm{O}-\mathrm{Mid}=$ Middle loss zone pressure, $\mathrm{O}-\mathrm{Bot}=$ Bottom box pressure

\section{Test Date 11/20/97}

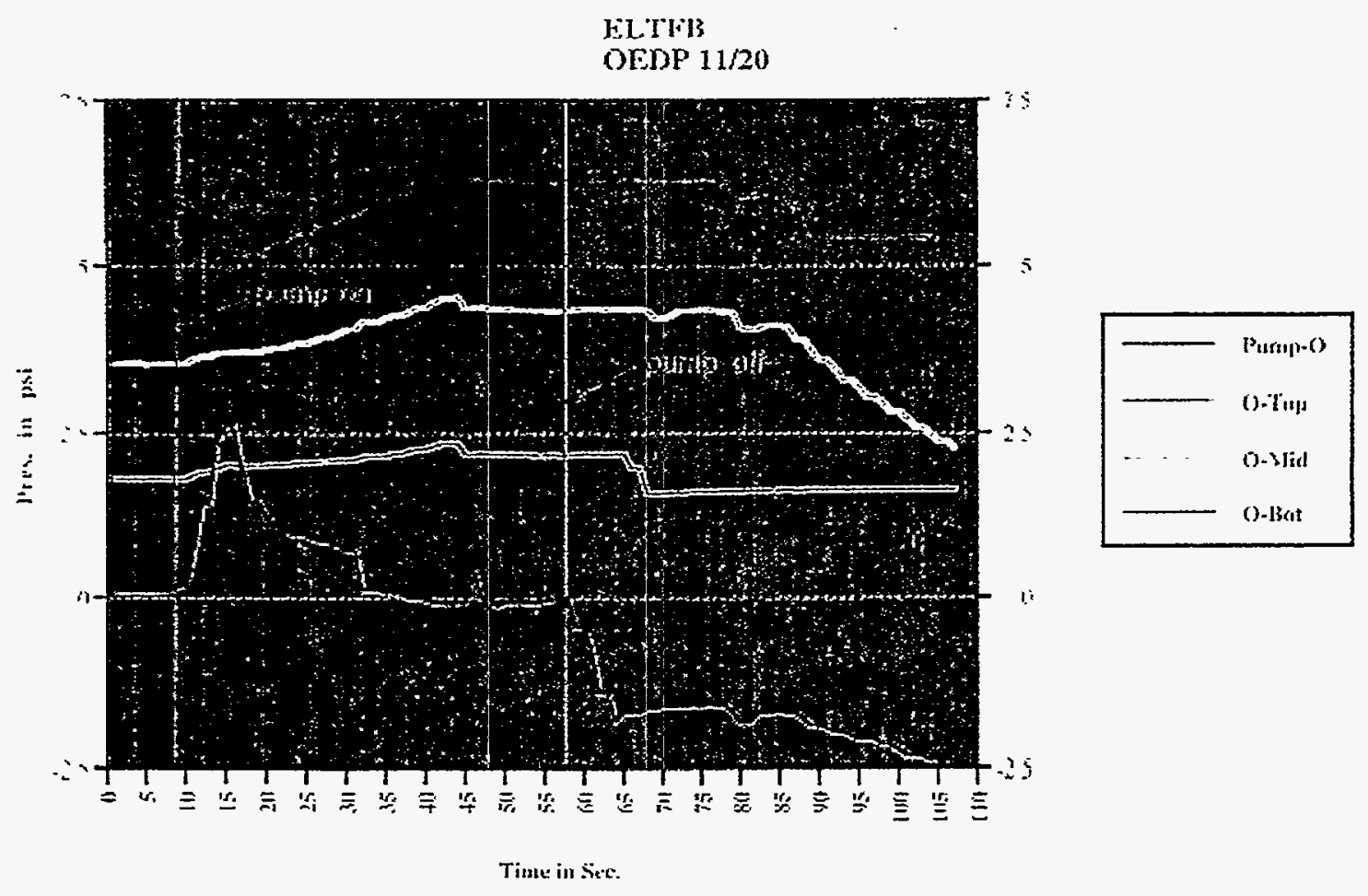




\section{6" TW DSP}

Pump-P = Cement pump pressure, $\mathrm{P}-\mathrm{Top}=$ Top box pressure, $\mathrm{P}-\mathrm{Mid}=$ Middle loss zone pressure, Mid-Bag $=$ Wellbore pressure between DSP bags, $\mathrm{P}-\mathrm{Bot}=$ Bottom box pressure

\section{Test Date 11/20/97}

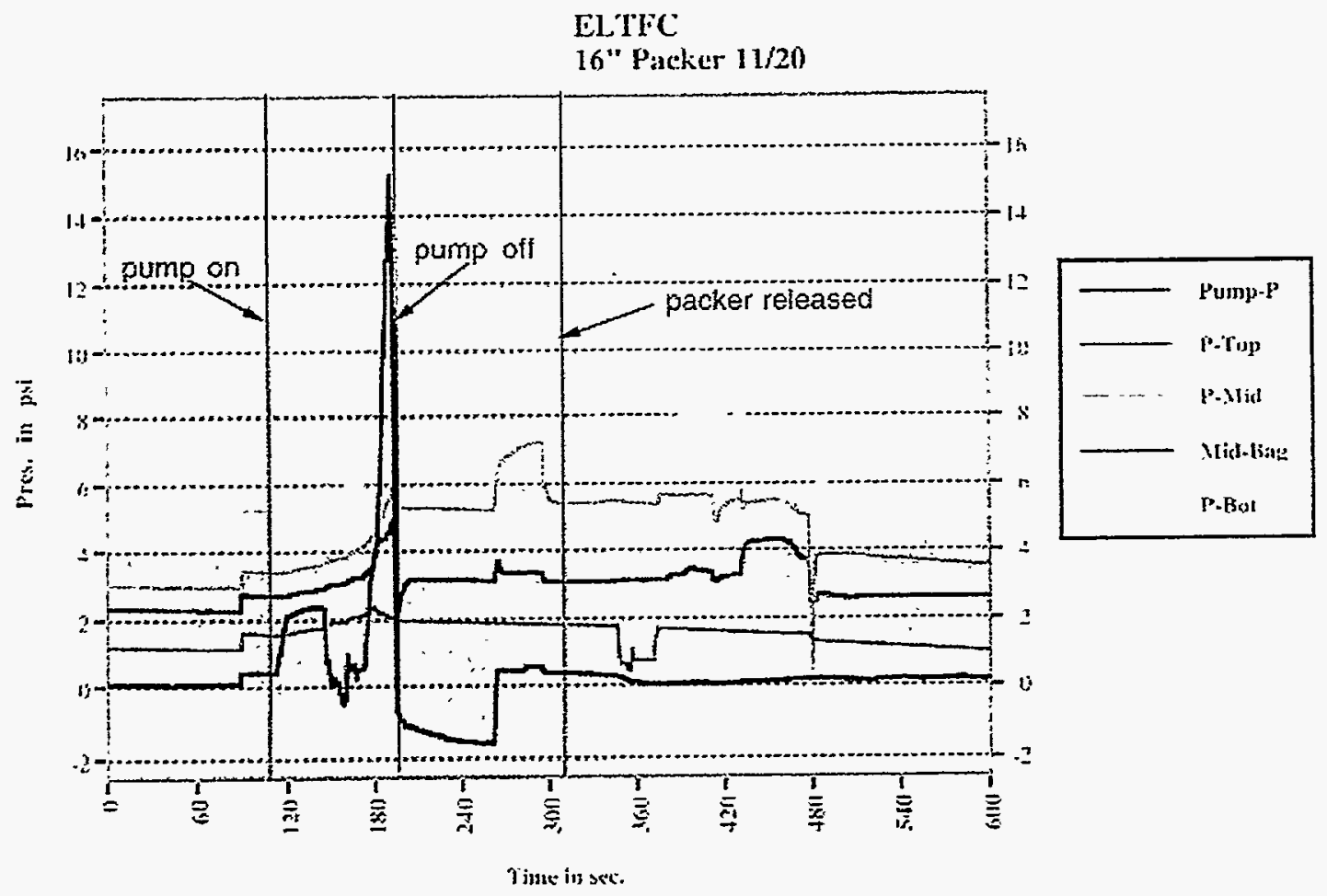




\section{6" TW DSP}

Packer Diff. Pres $=$ Differential pressure across DSP bags

\section{Test Date 11/20/97}

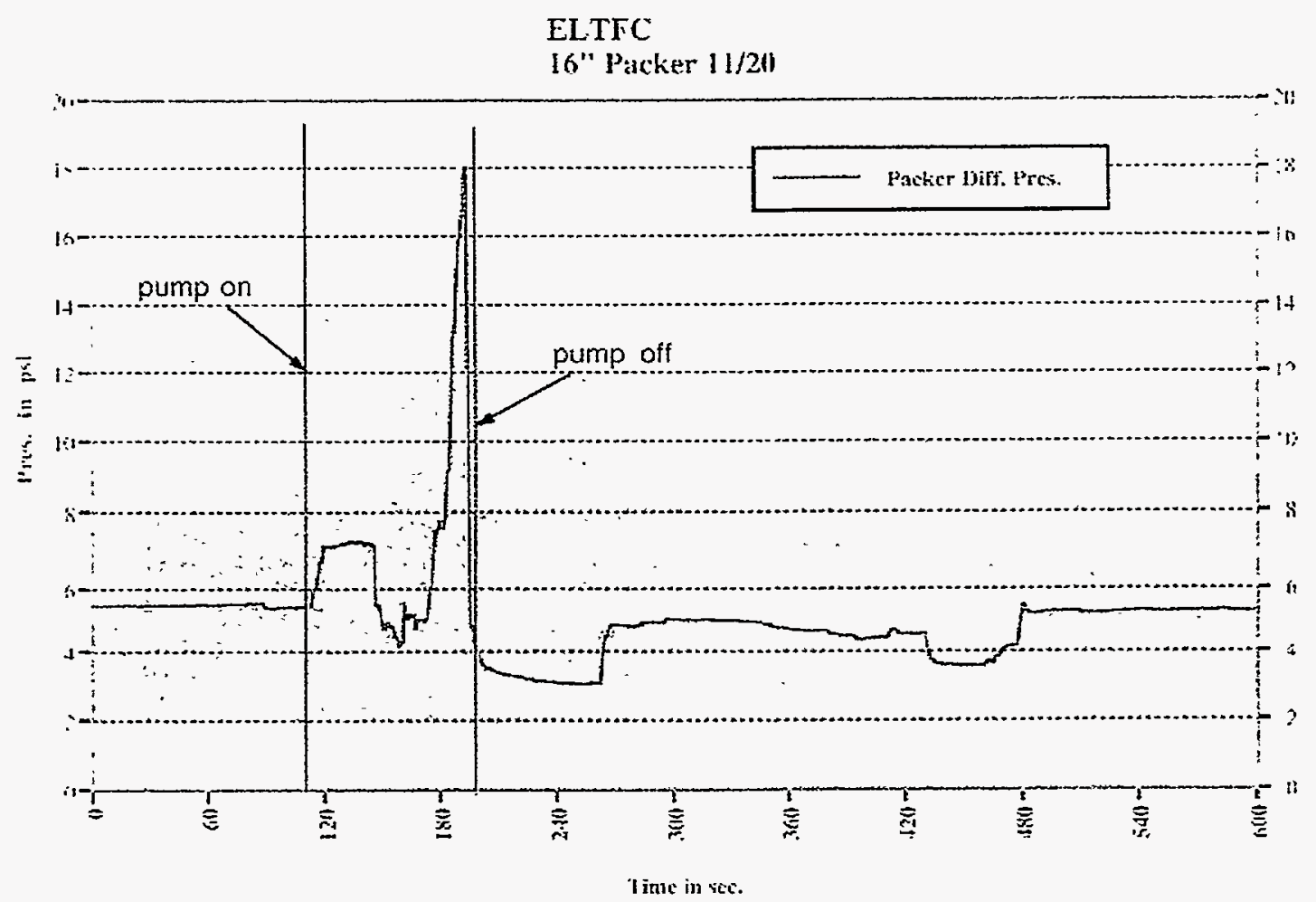




\section{6" TW DSP}

T-Close $=$ Middle loss zone thermistor located $6 "$ from wellbore centerline, $\mathrm{T}$-Far $=$ Middle loss zone thermistor located 24 " from wellbore centerline

\section{Test Date 11/20/97}

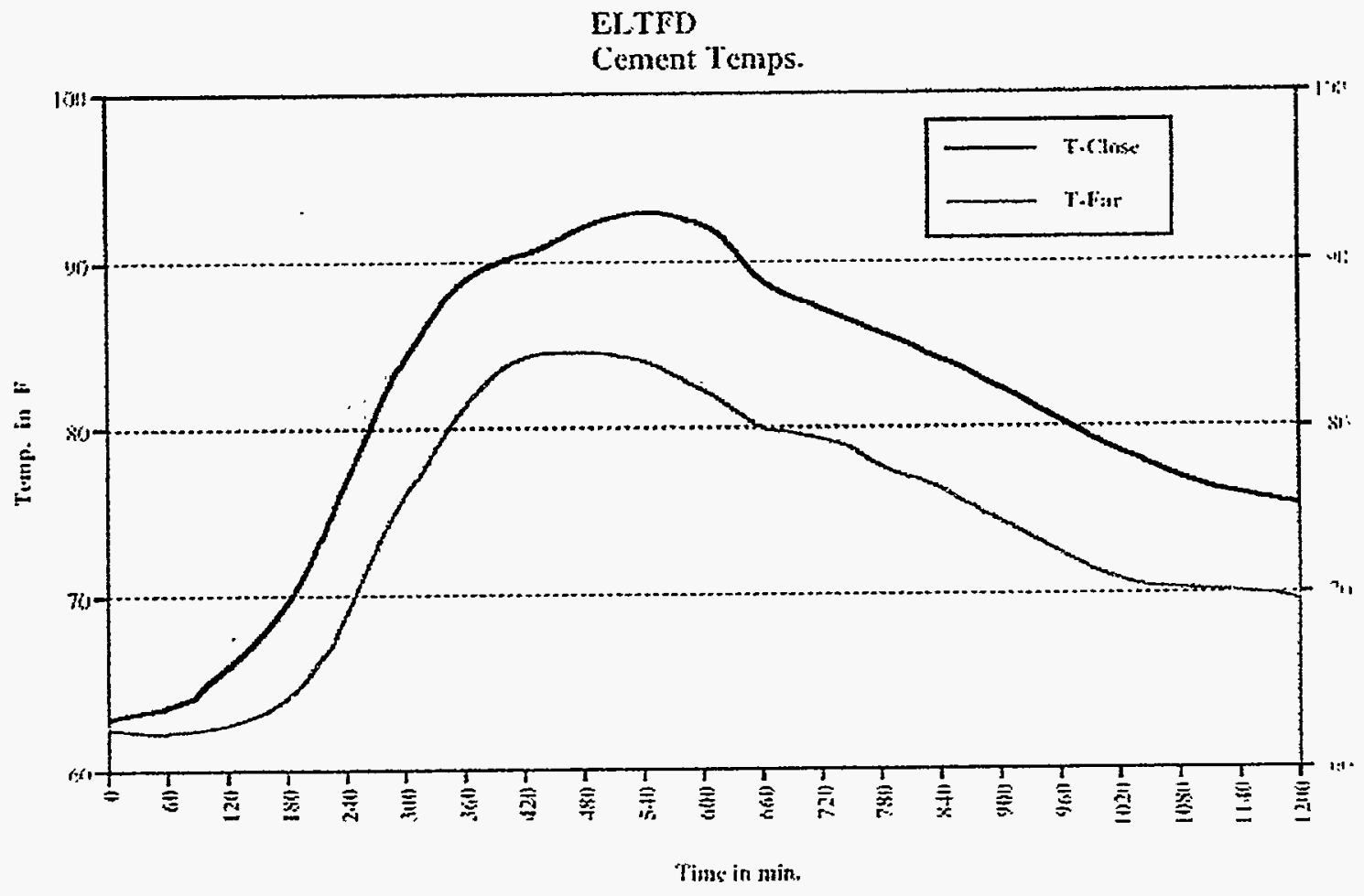




\section{6" FTW OEDP}

FM2(Inflow) $=$ Water flow into wellbore from production (top) zone, FM5(Overflow) $=$ Water flow to ELTF storage tank form pressure relief overflow pipe, FM6(Cement) = Cement flow into wellbore from pumping truck

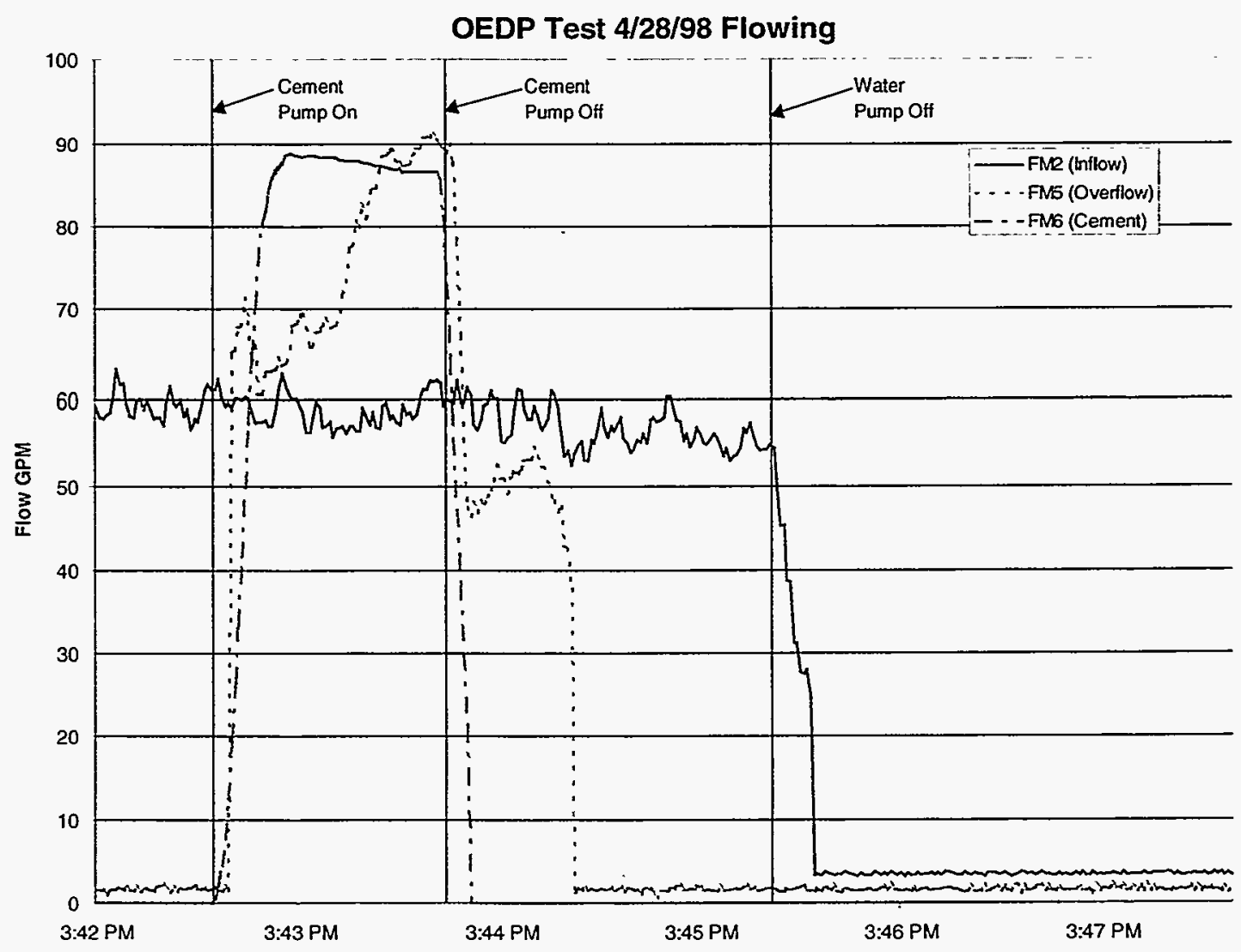




\section{6" FTW OEDP}

P6 = Cement pump pressure, $\mathrm{P} 7=$ Production (top) zone pressure, $\mathrm{P} 8=$ Middle loss zone pressure, $\mathrm{P} 9=$ Bottom box pressure, $\mathrm{P} 10=$ Wellbore pressure just above middle loss zone

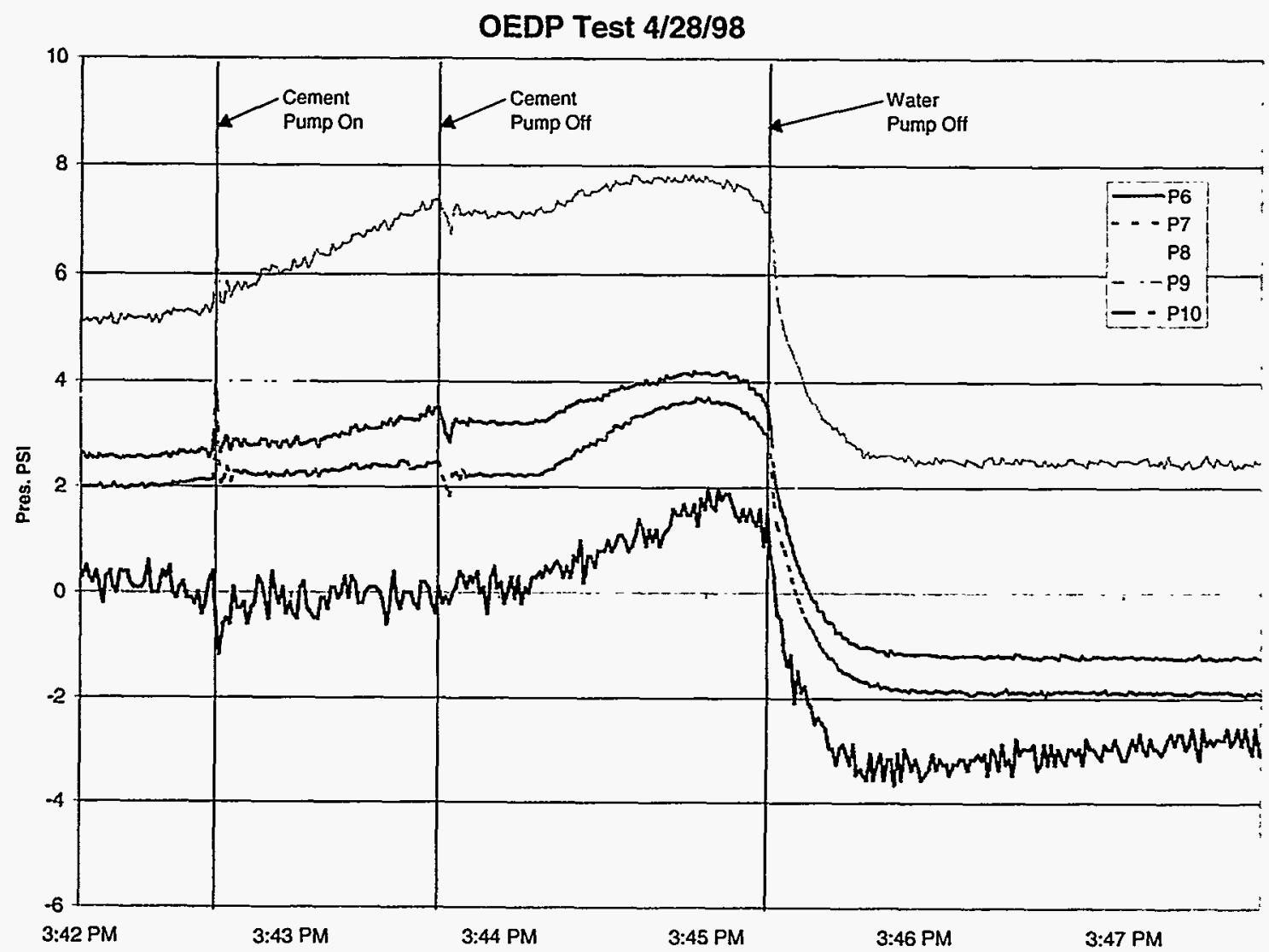




\section{6" FTW DSP}

FM1 (Inflow) $=$ Water flow into wellbore from production (top) zone, FM5(Overflow) $=$ Water flow to ELTF storage tank form pressure relief overflow pipe, FM6 (Cement) $=$ Cement flow into wellbore from pumping truck

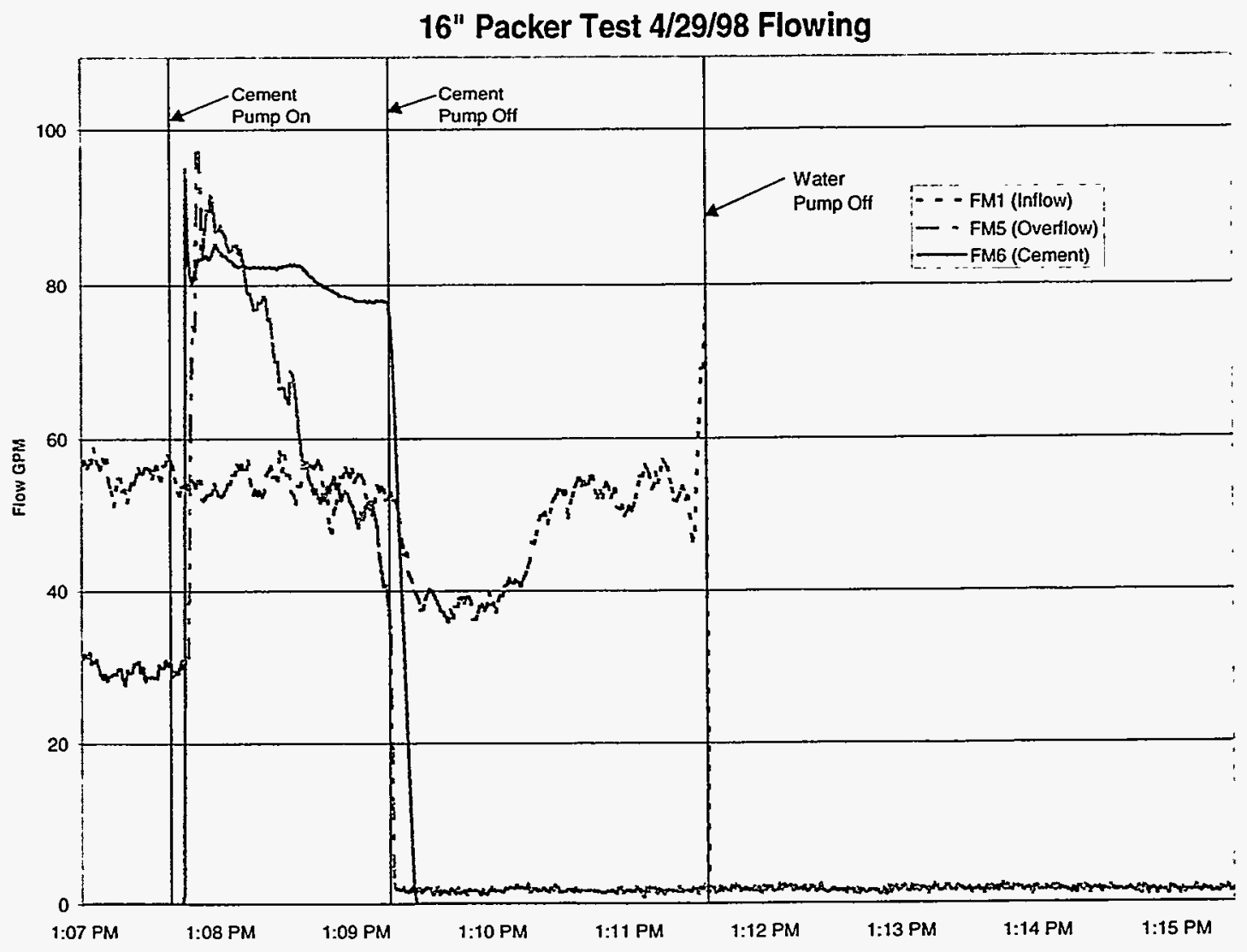




\section{6" FTW DSP}

$\mathrm{P} 1$ = Cement pump pressure, $\mathrm{P} 2=$ Production (top) zone pressure, $\mathrm{P} 3=$ Middle loss zone pressure, $\mathrm{P} 4=$ Bottom box pressure, $\mathrm{P} 5=$ Wellbore pressure between DSP bags, $\mathrm{P} 6=$ Wellbore pressure above upper DSP bag, Diff Packer Pres $=$ P1 $-\mathrm{P} 5+\mathrm{L} *: 433, \mathrm{~L}=$ distance between P1 and P5

16" Packer Test 4/29/98

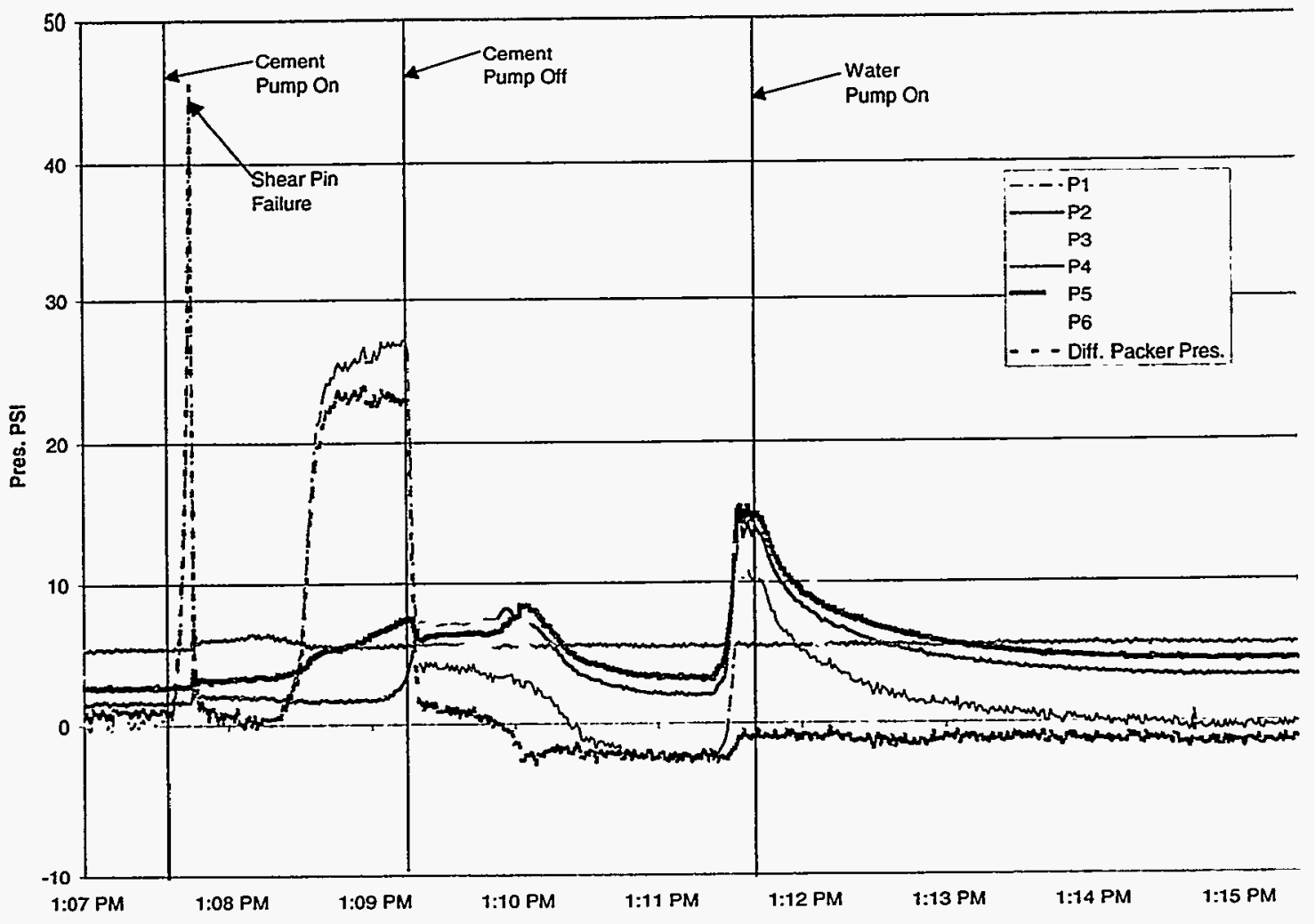


Distribution List 
APS TECHNOLOGY

Bill Turner, Managing Director

800 Corporate Row

Cromwell, CT 06416

TEL: (860) 613-4450

FAX: (860) 613-4455

\section{BALLEW TOOL COMPANY}

Leon D. Ballew

P.O. Box 361

Cobb, CA 95426

TEL: (707) 987-0837

FAX: (707) 987-0696

BAKER HUGHES INTEQ

Nic Nickels

2050 W. Steele Lane, Suite C-1

Santa Rosa, CA 95403

TEL: (707) 523-1751

FAX: (707) 523-1398

BOART LONGYEAR COMPANY

Roger Magee

P.O. Box 1000

Dayton, NV 89403

TEL: (702) 246-0296

FAX: (702) 246-3208

BOART LONGYEAR COMPANY

Steve Barnwell

P.O. Box 1000

Dayton, NV 89403

TEL: (702) 246-0296

FAX: (702) 246-3208

BOART LONGYEAR COMPANY

John Mastor, General Manager

Contracting Services

2340 West 1700 South

P.O. Box 27314

Salt Lake City, Utah 84127-0314

TEL: (801) 972-6430

FAX: (801) 977-3374

\section{CALENERGY}

Alex Schriener, Jr.

900 N. Heritage Dr., Bldg. D

Ridgecrest, CA 93555

TEL: (760) 499-2300, X 322

FAX: (760) 499-2308

\section{CALPINE CORPORATION}

Marc Steffen

1160 N. Dutton Ave., Suite 200

Santa Rosa, CA 95401

TEL: (707) 527-6700

FAX: (707) 544-2422

DRILL COOL SYSTEMS, INC.

Elwood Champness

Tom Champness

627 Williams Street

Bakersfield, CA 93305

TEL: (805) 633-2665

FAX: (805) 327-5890

EPOCH WELL LOGGING, INC.

Les Collins

3919 Rosedale Highway

Bakersfield, CA 93308

TEL: (805) 328-1595

FAX: (805) 328-1623

CAITHNESS RESOURCES, INC.

Gordon G. Gollan, Vice President

Senior Resource Operations Manager

6111 Kelso Valley Road

Weldon, CA 93283

TEL: (619) 378-3972

FAX: (619) 378-2293

E V I OIL TOOLS

MCALLISTER

Bob Johnson

P O Box 1824

Palm Springs, CA 92263

TEL: (760) 323-3297

FAX: (760) 416-6604 
E V I WEATHERFORD

Joe Turk

1000 Church Road

Rio Vista, CA 94571

TEL: (707) 374-6493

FAX: (707) 374-6192

E V I WEATHERFORD

Tom Bailey

515 Post Oak Blvd.

Houston, TX 77027

TEL: (800) 3257-3826

FAX: (713) 693-4291

GEO HILLS ASSOCIATES

James B. Combs

2395 Catamaran Drive

Reno, NV 89509-5731

TEL: (702) 827-1960

FAX: (702) 827-1960

GEOTHERMAL RESOURCE GROUP

Bill Rickard

P O Box 11898

40201 Sagewood Drive

Palm Desert, CA 92255

TEL: (760) 341-0186

FAX: (760) 341-9673

HALLIBURTON ENERGY SERVICES

Rusty Lockman, Technical Supervisor

P.O. Box 80118

Bakersfield, CA 93380-0118

TEL: (805) 393-8111

FAX: (805) 399-3915

LAYNE CHRISTENSEN CORP.

Brian Edwards

P.O. Box 3077

Salt Lake City, UT 84130-0777

TEL: (800) 453-8418

FAX: (801) 972-6769
LIVESAY CONSULTANTS, INC.

Bill Livesay

126 Countrywood Lane

Encinitas, CA 92024

TEL: (760) 436-1307

FAX: (760) 942-8375

LOS ALAMOS NATIONAL LABORATORY

Donna M. Smith, Ph.D., Program Manager

Extractive Industry Technologies

P O Box 1663, Mail Stop C331

Los Alamos, NM 87545

TEL: (505) 667-9473

FAX: (505) 667-0603

LOS ALAMOS NATIONAL LABORATORY

Andrea R. Pistone, Marketing Specialist

Extractive Industry Technologies

P O Box 1663, Mail Stop C331

Los Alamos, NM 87545

TEL: (505) 667-8718

FAX: (505) 667-0603

M-I DRILLING FLUIDS CO.

Ray Ravitz

6301 Seven Seas Avenue

Bakersfield, CA 93308

TEL: (805) 589-6370

FAX: (805) 589-6112

NABORS DRILLING USA, INC.

Ron Cleveland

3919 Rosedale Highway

Bakersfield, CA 93308

TEL: (805) 322-4983

FAX: (805) 322-4918

NOVATEK

David S. Pixton

2185 South Larsen Pkwy

Provo, UT 84606

TEL: (801) 374-6000

FAX: (801) 374-6009 
PAJARITO ENTERPRISES

John Rowley

3 Jemez Lane

Los Alamos, NM 87544

TEL: (505) 672-9770

FAX: (505) 672-0358

SMITH DRILLING AND COMPLETIONS

Mike Florence

3101 Steam Court

Bakersfield, CA 93308

TEL: (805) 589-8304

FAX: (805) 589-8306

THERMASOURCE, INC.

Louis E. Capuano, Jr.

P.O. Box 1236

Santa Rosa, CA 95402

TEL: (707) 523-2960

FAX: (707) 523-1029

THERMASOURCE, INC.

Jim Hanson

P.O. Box 1236

Santa Rosa, CA 95402

TEL: (707) 523-2960

FAX: (707) 523-1029

TONTO DRILLING SERVICES, INC.

Larry Pisto

2200 South 4000 West

Salt Lake City, UT 84126

TEL: (801) 974-0645

FAX: (801) 973-2994

TONTO DRILLING SERVICES, INC.

Nguyen Do

2200 South 4000 West

Salt Lake City, UT 84126

TEL: (801) 974-0645

FAX: (801) 973-2994
TRANS PACIFIC GEOTHERMAL

Tsvi Meidav

111 Broadway, Suite 300

Oakland, CA 94607

TEL: (510) 763-7812

FAX: (510) 763-2504

UNOCAL GEOTHERMAL

Tim Anderson

1300 North Dutton Avenue

Santa Rosa, CA 95401

TEL: (707) 521-7600

FAX: (707) 521-7603

UNOCAL CORPORATION

Michael E. Utt, P.E.

Technology \& Operations Support

14141 Southwest Freeway

Sugar Land, Texas 77478-3435

TEL: (281) 287-5215

FAX: (281) 287-5390

\section{U.S. DEPARTMENT OF ENERGY}

Paul Grabowski

Office of Geothermal Technologies, EE-12

1000 Independence Avenue, SW

Washington, DC 20585

TEL: (202) 576-0478

FAX: (202) 586-8185

U.S. DEPARTMENT OF ENERGY

Allan Jelacic

Geothermal Division, EE-12

1000 Independence Avenue SW

Washington, DC 20585

TEL: (202) 586-6054

FAX: (202) 586-8185

\section{U.S. DEPARTMENT OF ENERGY}

Lew W. Pratsch

Office of Geothermal Technologies, EE-12 1000 Independence Avenue, SW

Washington, DC 20585

TEL: (202) 586-1512

FAX: (202) 586-8185 
U.S. DEPARTMENT OF ENERGY Marshall J. Reed, Program Manager Geothermal Reservoir Technology

Office of Geothermal Technologies, EE-12 1000 Independence Avenue, SW

Washington, DC 20585

TEL: (202) 586-8076

FAX: (202) 586-8185

BAROID DRILLING FLUIDS, INC.

Gene Polk

Manager, Customer Service

2220 First Street

Albuquerque, NM 87102-1041

Phone: (505) 924-1511

Fax: (505) 924-1545

\section{BOART LONGYEAR COMPANY}

Patrick "Paddy" J. Langan

Product Manager

2340 West 1700 South

P O Box 27314

Salt Lake City, Utah 84127-0314

Phone: (801) 972-6430

Fax: (801) 977-3373

\section{BROOKHAVEN NATIONAL}

LABORATORY

Marita Allan, Ph.D.

Department of Applied Science

Building No. 526

Upton, NY 11973

Phone: (516) 344-3060

Fax: (516) 344-2359

D'OLIER, WILLIAM

Geothermal Energy Consultant

310 Hume Lane

Bakersfield, CA 93309-2427

Phone: (805) 832-5786

Fax: (805) 837-1478
DOWELL SCHLUMBERGER

Bob Fagan, WCS

Laboratory Manager, Western Division

6090 Greenwood Plaza Blvd.

Englewood, CO 80111

Phone: (303) 486-3205

Fax: (303 220-5372

DOWELL SCHLUMBERGER

Bud Frederick

Engineering \& Marketing Manager

P O Box 81437

Bakersfield, CA 93380-1437

Phone: (805) 393-5010

Fax: (805) 393-6525

DOWELL SCHLUMBERGER

Ron Wilson

Cement Cell Leader

6120 Snow Road (93308)

P O Box 81437

Bakersfield, CA 93380-1437

Phone: (805) 393-5010

Fax: (805) 393-6525

ENP CAPITAL RESOURCES, INC.

David A. Glowka, Director

811 Sussex Drive

Austin, TX 78745

Phone: (512) 442-7037

Fax: (512) $442-7754$

GEOTHERMAL DEVELOPMENT

ASSOCIATES

G. Martin Booth III

251 Ralston Street

Reno, NV 89503

Phone: (702) 322-0938

Fax: (702) 322-1320

GEOTHERMAL ENERGY

ASSOCIATION

Karl Gawell, Executive Director

1025 Thomas Jefferson, NW, Suite 109

Washington, DC 20007

Phone: (202) 944-8564

Fax: (202) 944-8568 
GEOTHERMAL RESOURCES COUNCIL

Ted J. Clutter, Executive Director

2001 Second Street, Suite 5

P O Box 1350

Davis, CA 95617-1350

Phone: (530) 758-2360

Fax: (530) 758-2839

GEOTHERMEX, INC.

James W. Lovekin

Manager of Field Operations

5221 Central Avenue, Suite 201

Richmond, CA 94804

Phone: (510) 527-9876

Fax: (510) 527-8164

GWB CONSULTANTS

Gary W. Batcheller

12122 W. Reno

Yukon, OK 73099

Phone: (405) 324-5828

Fax: (405) 324-2779

HALLIBURTON ENERGY SERVICES

Mike Barry

Geothermal Operations Engineer

$347227^{\text {th }}$ Standard Road

P O Box 80118

Bakersfield, CA 93380-0118

Phone: (805) 393-8111

Fax: (805) 399-3915

HALLIBURTON ENERGY SERVICES

John Messerschmidt

Field Technical Advisor

$347227^{\text {th }}$ Standard Road

P O Box 80118

Bakersfield, CA 93380-0118

Phone: (805) 393-8111

Fax: (805) 399-3915

J\&R ENERGY ASSOCIATES, INC.

Nyla Jones

1514 Lupine Road

Healdsburg, CA 95448

Phone: (707) 433-4918

Fax: (707) 433-4918
M-I DRILLING FLUIDS CO.

Tom Heinz

6301 Seven Seas Avenue

Bakersfield, CA 93308

Phone: (805) 589-6370

Fax: (805) 589-6112

NADET INSTITUTE

Peter H. Smeallie

600 Woodland Terrace

Alexandria, VA 22302

Phone: (703) 683-1808

Fax: (703) 683-1815

NADET INSTITUTE

Carl R. Peterson

MIT E40-481

77 Massachusetts Avenue

Cambridge, MA 02139

Phone: (617) 253-5782

Fax: (617) 253-8013

OCEAN DRILLING PROGRAM

Eugene C. Pollard, Jr.

Operations Superintendent

Texas A\&M University Research Park

1000 Discovery Drive

College Station, TX 77840

Phone: (409) 845-2161

Fax: (409) 845-4857

OXBOW POWER SERVICES, INC.

Walter R. (Dick) Benoit

Resource Manager

9790 Gateway Drive, Suite 220

Reno, NV 89511

Phone: (702) 851-1199

Fax: (702) 850-2211

SOUTHERN METHODIST UNIVERSITY

David D. Blackwell

Department of Geological Sciences

Dallas, TX 75275

Phone: (214) 768-2745

Fax: (214) 768-2701 
STATE OF CALIFORNIA

CALIFORNIA ENERGY COMMISSION

Robert Hare, M.S.

Energy Technology Development Division

Research and Development Office

$15169^{\text {th }}$ Street, MS-43

Sacramento, CA 95814-5512

Phone: (916) 653-8685

Fax: (916) 653-6010

SMITH INTERNATIONAL, INC.

John Campbell

16740 Hardy Street

P O Box 60068

Houston, TX 60068

Phone: (713) 443-3370

Fax: (713) 233-5590

TWO PHASE ENGINEERING

AND RESEARCH, INC.

Douglas Jung, P.E.

3209 Franz Valley Road

Santa Rosa, CA 95404

Phone: (707) 523-4585

UNIVERSITY OF UTAH

Energy \& Geoscience Institute

Dennis L. Nielson, Ph.D.

Department of Civil and

Environmental Engineering

423 Wakara Way

Salt Lake City, UT 84108

Phone: (801) 585-6855

Fax: (8010 585-3540

\section{Internal Distribution:}

MS-1033 M. R. Prairie (6211)

MS-1033 J. Gabaldon (6211)

MS-1033 P. Gronewald (6211)

MS-1033 S. D. Knudsen (6211)

MS-1033- D. W. Raymond (6211)

MS-1033 G. E. Staller (6211) 20 copies

MS-1033 J. J. Westmoreland (6211)

MS-1033 G. L. Whitlow (6211)

MS-1033 J. L. Wise (6211)

MS-1033 E. K. Wright (6211)

MS-9018 Central Technical Files, 8940-2

MS-0899 Technical Library, (4916) 2 copies

MS-0619 Review \& Approval Desk, (00111)

for DOE/OSTI 